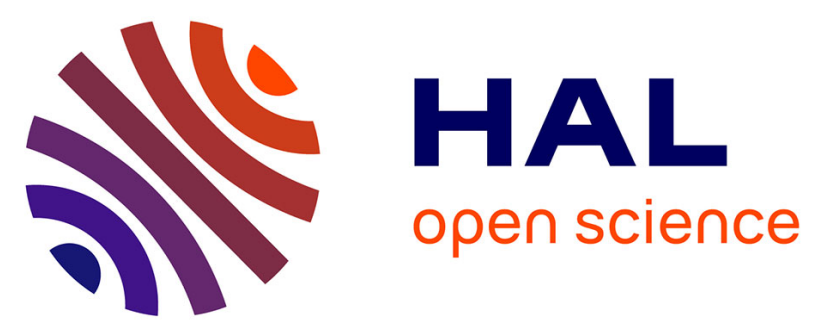

\title{
Essai d'interprétation du site paléolithique inférieur de Soucy 1 (Yonne)
}

Vincent Lhomme, Nelly Connet, Céline Bemilli, Christine Chaussé, Sylvie Beyries, Claude Guérin

\section{To cite this version:}

Vincent Lhomme, Nelly Connet, Céline Bemilli, Christine Chaussé, Sylvie Beyries, et al.. Essai d'interprétation du site paléolithique inférieur de Soucy 1 (Yonne). Gallia Préhistoire - Archéologie de la France préhistorique, 2000, 42, pp.1-44. 10.3406/galip.2000.2168 hal-02353607

\section{HAL Id: hal-02353607 https://hal.science/hal-02353607}

Submitted on 21 Jan 2020

HAL is a multi-disciplinary open access archive for the deposit and dissemination of scientific research documents, whether they are published or not. The documents may come from teaching and research institutions in France or abroad, or from public or private research centers.
L'archive ouverte pluridisciplinaire $\mathbf{H A L}$, est destinée au dépôt et à la diffusion de documents scientifiques de niveau recherche, publiés ou non, émanant des établissements d'enseignement et de recherche français ou étrangers, des laboratoires publics ou privés.

\section{(ㅇ)(1) $\$$}

Distributed under a Creative Commons Attribution - NonCommercial - NoDerivatives| 4.0 


\title{
ESSAI D'INTERPRÉTATION \\ DU SITE PALÉOLITHIQUE INFÉRIEUR DE SOUCY 1 (YonNe)
}

\author{
Vincent Lhomme*, Nelly Connet*, Céline Bemilli** et Christine Chaussé* \\ avec la collaboration de Sylvie BEYRIES ${ }^{* * *}$ et Claude GUÉRIN****
}

Mots-clés. Plëistocène moyen, contexte fluriatile, restes fauniques, industrie lithique, analyse spatiale, fonction du site.

Key-words. Middle Pleistocene, fluvial context, faunal remains, lithic industry, spatial analysis, site function.

Résumé. Soucy I est le premier des six gisements du Plëistocène moyen mis au jour en contexte fluviatile sur une ancienne terrasse de l'Yonne, ì Soucy (Yonne), dans une séquénce stratigraphique prudemment altrilnuée à l'interglaciaire holsteinien. Fouillé en sauvetage en 1995, il a livré plus de 2500 restes (lithique, faune el galets). L'analyse spatiale pratiquée sur le gisement met en évidence des zones de débitage, des concentrations de restes fauniques et une concentration de galets bruts indiquant des secteurs d'activités différenciées. Cies éléments permettent de proposer une interprétation de la fonction du site.

Abstract. Soucy 1 is the first of six. Middle Pleistocene sites found in fluvial context on an ancient terrace of the Yonne river at Soucy (North Buygumly), in a straligraphic sequence cautiously attributed to the Holsteinian interglacial. It was excavated during a salvage operation in 1995 and has yielded more than 2500 remains (lithic, fauna and pebbles). Spatial analysis reveals areas of flaking activities, concentrations of faunal remains and one concentration of unretouched pebbles, all indicating differential activities. These elements allow us to propose an interpretation about the site function.

Soucy 1 est le premier des six gisements du Paléolithique inférieur identifiés dans les formations fluviatiles de la gravière des Grandes Pièces à Soucy dans l'Yonne. Ces dépôts appartiennent à une nappe alluviale ancienne installćc sur lc versant est de la vallée de l'Yonne, au sud-est du Bassin parisien (fig. 1 et 2). La découverte des gisements de Soucy s'est inscrite dans le cadre de la surveillance archéologique systématique d'une exploitation de granulats en cours d'extraction. La fouille du gisement de Soucy l a procédé d'un sauvetage urgent qui se déroula au cours du printemps 1995. Les moyens attribués ont permis de traiter en fouille fine la totalité de la surface conservée du gisement, soit $394 \mathrm{~m}^{2}$.

Le niveau archéologique de Soucy 1, dilaté sur 15 à $25 \mathrm{~cm}$ d'épaisseur, a livré 2083 restes lithiques (dont 293 galets bruts) et 522 restes fauniques. Ce niveau archéo-

\footnotetext{
* AFAN et ESA 8018 du CNRS, laboratoire de Préhistoire et Quaternaire, université des Sciences et technologies de Lille, F-59655 Villeneuve d Ascq Cedex.

** AFAN et HP 1730 du CNRS, Ethnologie préhistorique, Maison René Ginouvès, 21 allée de l'L'niversité, F-92023 Nanterre Cedex.

*** L.MR 7055 du C.NRS. 250 ruc Albert Einstein. Sophia Antipolis, F-06560 Valbonne.

***: Lniversité de Lyon I Claude Bernard, département des Sciences de la terre, 27-43 boulevard du 11 Novembre, F-69622 Villeurbanne.
} 


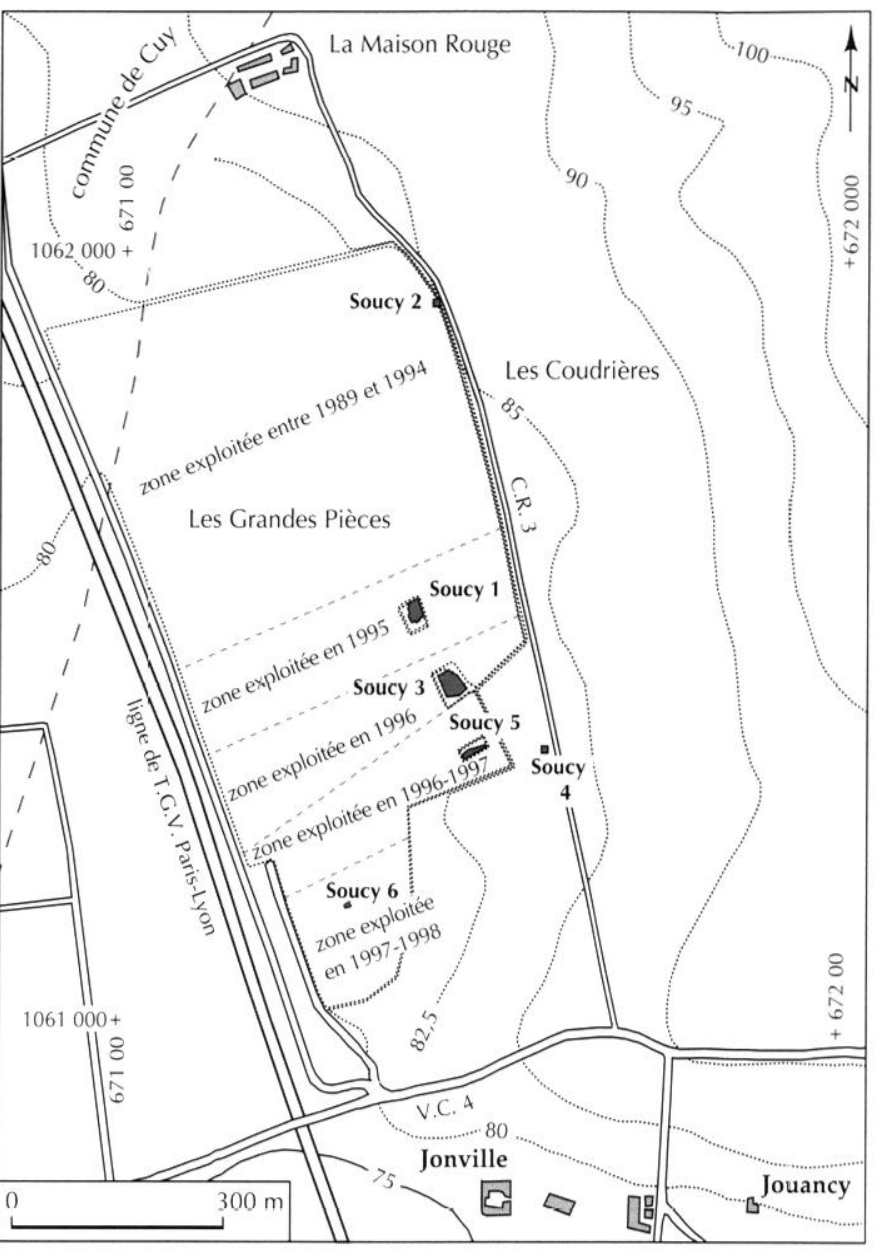

Fig. 2 - Localisation des sites préhistoriques dans la gravière des Grandes Pièces à Soucy.

logique était limité au nord et à l'est par deux fronts de taille de l'exploitation, et disparaissait au sud et à l'ouest de l'emprise de la fouille (fig. 3). Le site fouillé ne correspond donc qu'à la portion conservée d'une occupation préhistorique plus vaste installée dans une plaine alluviale.

L'étude proposée ici désire répondre à deux objectifs : d'une part présenter la synthèse des informations archéologiques obtenues sur le gisement, et d'autre part envisager une compréhension du fonctionnement du site par le biais de l'analyse de la répartition spatiale des différentes catégories de vestiges. Une telle approche nécessite au préalable de préciser les conditions de

$\longleftarrow$

Fig. 1 - Situation géographique de la gravière des Crandes Pièces à Soucy, Yonne (sources $I G_{i}$ ). 
conservation du niveau d'occupation et d'exposer les processus d'altération et de déformation susceptibles de limiter les informations extraites de la fouille. Ces précisions sont abordées après un bref rappel du contexte stratigraphique et chronologique.

\section{PRÉSENTATION DE LA STRATIGRAPHIE ET DE LA CHRONOLOGIE}

La Nappe de Soucy est installée sur un palier d'érosion, situé à $74 \mathrm{~m} \mathrm{NGF}$, qui domine d'une vingtaine de mètres le plancher crétacé de l'actuelle nappe de fond (54 m N(GF). D'après le premier schéma d'étagement des nappes alluriales de la vallée de l'Yonne, la Nappe de Soucy est la troisième nappe antérieure à la nappe de fond (Chaussé et al., sous presse).

Cette nappe est constituée de deux corps sédimentaires principaux. Sa base est composée d'un cailloutis alluvial grossier, localement interstratifié de bancs plus sableux. Ce corps est recouvert par des alluvions fines, sableuses puis sablo-limoneuses. L'ensemble du dépôt est dilaté sur 8 à $10 \mathrm{~m}$ d'épaisseur. Les sables et limons du sommet de l'édifice contiennent une malacofaune de rang interglaciaire à caractère continental (LimondinLomouet, in Chraussé el al., sous presse).

La nappe est surmontée par des formations issues du démantèlement des versants, installées sur une surface d'érosion doucement inclinée vers l'ouest. Cette surface et ces formations recoupent en partie les dépôts alluviaux les plus récents et les plus occidentaux dans l'emprise de la gravière, notamment ceux qui scellent le niveau archéologique de Soucy 1.

Les premières datations ont été obtenues par résonance paramagnétique électronique sur quartz (RPE) sur un niveau sableux interstratifié dans le cailloutis grossier de la base de la nappe. Les résultats situent la mise en place des graviers de fond entre 400000 et 300000 ans BP (So9801 $=349000 \pm 43000 \mathrm{BP}$ ). Les données aminochronologiques, obtenues sur des coquilles de mollusques prélevées à la base des alluvions fines, situent la mise en place du dépôt au cours des stades isotopiques 7 ou 9 (Chaussé et al., sous presse). D’après les premiers résultats géochronologiques et l'analyse des micromammifères (Kolfschoten, in Lhomme et al., sous presse), la mise en place des formations alluviales fines du sommet de l'édifice fluviatile de la Nappe de Soucy est contem- poraine d'une période interglaciaire qui peut être rapportée au stade isotopique 9, ou interglaciaire holsteinien sensu Lagwijn (1992).

\section{ÉVALUATION DU DEGRÉ DE CONSERVA- TION DU NIVEAU ARCHÉOLOGIQUE}

\section{LA PLACE DU GISEMENT DE SOUCY 1 DANS LE SCHÉMA DE L'ÉVOLUTION DE LA PLAINE ALLUVIALE}

Un premier schéma de reconstitution de l'évolution de la plaine alluviale a récemment été proposé (Chaussé et al., sous presse). Il distingue plusieurs étapes de construction de la plaine, postérieures au dépôt du cailloutis grossier de la base de l'édifice. Cette construction s'organise à partir de trois sustèmes d'écoulement qui se sont succédé. Ainsi, un premier chenal (chenal A), de type méandriforme, a été reconnu sur la moitié occidentale de la gravière. Par la suite s'installe un lit fluvial à chenaux multiples, repéré sur le tiers oriental de la gravière. Enfin, le chenal B incise son lit au droit du lit fluvial précédent (fig. 4 et 5 ).

Le chenal B est bordé sur sa rive occidentale par une levée de berge qui raccorde le lit mineur à la plaine d'inondation (fig. 4 et 5). Le gisement de Soucy 1, compris dans des sables lités, est installé sur cette levée. Le niveau archéologique présente un pendage général de direction est, qui montre que les hommes ont occupé la partie haute d'une surface doucement inclinée vers le chenal B. Cette situation, en retrait de la berge immédiate, place le site plus ou moins à l'écart des écoulements vifs, tout en restant cependant soumis aux processus de recouvrement par limonage en période de hautes eaux. D'un point de vue malacologique, le niveau d'occupation est installé sur le toit de la malacozone Scy2 qui décrit, de part et d'autre du chenal $\mathrm{B}$, un milieu ouvert ponctuellement colonisé par une ripisylve (boisements de rives: (Chaussé et al., sous presse).

Il est possible toutefois que l'occupation soit contemporaine de l'étape suivante caractérisée par la stabilisation relative de la plaine. En effet, l'édifice alluvial au droit du gisement de Soucy 1 est recoupé par les premières formations de versant et perturbé par les processus d'altération pédologique largement postérieurs comme nous le verrons ci-après. Cette stabilisation s'est 


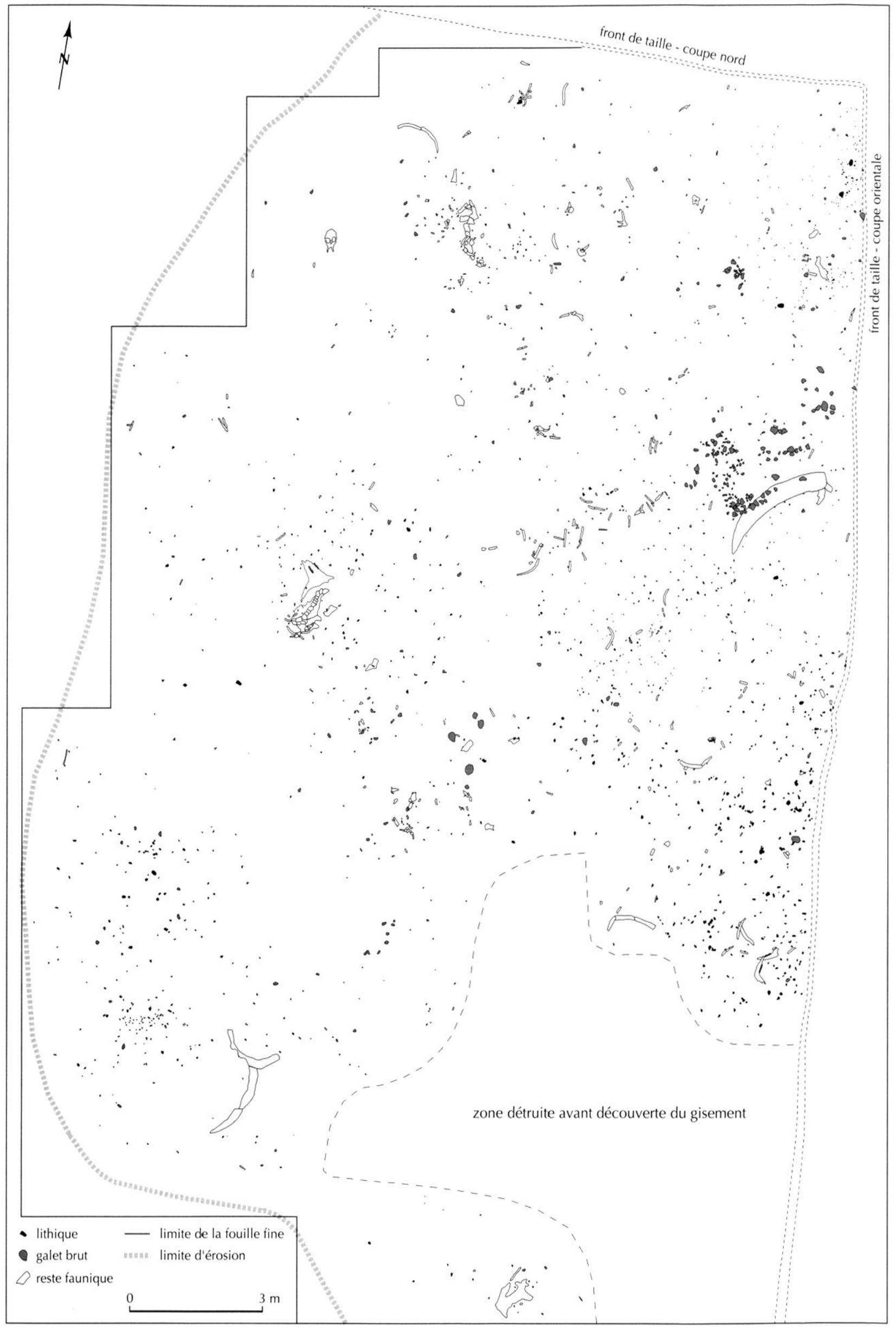

Fig. 3 - Soucy 1 : plan de répartition de l'ensemble des vestiges. 


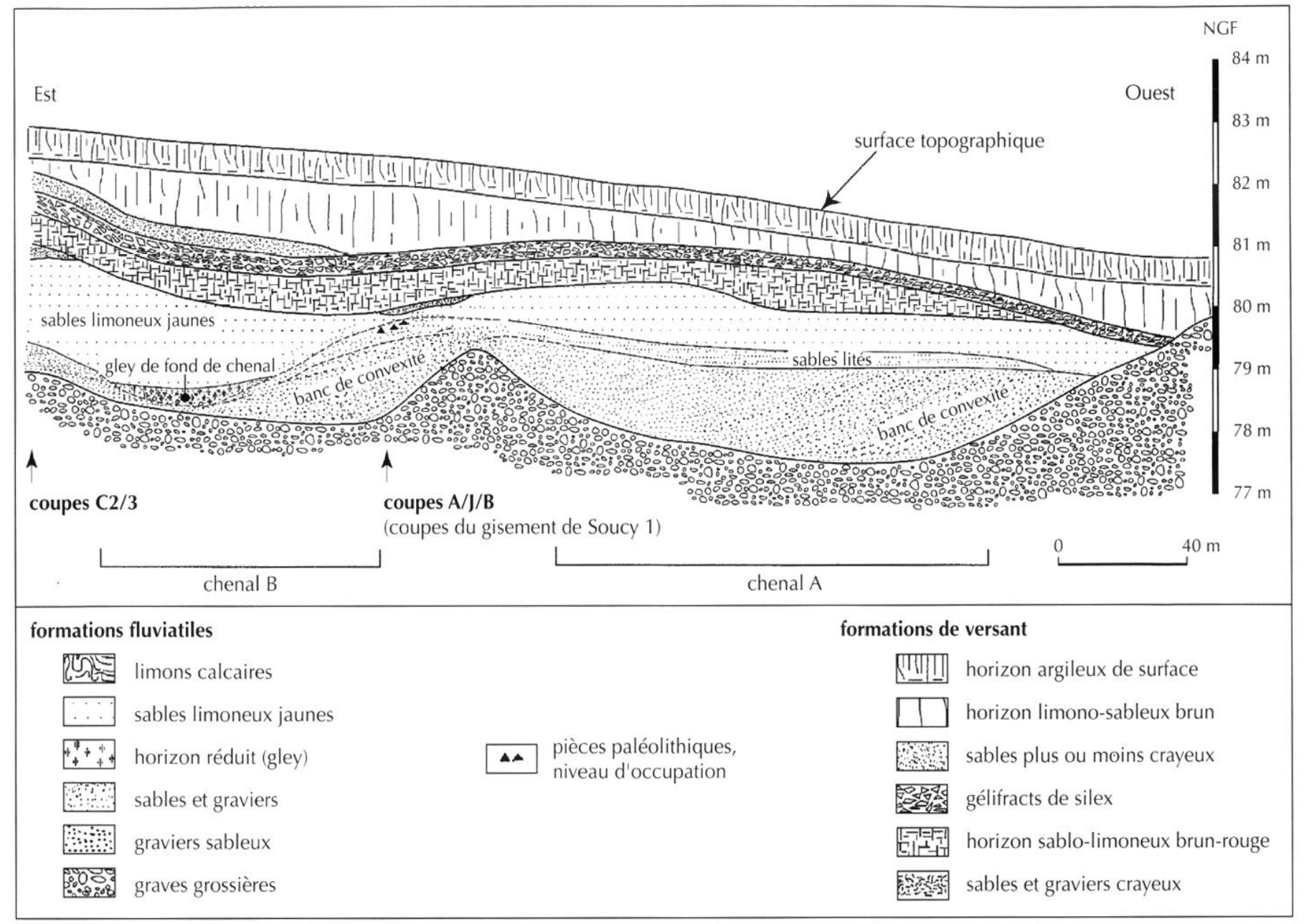

Fig. 4 - Transect est-ouest perpendiculaire à l'axe du paléo-cours (coupe J).

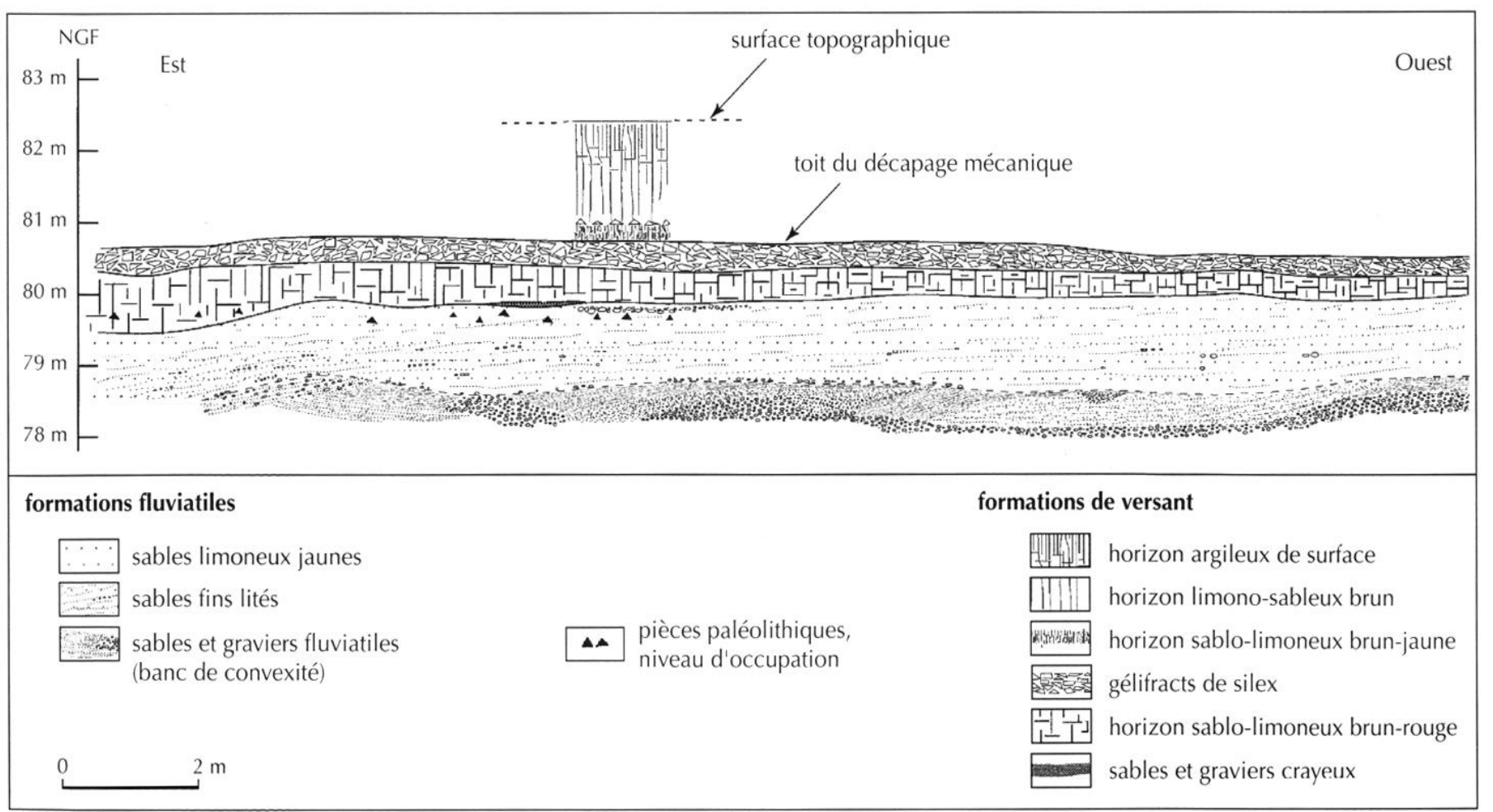

Fig. 5 - Coupe nord du gisement de Soucy 1. 


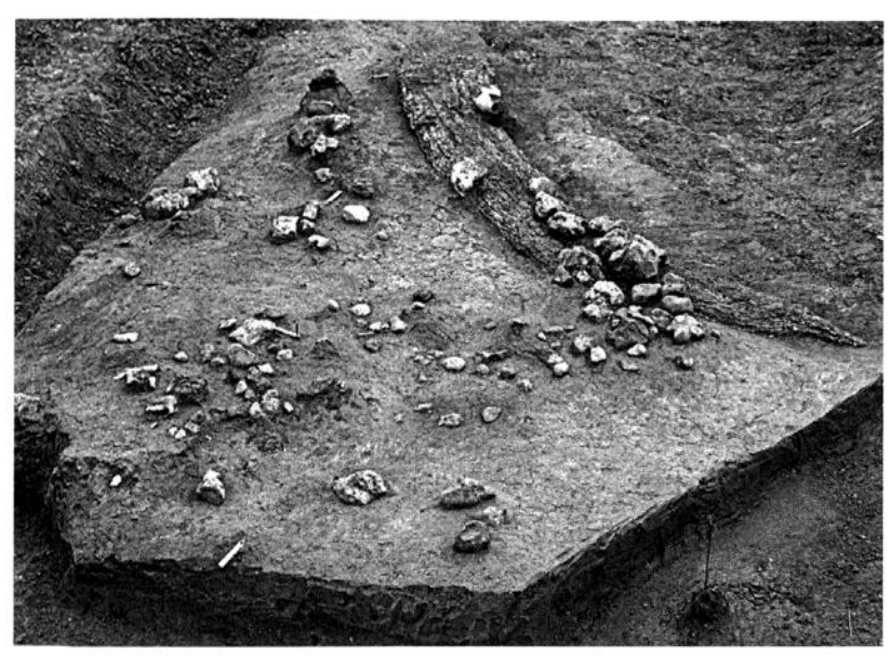

Fig. 6 - Soucy 1 : vue de la concentration de galets à proximité d'une défense de Palaeoloxodon antiquus.

traduite par l'élaboration d'un sol alluvial grisâtre qui implique l'arrêt des processus d'alluvionnement (baisse du niveau de l'étiage, migration des écoulements vers un autre chenal ?). Au cours de cette période et d'après les associations malacologiques, la légère couverture arbustive régresse et cède la place à une végétation plus basse, de type taillis ou buissons (malacozone Scy3). Dans le même temps, un gley se développe dans le fond du chenal $\mathrm{B}$ induisant un milieu stagnant (Chaussé et al., sous presse).

\section{PROCESSUS DE RECOUVREMENT DES VESTIGES}

Que l'occupation préhistorique de Soucy 1 soit contemporaine du fonctionnement du chenal B ou de la période de stabilisation qui lui succède, elle apparaît dans tous les cas installée sur un espace en retrait du lit mineur, au mieux atteint par des dépôts de débordement si l'on admet la première hypothèse. Dans ce contexte, le recouvrement alluvial du site est le fait d'un transport des particules en suspension uniforme dont la taille n'excède pas le millimètre, ainsi que cela a été montré d'après l'analyse de l'image C-M (Chaussé et al., sous presse).

D'un point de vue dynamique, le mode de recouvrement du gisement, d'un régime alluvial très bas, ne semble pas avoir pu perturber l'organisation du site, si ce n'est peut-être la position relative des plus petits restes. La présence de très petits éclats de silex ( $41 \%$ des restes lithiques mesurent moins de $20 \mathrm{~mm}$ ) et de petits élé- ments osseux sur l'ensemble du gisement, les nombreuses connexions anatomiques (bas de pattes, portions de carcasses), le bon état de fraîcheur des restes lithiques (absence d'émoussé des tranchants et de patine) plaident en faveur d'une conservation des vestiges dans une position globalement primaire. De plus, les orientations (très variées) des liaisons entre éléments lithiques remontés ne mettent pas en évidence de déformation naturelle du niveau archéologique comme l'aurait indiqué une orientation privilégiée des connexions des remontages (Bertran, Texier, 1995).

Les conditions climatiques (tempérées) et le type de gisement (plein air) sous-entendent que les vestiges osseux aient pu rester longtemps à l'air libre, ce qui implique leur fragilisation par les phénomènes climatoédaphiques (alternance humidité/sécheresse par exemple). L'exposition prolongée des restes osseux à l'air libre entraîne, sous l'effet des actions climatiques, un processus de détérioration de la matière osseuse appelé weathering (Behrensmeyer, 1978; Brain, 1981 ; Auguste, 1994). Celui-ci se traduit sur la surface de l'os par l'apparition de fissures qui vont progressivement s'élargir, provoquant une desquamation, puis une véritable dislocation.

Cependant, la situation du gisement, dans la plaine de débordement, induit que les processus de limonage ont pu recouvrir assez. rapidement les vestiges, favorisant la préservation des restes fauniques. La conservation de bois de cerf et la présence d'os de membres de cervidé et de boviné en connexion dans le niveau archéologique impliquent un recouvrement rapide des restes (Behrensmeyer, 1991).

Sur le secteur fouillé, à proximité d'une défense d'éléphant antique, $12 \mathrm{~m}^{2}$ concentraient 148 galets bruts de gros module (diamètre des éléments compris entre 30 et $200 \mathrm{~mm}$ ) (fig. 3 et 6 ). Le dépôt alluvial de ces matériaux suggérerait une capacité de transport élevée qui ne s'accorde pas avec celle déduite des résultats des analyses granulométriques réalisées sur les sédiments qui contiennent et encadrent le niveau archéologique (Chaussé et al., sous presse). La prise en charge et le déplacement de ce type de matériau grossier s'effectuent par roulement. Ce mode de transport intervient sur le fond des lits mineurs, là où les vitesses des courants sont les plus élevées. La présence de ces galets sur le site n'apparaît donc pas en accord avec la situation de quasi-plaine d'inondation définie par ailleurs ( $f$. p. 3). 
Il pourrait toutefois être objecté que ces galets peuvent représenter des dépôts issus d'une phase d'instabilité de haute énergie, localisée ou non, qui a engendré le charriage d'un cailloutis grossier, générant des dépôts de type "laisse de crue ". Il ne peut être accordé un crédit suffisant à cette hypothèse; le ou les érénements auraient suscité l'abandon de particules de classes granulométriques intermédiaires dont les diamètres auraient été compris entre ceux des sables et ceux des galets, avec affinement des granulométries vers la partie interne de la levée. Ces éléments et une telle dispersion des granulométries en direction de la plaine d’inondation n'ont pas été retrouvés sur la fouille malgré le soin apporté à leur recherche; les éléments grossiers sont tous de gros modules et apparaissent circonscrits dans l'espace. En outre, cette hypothèse explique difficilement que la concentration soit constituée de roches gréseuses, granitiques et calcaires dans des proportions qui varient selon les matériaux de 10 a $27 \%$ alors que, dans les dépôts grossiers strictement alluviaux de la nappe, ces roches constituent entre 0,5 et $5 \%$ des cortèges pétrographiques ( $c f$. p. 19).

Ces différentes remarques permettent de considérer que les processus de recourrement alluviaux ne sont pas à l'origine de cette accumulation de galets.

\section{INTERFÉRENCE DES PROCESSUS \\ DE MISE EN PLACE DES FORMATIONS DE VERSANT ET D'ALTÉRATION SUR LE NIVEAU D'OCCUPATION DE SOUCY 1}

Si la dynamique fluviale ne semble pas avoir perturbé d'une façon globale le niveau d'occupation après l'abandon du site, le passage à une dynamique de versant a participé au remaniement partiel du niveau archéologique.

L'encaissement du cours de l'Yonne met en relief la Nappe de Soucy. La plaine est alors définitivement abandonnée par les écoulements fluviatiles. Les processus d'érosion qui prennent le relais modèlent un glacis doucement incliné vers l'ouest. Cette surface a accueilli plusieurs générations de dépôts qui traduisent autant de cycles d'érosion (fig. 4). Alimentés par le démantèlement des versants, ces dépôts sont séparés les uns des autres par des sols d'altération. Relativement épaisses (entre 1 et $4 \mathrm{~m}$ ), ces formations sont, à Soucy, globalement responsables de la conservation de la nappe alluviale.
Au droit du gisement de Soucy 1, les sables lités qui contiennent le niveau d'occupation présentent un pendage est. Ils sont recoupés par cette surface d'érosion dont la pente est inclinée vers l'ouest. Le façonnement de cette surface est responsable du démantèlement partiel à total du niveau archéologique sur les secteurs les plus occidentaux du site où il était altimétriquement plus élevé (fig. 3 et 5 ).

Cette surface d'érosion a accueilli les premières formations détritiques. Elles sont représentées par des sables et graviers crayeux dont l'épaisseur peut atteindre $2 \mathrm{~m}$ sur les secteurs les plus orientaux de la gravière. Ces matériaux apparaissent moins épais et plus ou moins continus vers le sud et l'ouest de l'emprise de la gravière. Constitués pour l'essentiel de particules crayeuses, ils traduisent un important épisode de démantèlement des versants dans un contexte de dégradation globale des conditions climatiques.

Le toit de la formation détritique supporte un sol d'altération bien marqué par ses tonalités brun-rouge. Il s'agit d'un sol brun marqué par un lessivage important des argiles. Sous lame mince, les revêtements sont nombreux, épais (de l'ordre du millimètre), limpides et fortement orientés. Ce sol brun lessivé s'est développé aux dépens des sables et graviers crayeux après leur décarbonatation. Son élaboration est réalisée sons des conditions climatiques de rang interglaciaire.

Sur le gisement de Soucy 1, la décarbonatation des sables crayeux détritiques est quasi totale, seuls quelques rares lambeaux d'une dizaine de centimètres d'épaisseur ont été épargnés par les processus d'altération. En profondeur, le front de décarbonatation s'organise en poches qui perforent plus ou moins profondément les sables fins lités fluviatiles contenant le niveau archéologique. D'une façon générale, le niveau archéologique est apparu sous le front de décarbonatation, il est localement traversé par ce front ou bien se situe à son contact. Cette décarbonatation partielle et irrégulière constitue le principal facteur physico-chimique postdépositionnel mis en cause dans les processus d'altération des restes fauniques (en favorisant la dissolution de la matière osseuse). Ce phénomène est à l'origine de la médiocre conservation des restes fauniques, lesquels apparaissaient "écrasés " sur place, ne constituant parfois plus qu'un amas d'esquilles aux seuls contours évocateurs. Il est certain que postérieurement à cette décarbonatation partielle le poids des sédiments a joué un rôle dans cette 


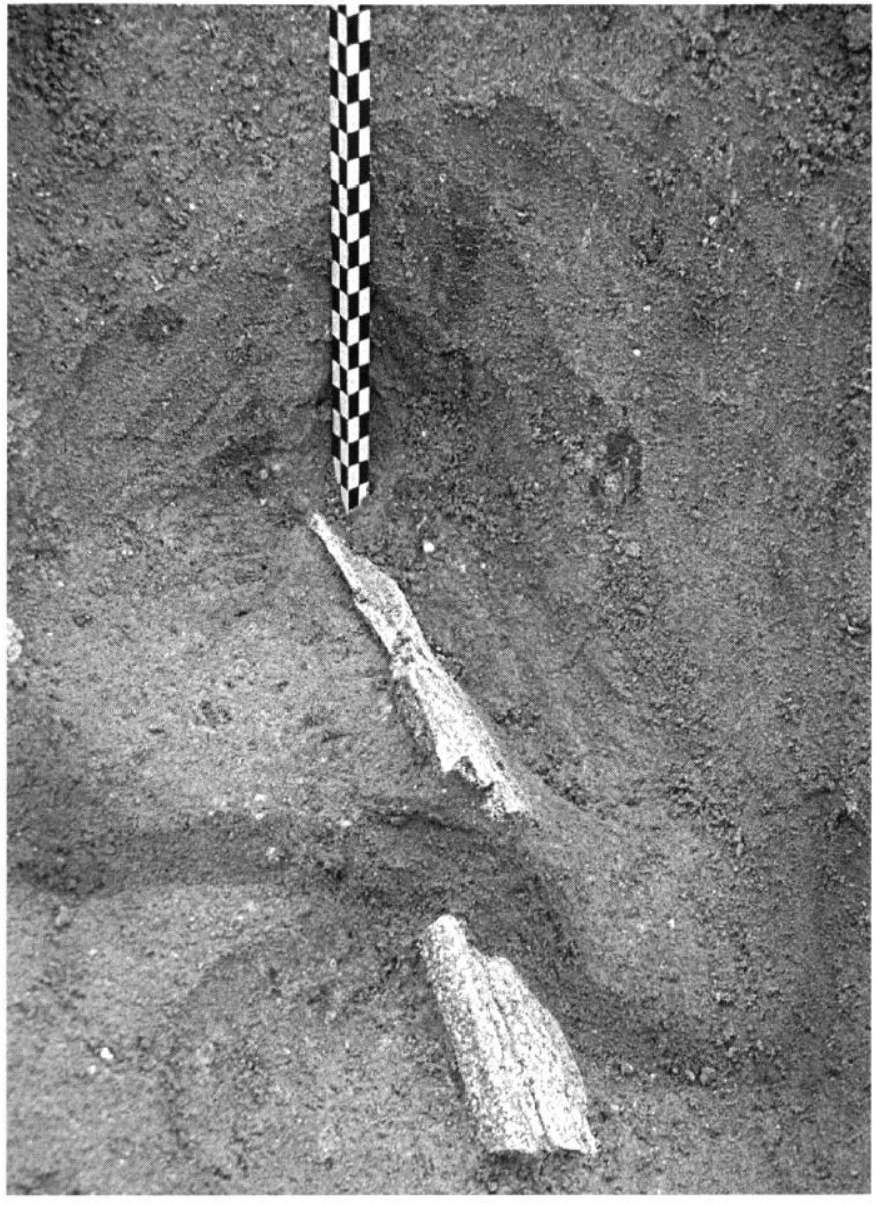

Fig. 7 - Soucy 1 : vnee diune côte de rhinocéros cassée en denx parties par une fente de gel.

dégradation des restes fauniques, le niveau se situant à $2,5 \mathrm{~m}$ sous les labours.

Le sol brun lessivé est scellé par un cailloutis de silex gélifractés. Épais de 30 à $40 \mathrm{~cm}$ en moyenne, ce banc de cailloutis a été observé en continu le long des différents fronts de taille de la gravière. Il admet un pendage général ouest et est localement déformé par des poches en chaudron et des fentes de gel qui perforent et déforment les volumes sédimentaires sous-jacents. Cés figures périglaciaires ont surtout été observées sur les secteurs les plus orientaux de la gravière. Plus à l'ouest, le long du glacis, les éléments caillouteux gélifractés sont disposés à plat et présentent une organisation litée parallèle à l'inclinaison du glacis. Leur agencement témoigne d'une mise en place par gélifluage en contexte périglaciaire (Van Vliet-Lanoë, Valadas, 1983). Sur le gisement de Soucy 1, l'incidence du gel est surtout remarquable en lames minces. Depuis le cailloutis gélifracté supérieur jus- qu'aux sables lités fluviatiles, les observations micromorphologiques ont enregistré le passage progressif d'une microstructure en ovoïdes à une microstructure lamellaire puis lamellaire discontinue dans les sédiments alluviaux. Ces traits microstructuraux d'origine cryogénique sont générés par la glace de ségrégation. Ils sont la manifestation de la cryoreptation du sol vers l'aval de la pente au cours d'une période prolongée d'alternance geldégel. L’amplitude du déplacement décroît avec l'augmentation de la profondeur (Van Vliet-Lanoë, Valadas, 1983; Van Vliet-Lanoë, 1987).

Dans les sables lités qui contiennent le niveau d'occupation, la structuration lamellaire apparaît moins continue et développée le long des discontinuités texturales sans fractionnement ni remaniement des éléments structuraux. L'intensité du déplacement cryogénique apparaît nul à faible. Localement, les sables et micrites constitutifs de l'assise alluviale sont perforés par des microfentes dans lesquelles s'entassent des ovoïdes et des papules. Ces figures, ponctuelles, sont à rapprocher d'un réseau de polygones de petites envergures $(1,50 \mathrm{~m}$ de diamètre en moyenne) qui disparait rapidement sous le niveau d'occupation.

Ces fentes ont affecté quelque peu le niveau archéologique. En effet, elles sont responsables du fractionnement (observé à la fouille) d'une faible partie du matériel osseux, tel, par exemple, un costal de rhinocéros fracturé en place de part et d'autre d'une fente (fig. 7). Le mobilier lithique ne porte, quant à lui, aucune séquelle liée au gel postérieurement à la taille et présente des arêtes vives.

Le banc de cailloutis gélifractés est recouvert par un horizon sablo-limoneux brun-jaune épais d'une vingtaine de centimètres. Il est recoupé par un second niveau de cailloutis gélifractés plus fin et discontinu que le précédent (fig. 4 et 5). D'après les observations en lame mince, cette colluvion sablo-limoneuse supporte un sol de type brun lessivé développé sous des conditions interglaciaires. En effet, la porosité du fond matriciel est occupée par des argilanes jaune limpide, hyalins, généralement bien orientés et fortement biréfringents. Ces traits sont recouverts par des revêtements microlités plus sombres, progressivement plus poussićreux à silteux. Ces accumulations argileuses décrivent une dégradation texturale. En profondeur, dans l'horizon sablo-limoneux brun-rouge, ces argilanes à dégradation texturale occupent la porosité cryogénique. Ces traits sont rencontrés 
jusque dans l'assise fluviatile inférieure. Ces processus d'illuviation ont accompagné localement l'approfondissement du front de décarbonatation, notamment le long des fentes de gel du réseau polygonal, participant dans une certaine mesure à l'altération du matériel osseux contenu dans le niveau archéologique.

L'ensemble est recouvert par une formation éo-colluviale (fig. 4 et 5 ). Les processus d'altération pédologique affectant cette couverture n'ont pas été reconnus dans les horizons qui sous-tendent le banc de cailloutis gélifractés. Les différents traits observés en lames minces dans ce complexe de sols ne paraissent pas, par conséquent, avoir participé aux processus d'altération qui ont affecté le niveau archéologique de Soucy 1.

\section{PERTURBATIONS D'ORIGINE BIOLOGIQUE}

Les phénomènes de bioturbation consécutifs à la mise en place d'une ripisylve pénécontemporaine de l'occupation préhistorique (petit sol alluvial) ont entrainé une dilatation du niveau d'occupation sur une vingtaine de centimètres d'épaisseur. Cette bioturbation est confirmée par les études malacologiques, qui, par la reconnaissance d'espèces forestières, suggèrent la présence d'un tissu racinaire dense et de développement important. Il a affecté l'ensemble du niveau archéologique sans toutefois changer fondamentalement la position relative des vestiges les uns par rapport aux autres. Cette dilatation de caractère altimétrique, visible à la fouille, constitue la seule déformation postdépositionnelle du niveau d'occupation.

Le niveau archéologique de Soucy 1 n'a pas subi d'altérations ni de déformations postdépositionnelles susceptibles de limiter l'intérêt d'une étude archéologique complète. L'altération des restes fauniques résulte d'une décarbonatation partielle des sédiments du niveau archéologique. L'essentiel des perturbations du niveau d'occupation mises en évidence se manifeste par une légère déformation planimétrique et altimétrique et est lié au développement d'un sol (tissu racinaire, terriers, etc.).

\section{ANALYSE ARCHÉOZOOLOGIQUE DÉNOMBREMENT DES VESTIGES OSSEUX}

Les faunes du Pléistocène moyen en contexte archéologique sont assez peu nombreuses en F.urope. Aussi, leur simple présence sur un gisement constitue un potenticl informatif qu il incombe d'exploiter exhaustivement. Une approche préliminaire du matériel osseux de Soucy 1 a été réalisée dans l'urgence par F. David en 1995 (Lhomme et al., 1995). L'étude présentée aujourd'hui a été poussée à son maximum, et ce bien que nous ayons conscience des limites imposées par ce matériel. Les informations suivantes ont des implications archéologiques qui vont au-delà du simple enrichissement du corpus des données fauniques d'une période encore mal documentée. En effet, outre cet aspect non négligeable, elles viennent compléter les connaissances sur les paléoenvironnements, la mise en place et l'évolution des dépôts archéologiques, mais aussi sur les comportements de subsistance des occupants du site.

\section{COMPOSITION DE L'ASSEMBLAGE OSSEUX}

Une proportion importante de restes osseux a pu être identifiée anatomiquement et spécifiquement (tabl. I). Cela nous a permis de réaliser une étude archéozoologique la plus exhaustive possible. Cependant, le faible nombre de restes dentaires $(4 \%)$ et d'épiphyses entières $(0,8 \%)$ nous a contraint à renoncer à l'étude paléontologique détaillée de l'ensemble des taxons.

Le nombre de restes (NR) décompté est de $522^{\prime} ; 171$ restes ont été déterminés totalement (anatomiquement et spécifiquement: NRDt) et 52 l'ont été anatomiquement (NRDa). Ces derniers ont été rapprochés des principaux taxons identifiés selon des classes de taille, mais n'ont pas été pris en compte dans l'analyse quantitative. Le taux de détermination atteint 32,8 \% (rapport $\mathrm{NRDt} / \mathrm{NR}$ ), ce qui est correct face au mauvais état de préservation du matériel.

Le spectre faunique est assez large avec neuf espèces (tabl. I). Les nombres minimums d'individus (NMI dans le texte) ont été obtenus par NMI de fréquence (NMIf), la mauvaise conservation générale ne permettant pas de tenter un NMI de combinaison (NMIc). Le nombre total d'individus sur le site s'élève au minimum à douze.

\footnotetext{
1. De nouveaux décomptes ont été effectués afin de faciliter la comparaison arec les autres gisements de Soucy. Le décompte effectué sur le terrain dommait un chiffere de 324 car les portions de carcasses avaient été comptabilisées en tant qu'unité. Nous les avons scindées en fonction des parties anatomiques qui y étaient représentées.
} 
Tabl. I - Composition du spectre faunique de Soucy 1.

\begin{tabular}{|c|c|c|c|c|}
\hline Espèces & NRD & $\%$ NRDt & NMIf & $\%$ NMIf \\
\hline \multicolumn{5}{|l|}{ Artiodactyles } \\
\hline Aurochs (Bos primigenius) & 74 & 43,3 & $2(3 ?)$ & 25,1 \\
\hline Cerf (Cervus elaphus) & 43 & 25,1 & 2 & 16,7 \\
\hline Chevreuil (Capreolus capreolus) & 4 & 2,3 & 1 & 8,3 \\
\hline Sanglier (Sus sp.) & 1 & 0,6 & & \\
\hline \multicolumn{5}{|l|}{ Périssodactyles } \\
\hline Cheval (Equus sp.) & 6 & 3,5 & 1 & 8,3 \\
\hline Rhinocéros (Dicerorhinus mercki) & 34 & 19,9 & 1 & 8,3 \\
\hline \multicolumn{5}{|l|}{ Proboscidien } \\
\hline Palaeoloxodon antiquus & 6 & 3,5 & 2 & 16,7 \\
\hline \multicolumn{5}{|l|}{ CARNIVORES } \\
\hline Ours (Ursus sp.) & 1 & 0,6 & 1 & 8,3 \\
\hline \multicolumn{5}{|l|}{ RONGEURS } \\
\hline Castor (Castor fiber) & 2 & 1,2 & 1 & 8,3 \\
\hline Total déterminés totalement (NRDt) & 171 & 100 & 12 & 100 \\
\hline cf. Rhinocéros ou éléphantidé & 18 & & & \\
\hline cf. Rhinocéros & 12 & & & \\
\hline cf. Boviné & 10 & & & \\
\hline cf. Cervidé & 12 & & & \\
\hline $\begin{array}{l}\text { Total déterminé anatomiquement (NRDa) } \\
\text { et attribué selon des classes de taille }\end{array}$ & 52 & & & \\
\hline Total NRD & 223 & & & \\
\hline Total indéterminés & (2)- & & & \\
\hline Total indéterminés & 299 & & & \\
\hline Total NR & 522 & & & \\
\hline
\end{tabular}

L'Aurochs (Bos primigenius), le Cerf élaphe (Cervus elaphus), le Rhinocéros de Merck (Dicerorhinus mercki) et l'Éléphant antique (Palaeoloxodon antiquus) sont les espèces les mieux représentées en nombre de restes (NR) ; les deux premiers l'étant également en nombre d'individus. Les autres espèces sont figurées chacune par seulement quelques restes d'un individu (tabl. I). Ce sont, par ordre décroissant, le Cheval (Equus sp.), le Chevreuil (Capreolus capreolus), le Castor (Castor fiber), le Sanglier (Sus sp.), et enfin l'Ours (Ursus sp.).

\section{LES ESPĖCES EN PRÉSENCE}

L'Aurochs. Soixante-quatorze restes appartiennent au Bovinae (43,3\% NRDt) et deux individus sont attestés. Il

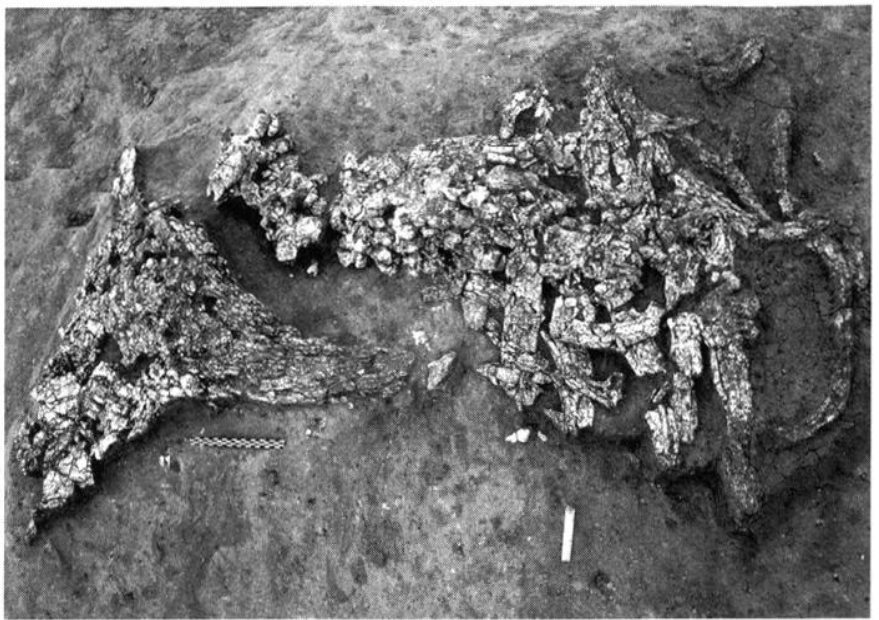

Fig. 8 - Soucy 1 : portion antérieure de carcasse d'aurochs.

s'agit d'une part d'un adulte et d'autre part d'un jeune âgé de deux à trois ans. L'appariement entre les molaires inférieures et supérieures ne s'est pas révélé suffisamment fiable pour distinguer un troisième individu. Les caractéristiques morphologiques des dents jugales (SlottMoller, in Jaubert ot al., 1990) définissent l'Aurochs. Celui-ci est essenticllement représenté par le squelette axial et les extrémités des membres (autopode) "2, et l'un des deux animaux se présente sous forme de portion de carcasse comprenant le crâne et la cage thoracique (fig. 8 et 9). L.Aurochs est l'espèce la mieux figurée à Soucy 1 en nombre de restes et se place également parmi les mieux représentées en nombre d'individus.

Le Cerf. Le Cerf élaphe est la deuxième espèce la mieux représentéc avec quarante-trois restes $(25,1 \%$ NRDt) provenant de presque toutes les parties du squelette. Une quinzaine d'autres fragments sembleraient pouvoir lui être attribués. Deux jeunes sont figurés par les dents: "l'un étant un faon très jeune de première année, l'autre probablement d'un an plus âgé " (David, in Lhomme et al., 1995). Les os longs sont présents et peu fragmentés et l'on remarque que deux portions distinctes de membre sont en connexions (fig. 10).

Quatre restes de cherreuil (2,3\% NRDt) appartiennent à un individu adulte. Il s'agit de deux molaires supérieures, d'un fragment de coxal et d'un fragment d'humérus.

2. Lautopode correspond aux basipodes (carpes/tarses), métapodes et acropodes (phalanges). 


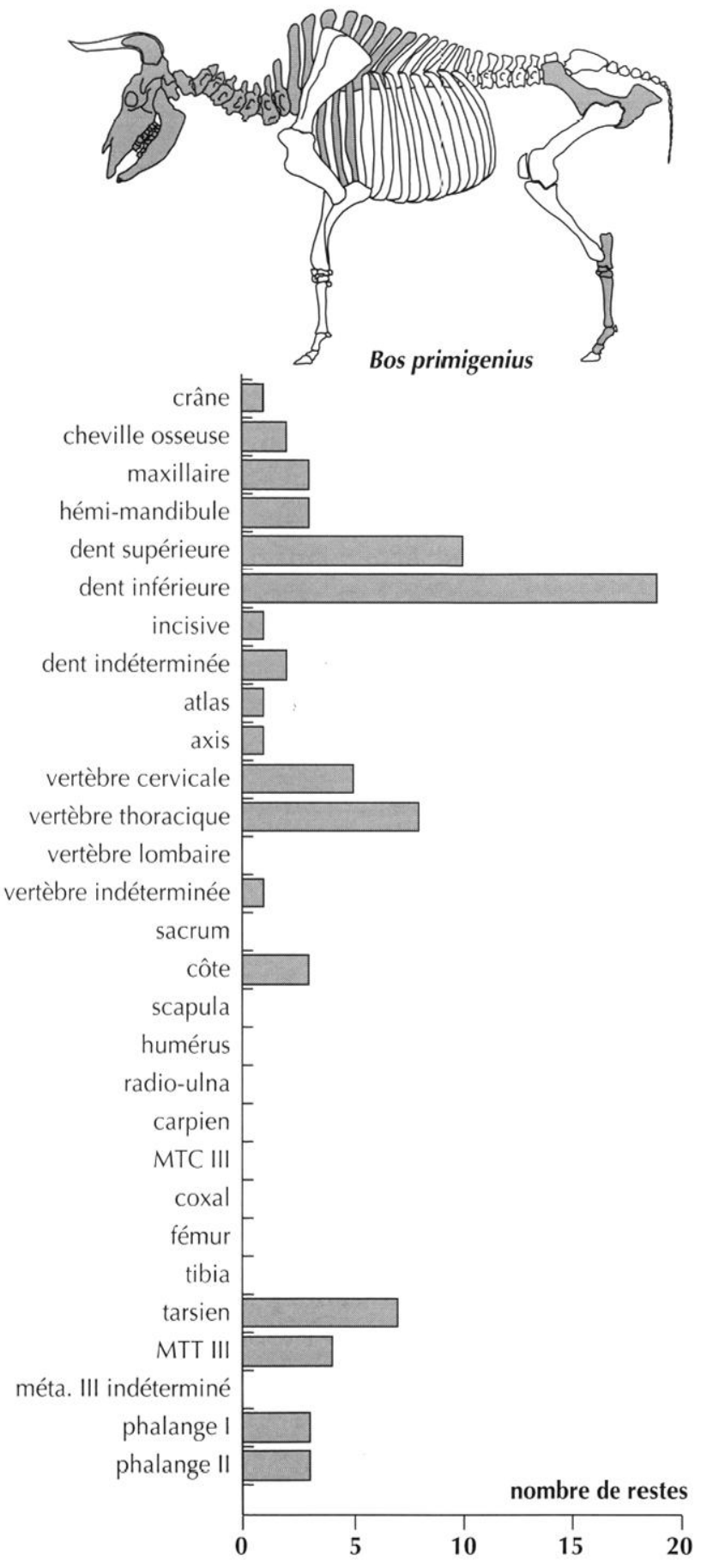

Fig. 9 - Soucy 1 : représentation de différentes parties du squelette de Bos primigenius (en NR).

Le Rhinocéros de Merck. Le Rhinocéros est représenté par trente-quatre restes $(19,9 \%$ du NRDt), et une douzaine d'autres fragments ont de fortes chances de lui appartenir. L'attribution au Rhinocéros de Merck (Dicerorhinus mercki Jaeger, Kaup) a été effectuée

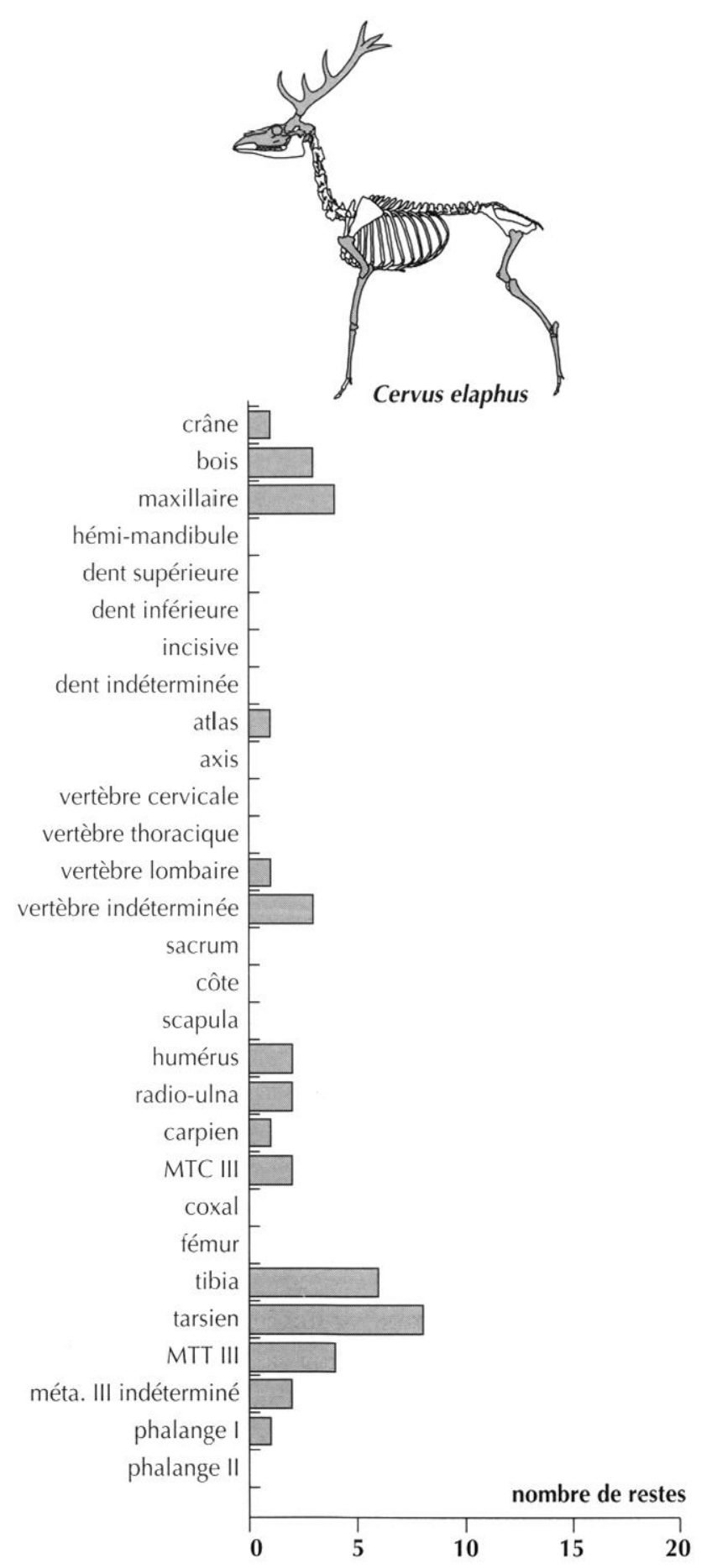

Fig. 10 - Soucy 1 : représentation de différentes parties du squelette de Cervus elaphus (en NR).

sur les dents par C. Guérin. Un seul animal, un individu assez jeune, a pu être identifié. Tout comme l'Aurochs, il n'est attesté que par le squelette axial, les dents et la mandibule, la portion arrière de sa carcasse (coxal et portion caudale de la colonne vertébrale) se 


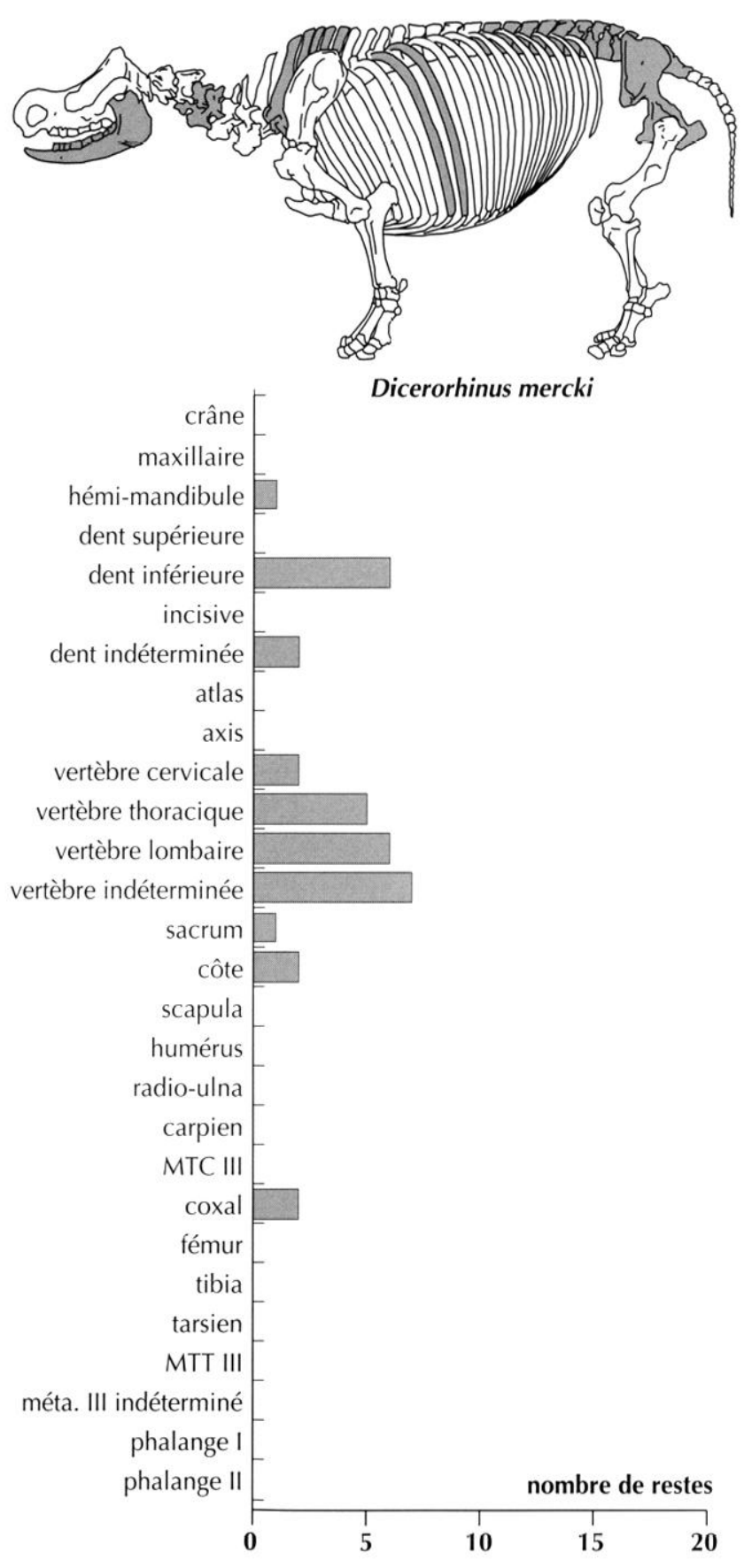

Fig. 11 - Soucy 1 : représentation de différentes parties du squelette de Dicerorhinus mercki (en NR).

présentant encore en connexion lors de sa découverte (fig. 11).

Le Proboscidien. Les restes de proboscidien sont au nombre de six $(3,5 \%$ du NRDt) relatifs à deux individus. Il s'agit essentiellement d'éléments crâniens (dents et défenses comprises) qui ont permis l'attribution à Palaeoloxodon antiquus (détermination S. Louguet) ". Il est probable qu'un certain nombre de fragments de diaphyses indéterminées de très grande taille lui appartiennent également. On notera que l'une des défenses, longue de $2,5 \mathrm{~m}$, était associée à des fragments de mandibule et maxillaire avec dent en formation (fig. 6).

Le Cheval. Six fragments osseux proviennent d'un cheval. Ce sont exclusivement des éléments du squelette postcrânien qui ne permettent pas d'obtenir des informations sur l'âge ou le sexe de l'unique animal qu'ils figurent.

Le Suidé. Le Sanglier est attesté à Soucy 1 par un seul reste, un distal d'humérus.

Le Castor. Cette espèce est représentée exclusivement par deux molaires attribuées à Castor fiber (détermination T. van Kolfschoten, université de Ledde).

L'Ours. Un crâne d'ours a pu être déterminé in situ (David, in Lhomme et al., 1995). C'est un individu âgé, unique témoin de la présence de carnivore sur le site.

\section{REPRÉSENTATION DES DIFFÉRENTES PARTIES ANATOMIQUES}

La représentation des différentes parties du squelette varie d'une espèce à l'autre (fig. 9 à 11). Les restes de grands mammifères (aurochs et rhinocéros) correspondent essentiellement à des portions de carcasses (squelette axial) car très peu d'os longs ont pu être déterminés anatomiquement et spécifiquement (il s'agit exclusivement de fragments de métapodes d'aurochs). Le nombre de fragments de diaphyses indéterminées pouvant se rapporter à ces deux taxons est lui aussi assez faible.

La configuration des restes de cerfs est différente. On trouve en effet pour cette espèce des portions de membres en connexion et les os sont proportionnellement mieux conservés. Les os longs représentent 46,5\% du NRD et, mis à part l'absence de côte, il n'existe pas de forte distorsion dans la représentation des différentes

3. Étude en cours à l'université de Lille I sous la direction de P. Auguste. 
parties du squelette. Par ailleurs, la plupart des os longs de cerfs ne sont pas fragmentés.

Les restes de cervidés sont, à cause de leur taille, plus exposés aux dégradations postdépositionnelles que ceux de rhinocéros ou d'aurochs, d'une épaisseur et d'une densité plus importantes (Bouchud, 1975 ; Brain, 1981 ; Lyman, 1984).

Le nombre de restes représentant les autres espèces n'apporte rien à cet aspect de l'analyse.

\section{PALÉOENVIRONNEMENT}

Bien que la représentation des espèces soit peut-être biaiséc par des phénomènes de conservation, la composition du spectre faunique constitue une première information pour la connaissance de l'environnement du site.

La forte interaction entre les ongulés, la végétation et le climat permet, par le biais des associations d'espèces, de proposer une reconstitution assez fiable du contexte paléoclimatique et paléoenvironnementale d'un site (Delpech et al., 1983; Guadelli, 1987). En ce qui concerne la liste des espèces qui composent l'ensemble faunique de Soucy 1, il existe une certaine variété, tant de la taille des animaux que des biotopes qu'ils représentent habituellement. Cependant, ils s'apparentent tous à un climat tempéré.

Le Cerf, le Sanglier et le Chevreuil appartiennent au groupe d'espèces de milieux boisés et correspondent à des phases d'améliorations climatiques. L'Ours se rattache plutôt à ce groupe.

Les exigences écologiques du Rhinocéros de Merck ont été établies par C. Guérin en fonction des flores et faunes qui lui sont habituellement associées et de ses caractéristiques anatomiques. Son biotope préférentiel est la forêt claire de type chênaie mixte, forêt de conifères ou forêt méditerranéenne, entrecoupée d'étendues herbeuses peuplées de graminées, cypéracées, chénopodiacées, composacées et fougères (Guérin, 1980).

Le Cheval et l'Aurochs appartiennent au groupe de milieux ouverts non arctiques et témoignent de la présence de prairies aux alentours du site. Ainsi les trois quarts des espèces représentées à Soucy 1 sont inféodés aux milieux boisés contre un quart aux milieux ouverts.

Par conséquent, l'ensemble de ces espèces suggère un paysage mixte de forêts et buissons mêlés de quelques étendues herbeuses tel qu'il en existe en climat tempéré.
La présence du Rhinocéros de Merck concourt à apporter un caractère relativement humide à ce climat.

Ces informations s'accordent avec un environnement de rang interglaciaire et ne contredisent pas l'attribution chronologique du gisement.

\section{APPROCHE ARCHÉOZOOLOGIQUE}

Les différents paramètres sur l'origine de l'accumulation doivent être dégagés afin de déterminer les hypothèses de fonctionnement du site qui pourront être proposées. Un assemblage osseux archéologique n'est pas forcément d'origine intégralement anthropique, même dans le cas de Soucy 1 où une intervention humaine est attestée par la présence de nombreux artefacts lithiques. Il peut résulter de facteurs naturels et/ou d'une activité de prédation émanant tout autant des carnivores que de l'homme.

Nous ne reviendrons pas sur les processus d'altérations postdépositionnelles d'origines climato-édaphiques qui ont été traités lors de l'analyse taphonomique du niveau archéologique (cf. p. 6-9). Il sera question ici de rechercher des agents responsables de l'accumulation osseuse.

\section{LES CAUSES DE LA MORT DES ANIMAUX}

\section{Les courbes de mortalité}

L'analyse des courbes de mortalité des populations animales découvertes en contexte archéologique peut orienter les hypothèses sur l'origine de l'accumulation de restes osseux, car leur profil est souvent en corrélation avec la configuration des vestiges (Lyman, 1994). Dans le cas d'une mortalité catastrophique, de nombreux animaux (dont une espèce exclusive ou très majoritaire) meurent au même moment dans le même lieu. Les causes de cette mort massive peuvent être diverses: sécheresse, noyade lors des migrations, etc. La courbe de mortalité décroît régulièrement des plus jeunes vers les plus âgés.

Dans le cas d'une mortalité naturelle, appelée aussi attritionnelle, les animaux meurent de façon régulière et continue dans le temps « la localisation des ossements est alors plus diffuse, mais l'enfouissement est progressif " (Shipman, 1983; Behrensmeyer, 1983). La courbe de 
mortalité de ces animaux se profile en $\mathrm{U}$, les individus jeunes et les très vieux étant plus représentés que le reste de la population.

Indépendamment de ces deux modèles, les animaux peuvent également, quel que soit leur âge, se faire piéger par les sédiments meubles qui bordent les cours d'eau et être transportés par l'eau le long des berges avant de s'y échouer définitivement (Fosse, 1994).

Enfin, lors d'une chasse sélective d'origine anthropique, on parle de mortalité cynégétique. La courbe de mortalité met alors en évidence une forte prépondérance de la classe des jeunes adultes et des adultes.

Que ce soit dans le cas d'une mortalité catastrophique ou dans celui d'une mort attritionnelle, une activité de charognage des carnivores, mais également de récupération opportuniste par l'Homme est envisageable.

\section{L'âge des animaux de Soucy 1}

Avant même de connaître le profil de la courbe de mortalité des animaux de Soucy 1, nous pouvons dire qu'avec onze animaux provenant de neuf espèces différentes, ce site ne correspond pas au modèle catastrophique. Une mort naturelle de tous ces animaux sur une surface de $400 \mathrm{~m}^{2}$ semble également peu probante.

Sur ces onze animaux dénombrés, nous ne connaissons l'âge relatif que de cinq d'entre eux : il s'agit de quatre jeunes (les deux cerfs, un aurochs et le rhinocéros) et d'un très vieux (l'ours), ( $f$. p. 10-12). Cette configuration pourrait se rapprocher du modèle attritionnel, mais cet échantillon ne constituant pas la moitié de l'effectif, il est impossible de trancher.

Il est difficile d'envisager le modèle cynégétique d'après la structure des populations en raison de la présence des deux classes d'âge extrêmes et de l'ignorance de l'âge des sept autres animaux, mais il n'est pas à exclure dans la mesure où les hypothèses précédentes ne sont pas satisfaisantes.

\section{ORIGINE DE L'ASSEMBLAGE}

\section{Un dépôt par la rivière?}

Le contexte alluvial du site de Soucy 1 nous a astreint à nous interroger sur l'éventualité d'un transport et d'un dépôt des restes osseux par la rivière. Au regard de l'analyse du contexte archéologique et du matériel osseux cette hypothèse paraît difficilement envisageable pour la totalité des taxons représentés. En premier lieu, le dépôt de plusieurs animaux par une crue implique un débit torrentiel qui n'est corroboré ni par les analyses morphostratigraphiques et malacologiques, ni par la présence d'un certain nombre d'esquilles osseuses (près de $17 \%$ des indéterminés). Le site n'est pas implanté sur la berge du chenal dont le débit est d'ailleurs assez limité, comme en témoignent la baisse de l'alluvionnement et l'installation d'une ripisylve ( $c$.p. 3,6) ; les vestiges se situent, par conséquent, en dehors des battements réguliers de l'eau. On peut ajouter qu'aucune altération visible se rapportant à l'action de l'eau n'a été relevée (os roulé) et que l'orientation des os longs et des carcasses ne laisse pas apparaitre d'axe de dispersion unidirectionnel.

Par ailleurs, la mise en évidence de séquences générales de transport d'éléments osseux par différents auteurs (Brugal, 1994; Lyman, 1994) définit trois groupes d'ossements qui peuvent être déplacés indépendamment par l'eau. Le groupe I correspond au squelette axial, aux phalanges ainsi qu'aux os courts, le groupe II aux os des membres et le groupe III aux éléments crâniens ; « un assemblage contenant des éléments des trois groupes est probablement non transporté " (Brugal, 1994), re qui est le cas pour les trois espèces dominantes de Soucy 1.

Ainsi, l'hypothèse d'une accumulation des vestiges osseux par l'eau doit être rejetée pour les espèces les mieux représentées.

\section{Prédation par des grands carnivores?}

Le peu d'exemples d'étude de repaires de carnivores actuels sur lesquels peut être établie une comparaison concernent ceux d'hyènes en Afrique et sont principalement situés en grotte (Cruz-Uribe, 1991 ; Blumenschine, Marean, 1993). Ces données sont complétées par un certain nombre de recherches archéologiques et paléontologiques récentes sur des repaires d'hyènes fossiles (Fosse et al., 1998).

Un des premiers critères d'identification d'un repaire de carnivores est l'altération des surfaces osseuses due au rongement de ces derniers. Le mauvais état des os de Soucy 1 n'a pas facilité la recherche de tels stigmates, mais même sur les éléments les moins abîmés nous n'avons pas observé d'altération imputable aux carnivores. 
Des os consommés par les hỵènes, il ne subsiste plus que les diaphỵses (les épiphỵses sont attaquées en premier) ; la fragmentation peut être conséquente (Binford, 1981 ; Brain, 1981), mais le taux de "cylindre " est généralement élevé. Les éléments squelettiques les mieux représentés pour les grandes espèces sont ceux des membres, tandis que les éléments du squelette axial ont peu de chance de survie (Blumenschine, Marean, 1993; Fosse et al., 1998). Ce schéma pourrait s'appliquer aux restes de cervidés attestés principalement par des os longs entiers dont les épiphyses ne sont pas conservées, mais il va à l'encontre de la configuration des vestiges d'aurochs et de rhinocéros.

On peut également ajouter qu'aucun reste de carnivore - hormis celui d'ours - n'a été trouvé sur le gisement. Or dans les repaires fossiles il est fréquent de trouver des restes de carnivore, notamment de jeune (Fosse, 1994). ¿̀ Soucy 1, la mauraise conservation explique l'absence des restes d'os d'immatures mais moins celle de dents. Par conséquent, une attribution aux carnivores de l'accumulation de restes osseux n'est pas satisfaisante pour la totalité des vestiges, même si on ne peut totalement l'écarter.

\section{Une prédation anthropique à Soucy 1 ?}

La démonstration précédente, en tenant compte des seuls vestiges fauniques, montre qu'une origine naturelle ou émanant de carnivores n'est pas satisfaisante pour l'ensemble de l'accumulation osseuse ; aussi une prédation anthropique est à envisager. Le mauvais état général des restes fauniques de Soucy 1 n'a pas rendu possible la lecture d'éventuelles traces de découpe, pas plus que celle de la morphologie des fractures. En revanche, la présence de nombreux artefacts lithiques associés à la faune contribue à attester une relation entre l'homme et certains animaux (aurochs, cerfs et rhinocéros). L'analyse de la fréquence des parties squelettiques peut aussi nous aider à mieux appréhender l'histoire de l'assemblage osseux, notamment par des essais de comparaison.

En effet, les observations effectuées sur des groupes de chasseurs-collecteurs modernes montrent qu'ils emportent préférentiellement les parties carnées des membres non désossés (Isaac, 1978 ; Brain, 1981 ; Hill, Behrensmeyer, 1984). Cela s'accorderait avec la configuration des restes d'aurochs et de rhinocéros de Soucy 1. Il est donc possible d'évoquer un site de boucherie et peut-être un site d'abattage.

\section{RÉPARTITION SPATIALE ET INTERPRÉTATION}

Les restes osseux de Soucy 1 se présentent essentiellement sous forme de portions de carcasses et de fragments de pattes en connexion ( $c f$. p. 10-12). Les taxons sont dispersés sur l'ensemble du niveau bien que l'on observe quelques concentrations particulières. On peut noter trois " unités " principales: une portion de carcasse d'aurochs, une portion de carcasse de rhinocéros et les restes de l'un des deux cervidés relativement concentrés sur environ $8 \mathrm{~m}^{2}$ (fig. 12).

Sur une surface d'environ $40 \mathrm{~m}^{2}$ au sud-est du site, on décompte six espèces différentes (Castor, Cheval, Cerf, Rhinocéros, Aurochs et Proboscidien).

I a seule configuration des restes fauniques de Soucy 1 ne permet pas une interprétation complète et c'est pourquoi il est intéressant de prendre en compte les études sur les répartitions spatiales des sites archéologiques anciens. Parmi de nombreux travaux sur les accumulations de faune des sites du Pléistocène ancien de l'Est africain (Bunn, 1983 ; Isaac, 1978), ceux d'Isaac et Harris ont permis de proposer trois modèles de sites :

- les sites de type A, qui présentent une concentration de vestiges lithiques et peu ou pas de faune, sont parfois interprétés comme des bases de travail ;

- les sites de type B, comportant une ou deux carcasses de gros animaux plus quelques restes d'autres espèces associés à quelques vestiges lithiques, sont interprétés habituellement comme des sites de chasse ou de boucherie ;

- enfin, les sites de type $C$, présentant eux une forte concentration de vestiges lithiques et osseux (de plusieurs espèces), sont considérés comme des camps d'occupation.

D'autres travaux sur les comportements alimentaires de chasseurs africains actuels, les Bisa, ont mis en évidence la difficulté à reconnaître un véritable site de type $B$, en raison d'interventions diverses comme celles des carnivores, mais aussi du fait que les techniques de débitage des carcasses ne laissent pas forcément de traces sur les os (Crader, 1983).

Il a pu être observé sur les accumulations consécutives aux activités de chasse et de boucherie des sites Bisa :

- que si les hommes ne transportent pas les restes d'éléphant, ils emportent ceux d'hippopotame (par extension, ils pourraient emporter ceux de rhinocéros) ; 


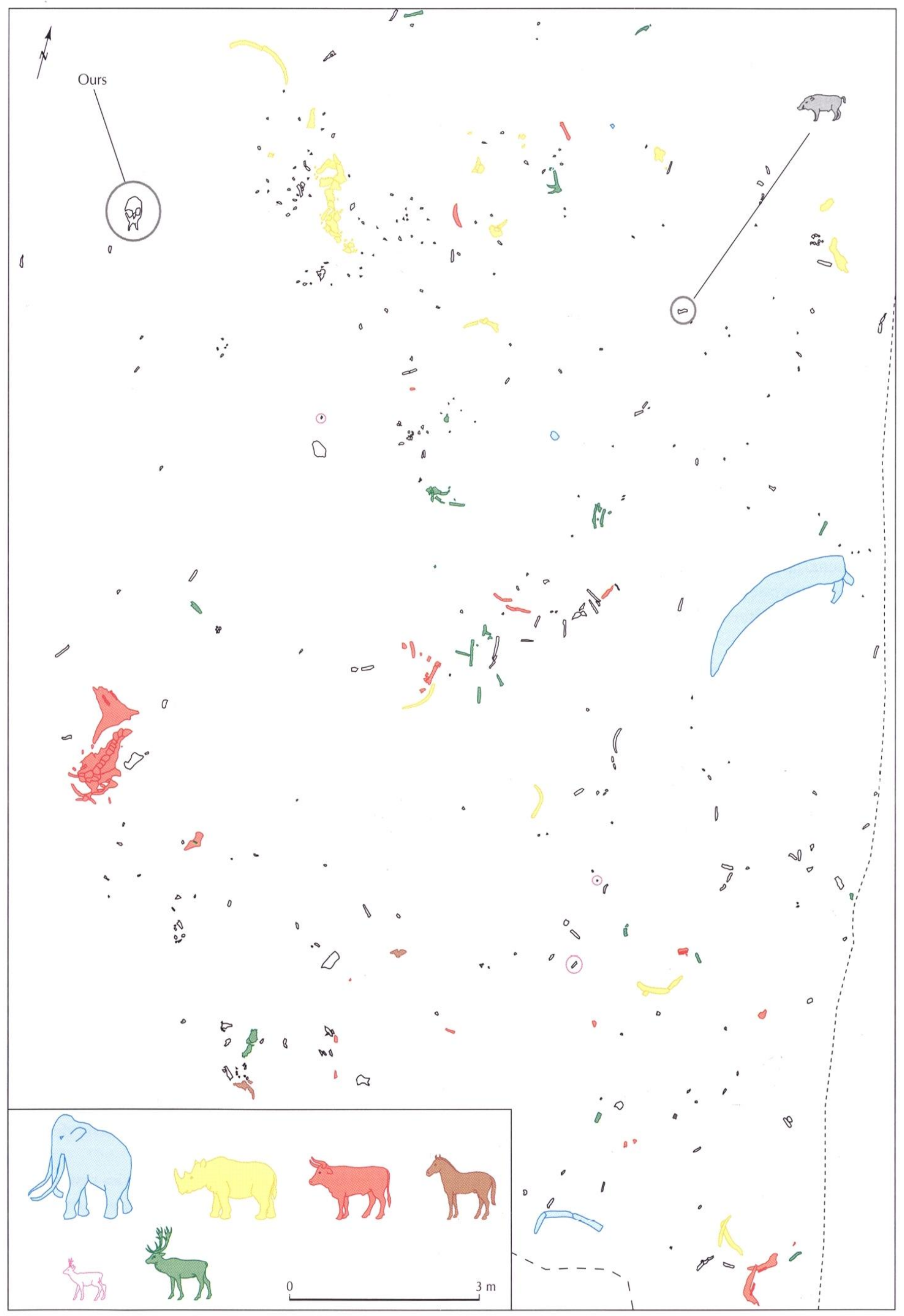

Fig. 12 - Soucy 1 : répartition spatiale des restes fauniques par espèces. 
- que les carcasses de grandes tailles sont systématiquement désarticulées mais pas forcément dans le but de transporter les os des membres; cette désarticulation facilite en fait le décharnement ;

- qu'en cas d'intervention des carnivores, l'axe vertébral des très grands herbivores (Éléphant) peut avoir été emporté par ceux-là, a fortiori celui des grands herbivores.

Du point de vue de la répartition spatiale des restes, ces sites peuvent présenter simultanément des zones denses en restes osseux et des portions de carcasses dispersées sur environ $150 \mathrm{~m}^{2}$.

Ainsi, si les sites de type B ne se présentent jamais tels que l'on pourrait s'y attendre dans un contexte actuel, cela doit s'avérer encore plus délicat en contexte archéologique. Cet exemple est intéressant, car il met en évidence la complexité de l'histoire d'une accumulation de vestiges et la difficulté de l'interpréter quand on n'en maîtrise pas les agents accumulateurs.

En suivant le premier schéma et en intégrant les données taphonomiques, on serait tenté d'éliminer le rapprochement de Soucy 1 avec le type A et, dans une moindre mesure, avec le type $\mathrm{C}$, pour favoriser un rapprochement avec la configuration des sites de type $\mathrm{B}$. Cela nous amènerait à interpréter Soucy 1 comme un site de chasse ou de boucherie, représentant les restes d'une accumulation d'origine majoritairement anthropique, consécutive à une activité de traitement des matières carnées. L'occupation pourrait correspondre à plusieurs fréquentations peu espacées dans le temps puisque l'enfouissement a été relativement rapide.

\section{L'INDUSTRIE LITHIQUE}

L'industrie lithique comprend 1790 restes taillés (tabl. II) parmi lesquels les outils avérés, composés d'outils sur éclats et de pièces bifaciales, constituent seulement 3,3\%. Deux chaînes opératoires sont représentées sur le site, une chaîne opératoire de production de pièces bifaciales et une chaîne opératoire de débitage d'éclats.

\section{MATIÈRE PREMIÈRE ET APPROVISIONNEMENT}

Les 1790 restes lithiques résultent de l'exploitation de blocs de silex issus de différents étages du Crétacé
Tabl. II - Composition de l'industrie lithique de Soucy 1.

\begin{tabular}{|l|c|r|r|r|}
\hline \multicolumn{1}{|c|}{ catégories } & $\begin{array}{c}\text { effectif } \\
\text { (hors outils) }\end{array}$ & outils & total & \multicolumn{1}{c|}{$\%$} \\
\hline blocs testés & 7 & & 7 & 0,4 \\
éclats de débitage & 758 & 38 & 796 & 44,5 \\
éclats de façonnage & 137 & 5 & 142 & 7,9 \\
pièces bifaciales & & 15 & 15 & 0,9 \\
galets aménagés & 711 & 2 & 2 & 0,1 \\
petits et très petits éclats & 27 & & 711 & 39,7 \\
nucléus & 90 & & 90 & 1,5 \\
cassons & $\mathbf{1 7 3 0}$ & $\mathbf{6 0}$ & $\mathbf{1 7 9 0}$ & $\mathbf{1 0 0}$ \\
\hline Total & & & & 5 \\
\hline
\end{tabular}

supérieur et présents sous forme de galets dans les alluvions grossières. Ces silex sont de qualités variées : d'une texture extrêmement fine et cassante à des matières légèrement grenues. Des anfractuosités et des zones de clivage avec développement d'opale ont fréquemment généré l'abandon de blocs à différentes étapes de leur exploitation, quatre blocs, fragilisés par le gel, ont complètement éclaté dès le début de leur taille.

Les remontages les plus complets permettent d'évaluer les modules des blocs débités. Ces derniers, de forme subsphérique, montrent des dimensions maximales très souvent supérieures à $100 \mathrm{~mm}$ et pouvant atteindre $200 \mathrm{~mm}$.

Les traces d'alluvionnement visibles à la surface de ces matériaux témoignent d'un approvisionnement dans l'environnement immédiat du site.

La fouille a révélé la présence sur le gisement de 293 galets bruts. Cet ensemble est principalement composé de galets de silex (207 pièces; $70,6 \%$ ), de granite (43 pièces; $14,7 \%$ ), de grès et de calcaire (chacun 17 pièces ; $5,8 \%$ ), enfin de quartz et de gneiss (respectivement 5 et 4 pièces; $1,7 \%$ et $1,4 \%$ ). Les dimensions de ces galets varient d'une trentaine de millimètres à plus de deux cents millimètres.

Plus de la moitié des galets (148 pièces) sont concentrés sur $12 \mathrm{~m}^{2}$ du site ( $c$. p. 6 et fig. 3, 6 et 13). Afin de tenter une interprétation de cette concentration de blocs, nous avons constitué des séries de comparaison en pratiquant deux tests au sommet de la nappe graveleuse, à proximité de l'emprise du gisement (séries aléatoires 

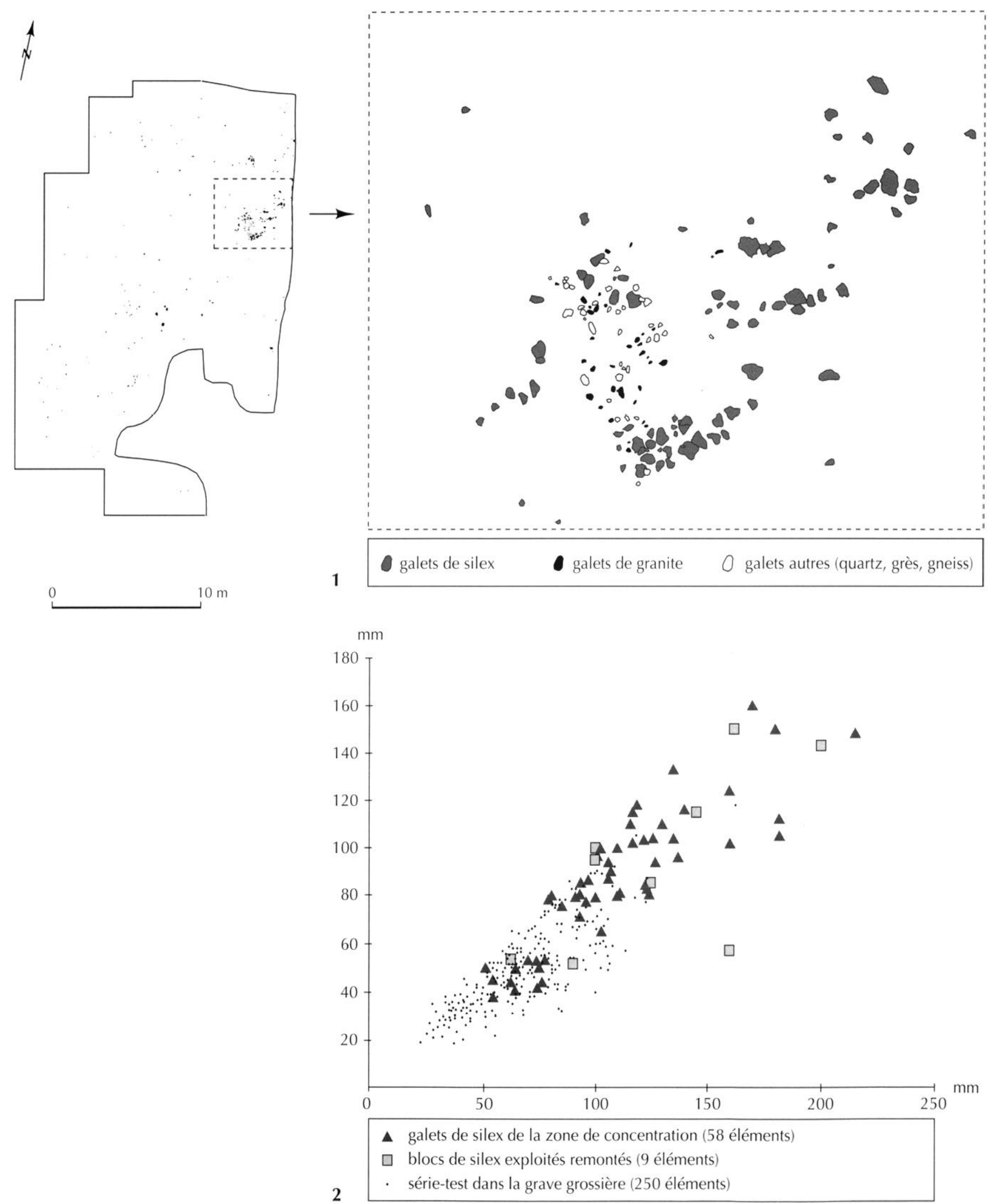

Fig. 13 - Soucy $1: 1$, plan de répartition des galets bruts sur le site; 2, dispersion de trois séries de galets bruts de silex selon l'axe de la plus grande longueur et l'axe qui lui est perpendiculaire (pour les séries tests, ne sont pas représentés les galets dont la plus grande dimension est inferieure à $20 \mathrm{~mm}$ ). 
de 200 éléments chacunes constituées à partir d'une échelle d'arpenteur).

La comparaison entre les deux séries-tests et les galets mis au jour dans le niveau archéologique met en avant une surreprésentation des galets de granite et de grès dans la zone de concentration du gisement. Ils correspondent à $37 \%$ des galets présents dans la concentration, alors que dans les deux séries-tests, ils ne dépassent pas $6 \%$ (série $1: 3,5 \%$, série $2: 5,7 \%$ ).

Quelques remontages très complets permettent de réaliser une étude comparative entre les modules des galets de silex exploités et non exploités présents sur le site et les galets provenant des séries-tests (fig. 13). Les populations comparées ne permettent pas une étude statistique mais autorisent quelques observations :

- les blocs de silex exploités et bruts du site sont de modules comparables, leur plus grande dimension dépassant souvent $100 \mathrm{~mm}$;

- dans les séries-tests, seulement $13 \%$ des galets de silex dépassent $100 \mathrm{~mm}$ dans leur plus grande dimension, $60 \%$ étant inférieurs à $80 \mathrm{~mm}$ (notons que pour les séries-tests nous n'avons pas enregistré les galets inférieurs à $20 \mathrm{~mm}$ ).

Les différences relevées dans les modules et les natures des galets entre les séries-tests et la zone de concentration des galets bruts du site, les similitudes morphométriques qu'entretiennent les blocs exploités et bruts du site, ainsi que la nature et la répartition spatiale des blocs au sein de la concentration, permettent de proposer que nous pouvons être en présence d'un dépôt de matière première résultant d'une collecte (sélection et transport) de galets alluviaux par les hommes.

\section{LA CHAÎNE OPÉRATOIRE DE PRODUCTION DE PIÈCES BIFACIALES}

Les pièces bifaciales sont au nombre de 15 (dont 8 pièces entières et 7 fragments). La totalité des éléments de la chaîne opératoire de production de pièces bifaciales est représentée sur le site, des éclats corticaux et ébauches avortées aux pièces bifaciales abandonnées et aux petits éclats de façonnage. Les éclats attribuables à cette chaîne opératoire constituent un corpus de 142 pièces parmi lesquelles $\mathfrak{5}$ ont été sélectionnées comme supports d'outils ( $c f$. p. 25).
Les pièces bifaciales entières (hors ébauches) présentent des longueurs comprises entre 70 et $128 \mathrm{~mm}$ (une seule pièce dépassant les $100 \mathrm{~mm}$ ) pour un allongement (rapport L/l) compris entre 1,37 et 2,19. Il s'agit donc de pièces bifaciales de petits modules et plutôt allongées. Exception faite de la plus grande, ces pièces présentent des bases réservées.

L'observation de la morphologie des extrémités apicales et de la délinéation des bords permet de distinguer deux ensembles :

- les pièces bifaciales aux deux bords rectilignes ou légèrement convexes et à l'extrémité apicale convexe $(n=4)$ (fig. 14) ;

- les pièces aux deux bords légèrement concaves associés à une extrémité plus aiguë $(\mathrm{n}=3)$ (fig. 15) ; ces dernières peuvent être rapprochées du morphotype «biface micoquien " de F. Bordes (1961).

La reconstitution de la chaine opératoire de production de pièces bifaciales s'appuie sur les observations faites sur les ébauches (2 cas), les outils abandonnés et sur les remontages de déchets de façonnage.

Les Préhistoriques ont sélectionné des galets plats et allongés. L’investissement technique a essentiellement porté sur le dégagement des deux tiers distaux de la pièce par enlèvements plats et envahissants.

Dans un premier temps, les deux surfaces sont traitées successivement par des séries d'enlèvements détachés le long d'un bord. Ces séquences s'organisent alternativement d'une surface à l'autre et d'un bord à l'autre de la pièce (fig. 16) et confèrent à l'ébauche un profil biplan.

Dans le cas des pièces bifaciales à extrémité apicale convexe, une dernière série de petits enlèvements plats, constituant une régularisation des bords, intervient sur la moitié ou le tiers distal du support. Pour ce type de pièces bifaciales, la séquence opératoire est condensée dans la mesure où le dégagement de l'extrémité convexe tranchante est obtenu par la rencontre de deux enlèvements (alternes ou non) débordants (fig. 14).

En ce qui concerne les pièces à bords concaves et à extrémité aiguë, la mise en forme de l'extrémité apicale et de la délinéation des bords est pratiquée par des séries d'enlèvements plats et envahissants. Si l'ébauchage a été réalisé par percussion à la pierre dure, cette phase de façonnage/confection de la pointe a pu requérir l'utilisation d'un percuteur tendre. 

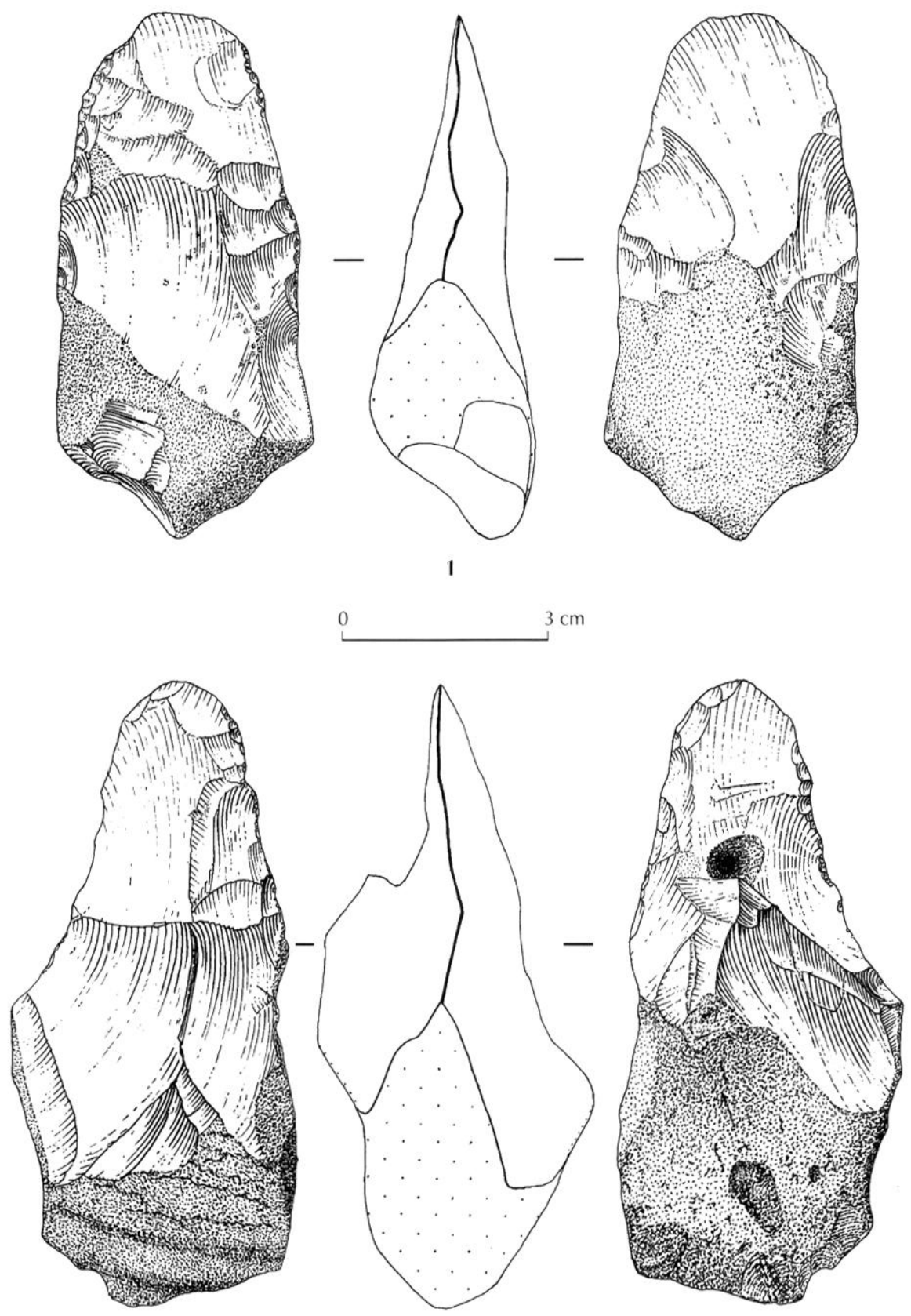

2

Fig. $14-$ Soucy 1 : pières bifaciales.

\section{LA CHAÎNE OPÉRATOIRE DE DÉBITAGE}

La chaîne opératoire de débitage est intégralement représentée sur le site et regroupe près de $90 \%$ de l'industrie lithique. Cet ensemble se compose de 1507 éclats, dont 711 mesurent moins de $20 \mathrm{~mm}$, pour 27 nucléus (tabl. II).
Les produits de débitage portent des stigmates illustrant l'utilisation d'une technique de percussion à la pierre dure, ce que vient confirmer la présence de deux percuteurs de granite dans le niveau archéologique.

L'étude technique met en évidence la présence d'une seule méthode de débitage pouvant s'appliquer suivant plusieurs schémas adaptés à la morphologie des blocs. La 

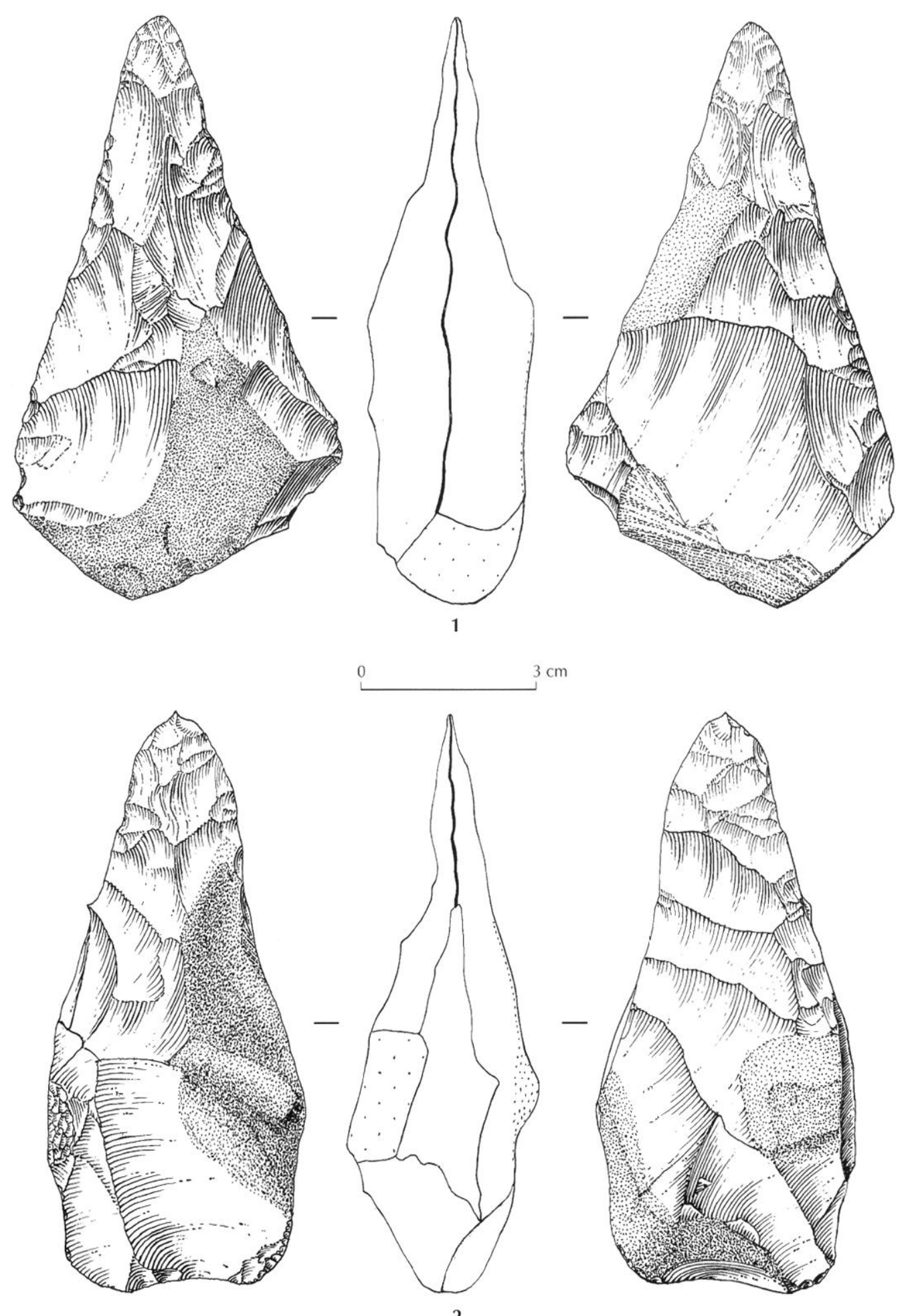

Fig. 15 - Soucy 1 : pièces bifaciales.

préparation des blocs est limitée à la mise en place d'un plan de frappe. Cette ouverture des plans de frappe a nécessité un faible investissement (70) des talons sont lisses) et l'angle formé par le talon des éclats et les surfaces d'éclatement est de l'ordre de $100^{\circ}$. La phase de plein débitage se traduit par la production d'une série 

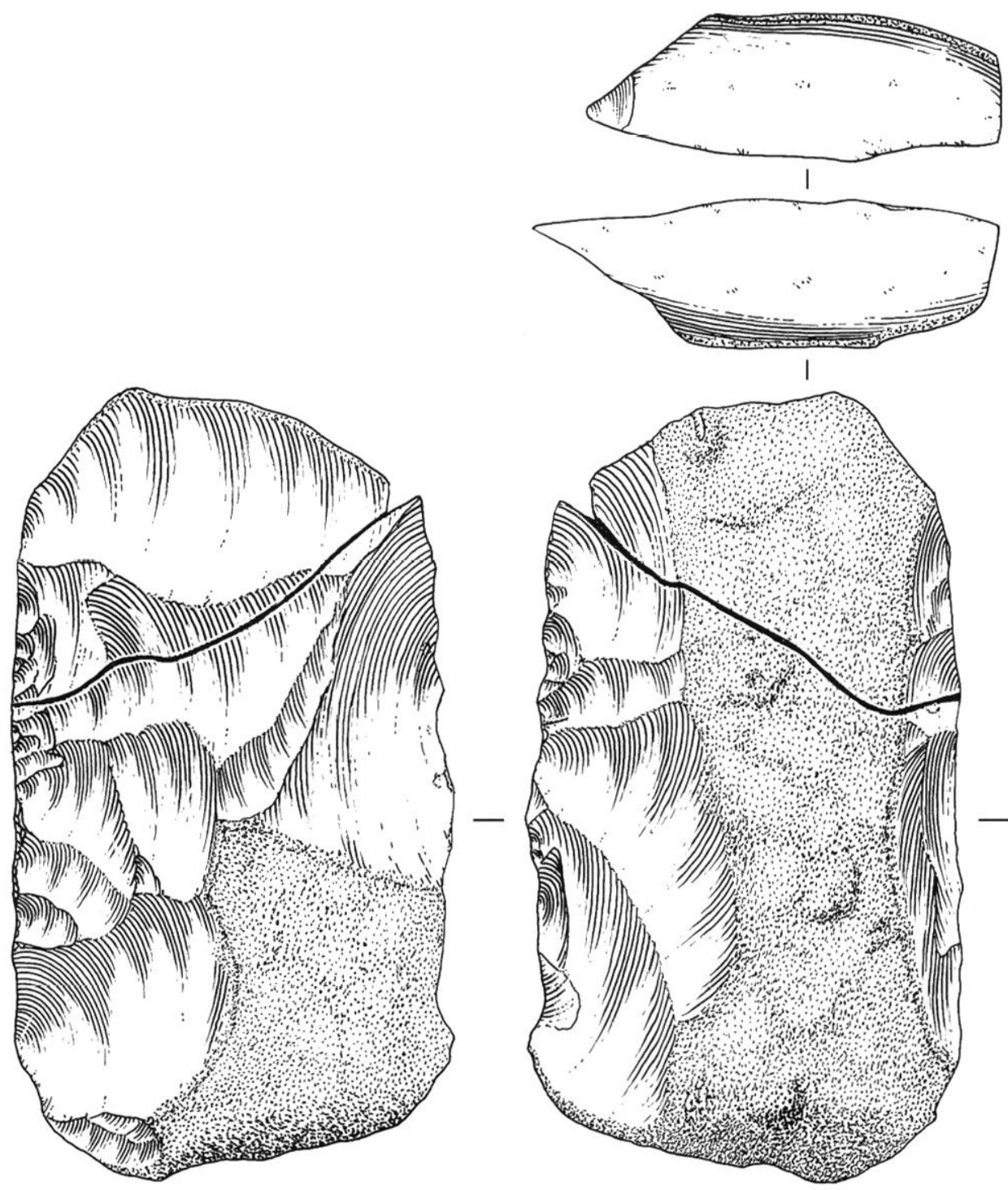

।
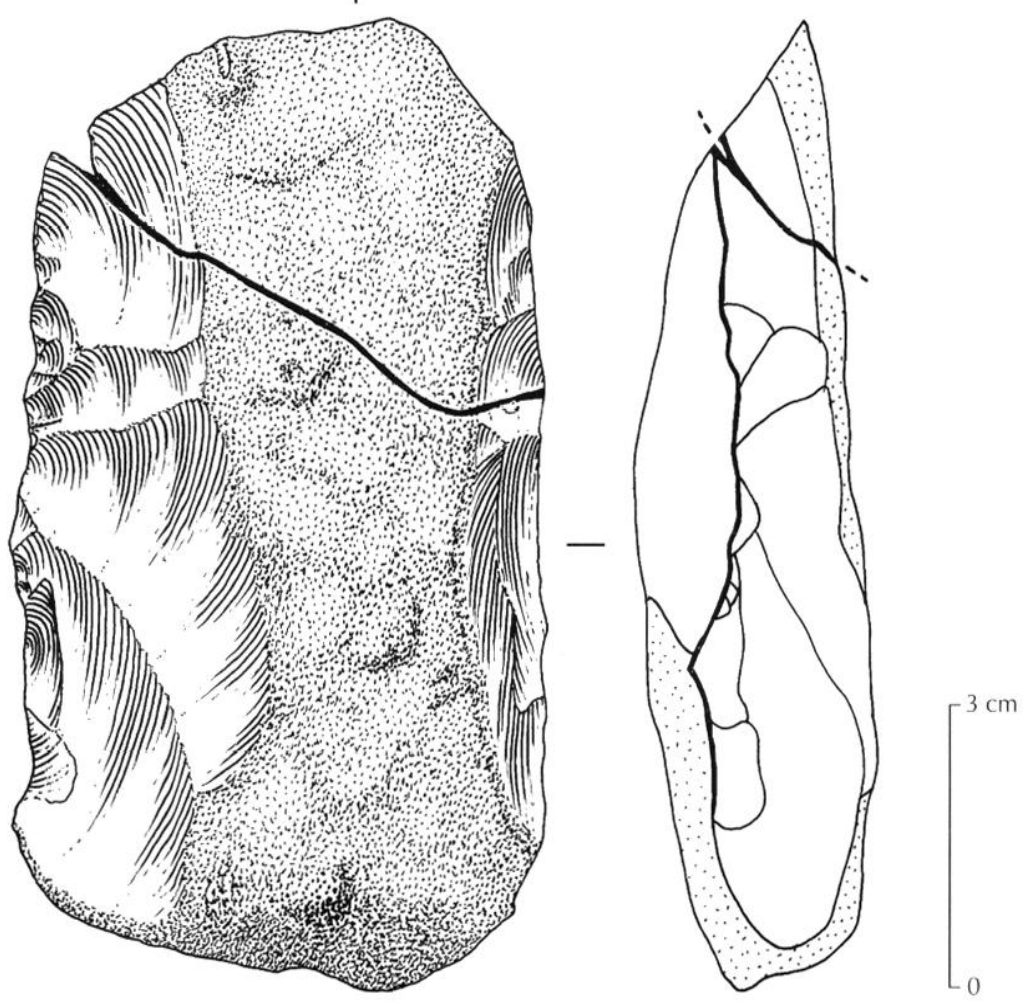

Fig. 16 - Soucy 1 : ébauche de pièce bifaciale cassée au cours du façonnage.

d'éclats allongés à partir du même plan de frappe incluant les premiers éclats corticaux. Après épuisement de cette surface, le débitage se déplace sur le bloc selon un enchaînement simple: ouverture de plan de frappe/production d'une série d'éclats (fig. 17).

La combinaison des différentes phases de débitage sur un même nucléus procède donc de la multiplication d'un algorithme de base qui se traduit par la recherche de deux surfaces sécantes définissant une angulation peu fermée, dont l'une présente une surface suffisamment importante pour permettre l'obtention de produits allongés. L'algorithme de base observé dans le débitage du site est similaire à celui mis en évidence à High Lodge
(Ashton of al., 1992; Forestier, 1993; Bö̈da, 1997). Toutefois, à Soucy 1, cet algorithme se répète en plusieurs phases sur chaque nucléus en privilégiant le plus souvent l'une des surfaces.

En fin de course, plusieurs nucléus présentent une phase de débitage centripète et deux nucléus peurent morphologiquement être qualifiés de discoïdes. Cette variabilité des nucléus en leur état d'abandon est la conséquence de l'enchaînement de l'algorithme de base sur un volume particulier (Boëda, 1997).

Cette méthode, qui peut être qualifiée d'assez peu élaborée dans le sens où elle ne nécessite pas une mise en forme appropriée des nucléus (Inizan et al., 1995), 

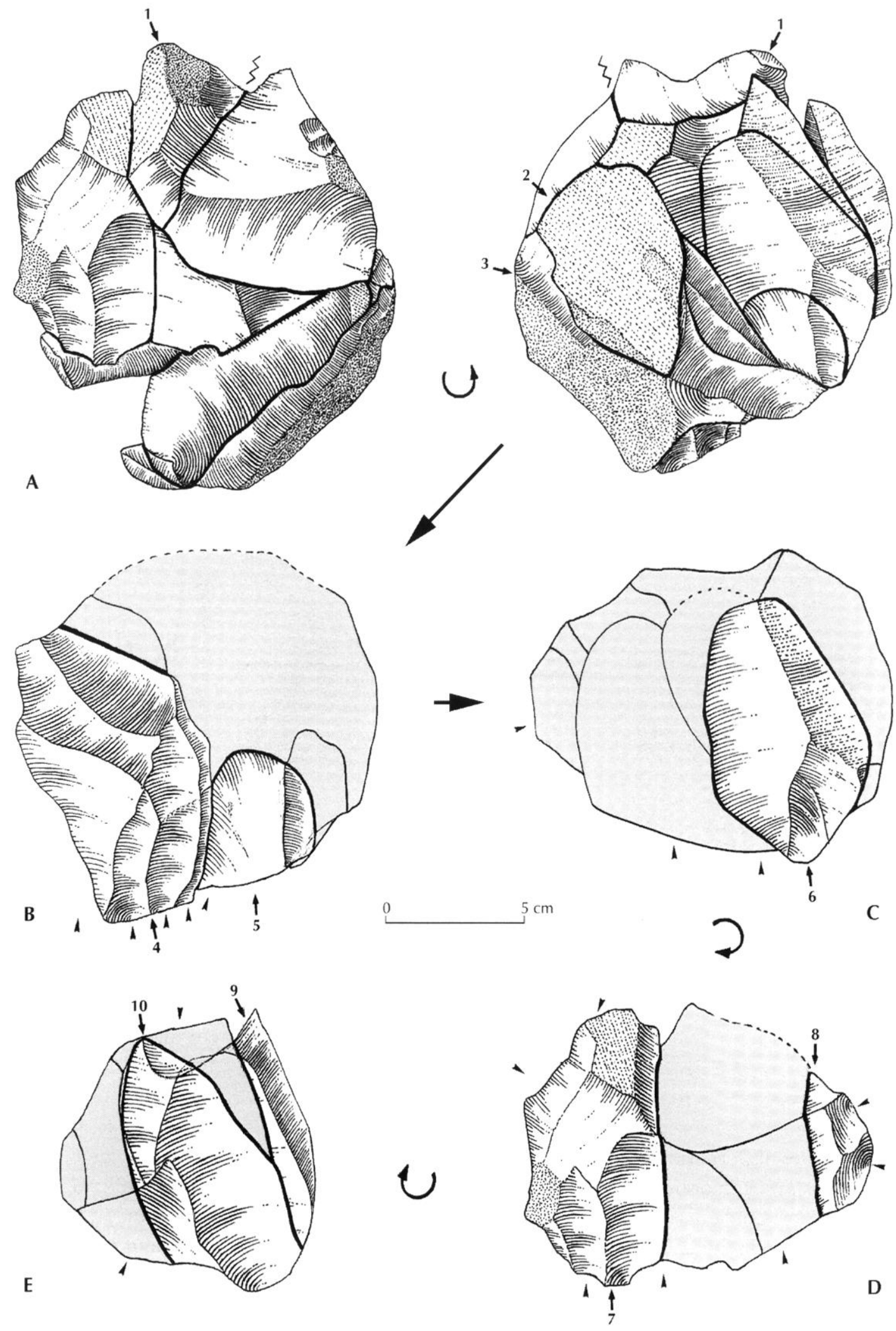

Fig. 17 - Soury 1 : schéma diachronique du remonlagp $R 9$. 

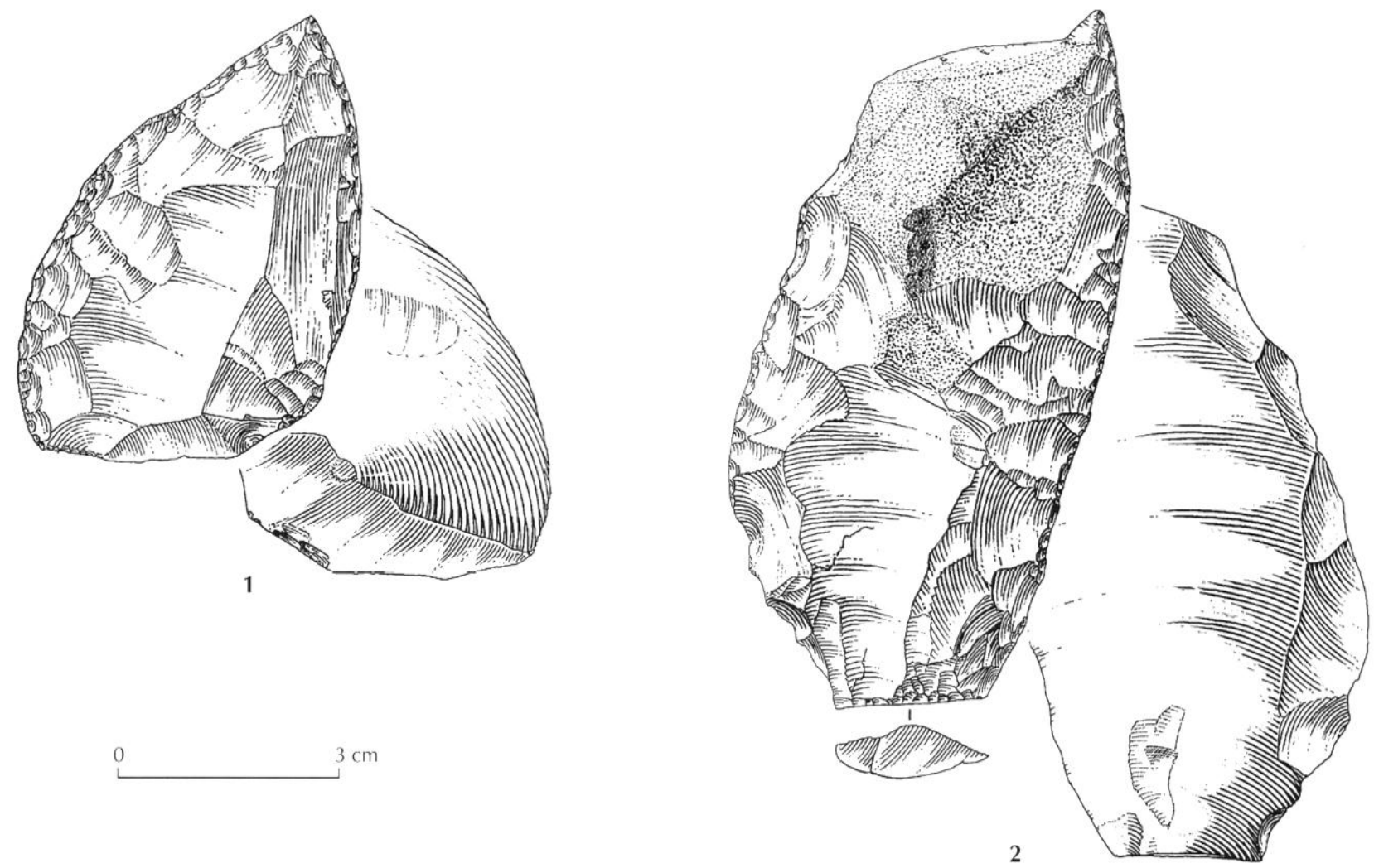

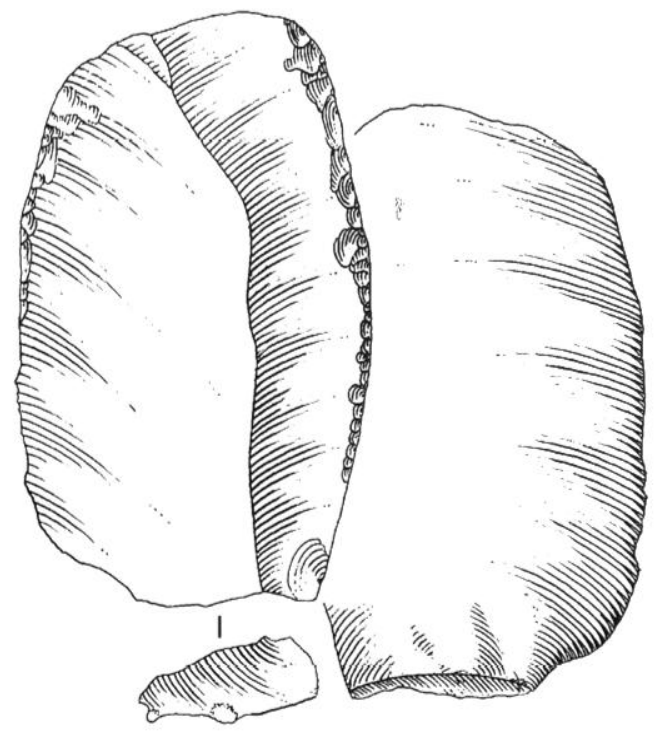

3

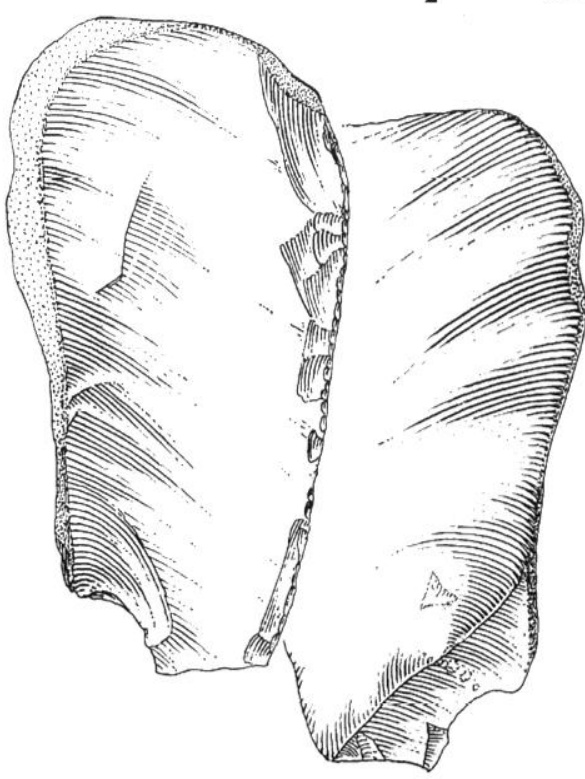

4

Fig. 18 - Soucy 1 : racloirs.

permet une exploitation optimale des blocs dans la mesure où le plein débitage est effectif dès les premicrs enlèvements corticaux.

Près de $70 \%$ des produits entiers non réfléchis sont allongés, mais les lames vraies $(\mathrm{L} / \mathrm{l}>3)$ restent très rares.
Les modules des produits débités montrent une grande homogénéité : des entames aux éclats de plein débitage, les longueurs (hors réfléchissements) dépassent rarement $80 \mathrm{~mm}$. Une telle homogénéité est liée à la méthode de débitage dans laquelle le décorticage n'est 
pas dissocié du plein débitage. Du reste, la présence de cortex ou de néo-cortex sur les éclats ne semble pas aroir été un facteur discriminant dans le choix des supports d'outils (21 des 38 outils sur produits de débitage présentent une plage corticale).

Les méthodes de débitage du Paléolithique inférieur sont assez mal connues et rarement décrites. Le débitage unipolaire selon une ou plusieurs surfaces est présent dans quelques gisements acheuléens de l'Europe du Nord-Ouest (Lamotte, 1995) où il semble présenter une certaine variabilité tant dans le taux d'exploitation des nucléus que dans leur organisation. Le niveau $\mathrm{H}$ du gisement acheuléen de Cagny-L'Épinctte (Tuffeau ot al., 1995) présente selon A. Lamotte un débitage uni- ou bipolaire qui nous paraît assez comparable à celui de Soucy 1.

\section{L'OUTILLAGE SUR ÉCLATS}

Les outils sur éclats sont au nombre de 35. Cet ensemble comprend 17 racloirs (simples, doubles et convergents), 6 encoches, 1 denticulé et 11 éclats retouchés.

Parmi les racloirs, les racloirs simples latéraux sont les mieux représentés avec 10 pic̀ces, les racloirs doubles regroupant 6 pièces. Ils sont confectionnés sur des supports plutôt allongés issus du débitage ou plus rarement du façonnage (1 cas). Les bords retouchés sont rendus convexes ou rectilignes par des retouches obliques marginales à moyennes (fig. 18). Un racloir double présente un amincissement du bord gauche par enlevements inverses. Un seul racloir convergent a été mis au jour, il est confectionné par retouches envahissantes sur un éclat épais.

Les encoches sont obtenues par retouches profondes, régularisées par de petits enlèvements, sur des supports peu allongés issus du débitage ou du façonnage ( 2 cas).

Un éclat porte une série de retouches creuses sur l'un des bords formant une denticulation.

Les éclats retouchés sont allongés et présentent sur un bord des retouches discontinues, sourent marginales, généralement directes et roujours obliques.

L'analyse fonctionnelle menéc par S. Beyries sur les outils sur éclats et pièces bifaciales (39) pièces) a permis de mettre en évidence deux grandes classes d'activité : la boucherie et le travail des végétaux. Ln certain nombre de pièces niont pas présenté de traces lisibles, notamment daus la portion nord du site. En l'état actuel de l'analyse, une quinzaine de pièces a livé des intormations :

- 5racloirs ou éclats retouchés montrent un contact avec l'os et témoignent d'une probable activité de boucherie (fig. $\left.18, n^{\circ} 1\right)$;

- 4 racloirs et 1 encoche attestent une action transversale sur des végétaux ligneux (fig. 15, $n^{\circ} 2$ ) ;

- enfin, 4 pièces bifaciales montrent des taaces particulières se développant sur le premier tiers distal et pourant être interprétées comme le résultat d'une découpe de régétaux selon un geste précis et court (Berries, in Lhomme ot al., 1998) (fig. 15, n*1, 2 ; fig. 14, $\left.n^{\circ} 2\right)$.

L'outillage de Soucy l présente l'association de pièces bifaciales, de racloirs et d'encoches auxquels il faut ajouter deux galets aménagés de petits modules (moins de $100 \mathrm{~mm}$ ). Les outils sur éclats sont confectionnés sur des supports allongés (environ une dizaine de centimètres) préférentiellement sélectionnés parmi les produits issus de la chaîne opératoire de débitage et plus rarement de la chaine opératoire de façomnage. Le registre d'outils et les méthodes de débitage observées à Soucy l s’intègrent sans difficulté dans l'ensemble de variabilité technotypologique des industries qualifiées d'acheuléennes dans l'Europe du Nord-()uest (Lamotte, 1995).

\section{ANALYSE DE LA RÉPARTITION SPATIALE DES VESTIGES LITHIQUES}

Le plan général des restiges (fig. 3, 19 et 20) montre que les restes lithiques sont présents sur l'ensemble de la surface foullée tout en formant des zones de densités variées et des aires de remontages relativement bien individualisées.

- La bordure nord du gisement située au nord de la concentration de galets (zone nord) est asse pauve en restes lithiques, excepté dans sa partie orientale où les remontages sont denses ;

- au sud des restes de cerf et de la concentration de galets, la partic sud-est du gisement (zome centrale est) se révèle extrêmement riche en restes lithiques; cette aire restreinte du site (unc cinquantaine de mètres carrés) renferme un tissu de remontages extrêmement dense ; 


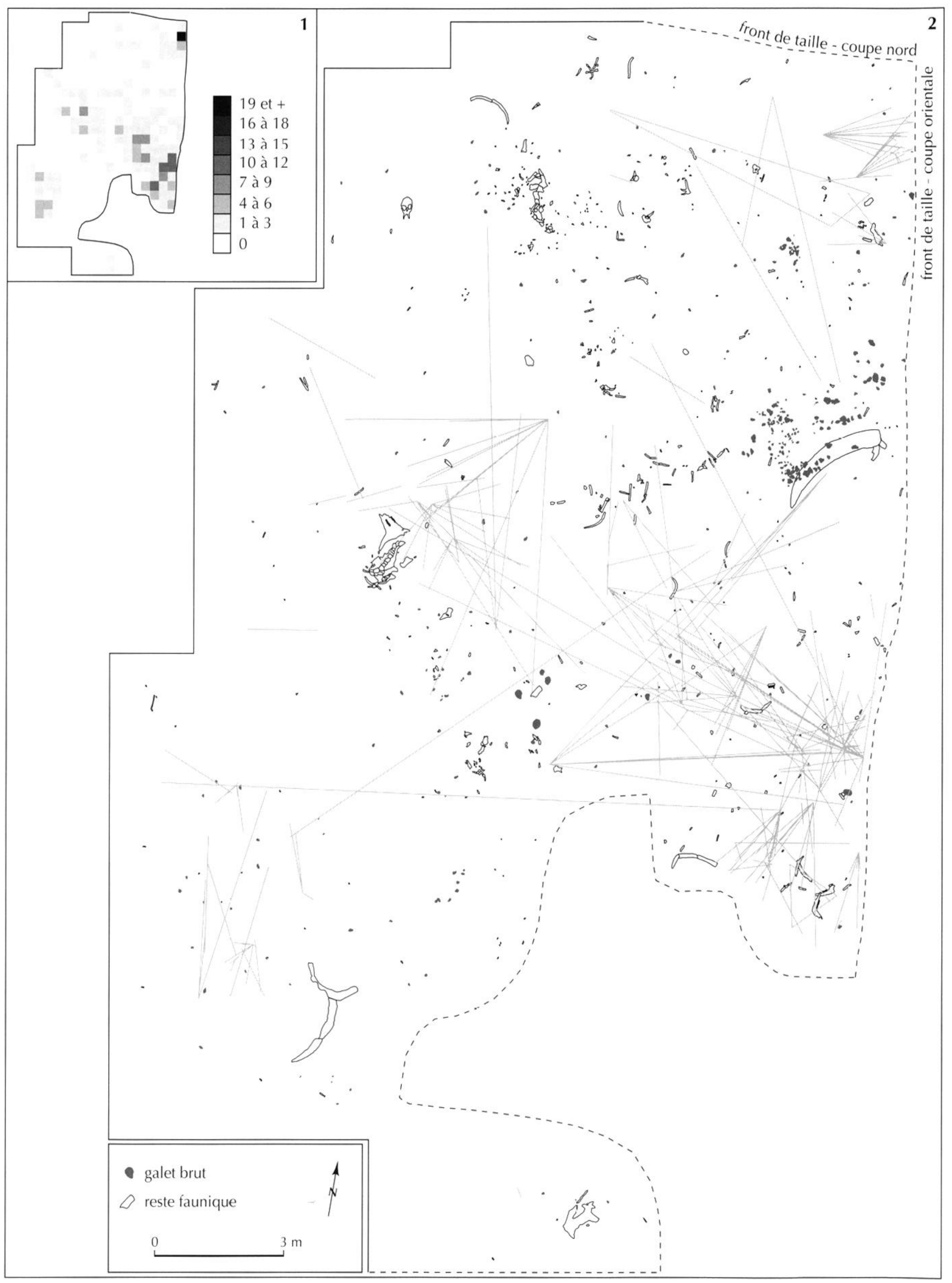

Fig. 19 - Soucy $1: 1$, nombre de pièces remontées par mètres carrés ; 2, disiribution horizontale en étoile des remontages et des raccords d'éléments cassés (les différents éléments d'une unité sont reliés au nucléus ou le cas échéant au dernier éclat extrait). 


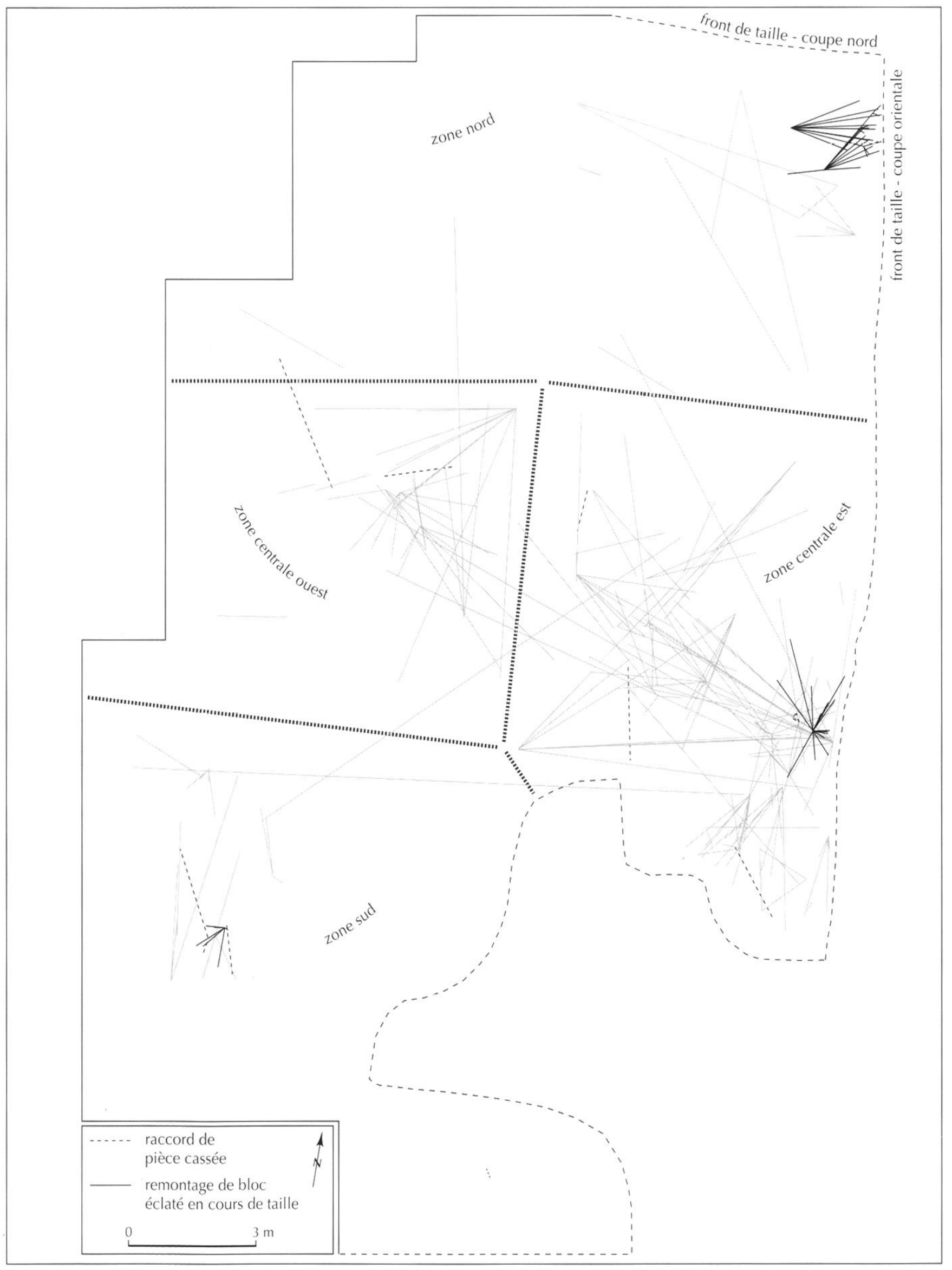

Fig. 20 - Soucy 1 : materialisation des zones nord, sud, centrale est et centrale ouest; figuration des raccords de piéces cassées et des remontages de blocs éclatés lors de la taille au sein de liensemble des remontages. 


\begin{tabular}{|l|r|l|c|c|c|c|c|}
\cline { 2 - 8 } \multicolumn{1}{l|}{} & Total & $\begin{array}{c}\text { raccords de } \\
\text { fractures }\end{array}$ & décorticage & $\begin{array}{c}\text { phases de } \\
\text { plein débitage }\end{array}$ & $\begin{array}{c}\text { étapes de } \\
\text { façonnage }\end{array}$ & $\begin{array}{c}\text { blocs } \\
\text { gélifs }\end{array}$ & $\begin{array}{c}\text { petits éclats } \\
\text { et cassons }\end{array}$ \\
\hline zone nord & 6 & 1 (outil) & & 1 & 2 & 2 & \\
zone centrale est & 37 & 4 & 11 & 20 & & 1 & 1 \\
zone centrale ouest & 8 & 1 & 2 & 5 & & & \\
zone sud & 12 & $4(1$ outil) & 1 & & 5 & 1 & 1 \\
interzones & 11 & 1 & 3 & 7 & & & \\
\hline Total & $\mathbf{7 4}$ & $\mathbf{1 1}$ & $\mathbf{1 7}$ & $\mathbf{3 3}$ & $\mathbf{7}$ & $\mathbf{4}$ & $\mathbf{2}$ \\
\hline
\end{tabular}

Tabl. III - Soucy 1 : distribution des differentes caligories de remontages et racrords au sein des zomes définies.
- plus à l'ouest et autour de la carcasse d'aurochs (zone centrale ouest), les vestiges lithiques sont abondants et montrent également à travers les remontages un tissu de liaisons serrées ;

- enfin, la partie sud-ouest du site (zone sud) présente un secteur oriental assez riche en restes lithiques séparé du reste du site par une bande de plusieurs mètres carrés dépourrue de restiges lithiques.

Sur l'ensemble de l'industrie, 74 remontages (comportant de 2 à 19 éléments) et 9 raccords d'éléments cassés, impliquant respectivement 315 et 19 pièces, ont pu être réalisés (fig. 19). Le taux de remontage sur Soucy 1 est de $17,6 \%$, soit, si l'on exclut les éclats de dimensions inférieures à $30 \mathrm{~mm}$ plus difficilement remontables, un taux de remontages qui atteint $31,27 \%$. Les remontages rapportables à la chaine opératoire de débitage impliquent 217 pièces au sein de 50 unités. Les remontages d'éclats de façonnage réunissent 23 pièces dans 7 unités. Enfin 4 blocs gélifs, éclatés dès les premières tentatives de taille et pour lesquels les intentions du tailleur sont difficilement discernables, regroupent 49 ćléments.

L'aire de répartition des restes lithiques appartenant à un même remontage varie de moins de $1 \mathrm{~m}^{2}$ à $33 \mathrm{~m}^{2}$. Les plus faibles dispersions observées pour des remontages associant plus de 5 ćléments ( 0 à 40 cm de distance) correspondent dans la plupart des cas au remontage de blocs gélifs testés et éclatés (notamment le long de la coupe orientale, au nord et au sud du site) (fig. 20).

L.e plan général figurant l'ensemble des remontages (fig. 19) présente le développement de réseaux de liaisons au sein des quatre zones définies plus haut (zone nord, zones centrales est et ouest, zone sud). Les secteurs de concentration de restes lithiques paraissent correspondre à des secteurs d'activité assez distincts ; toutefois, quelques déplacements de pièces entre ces secteurs

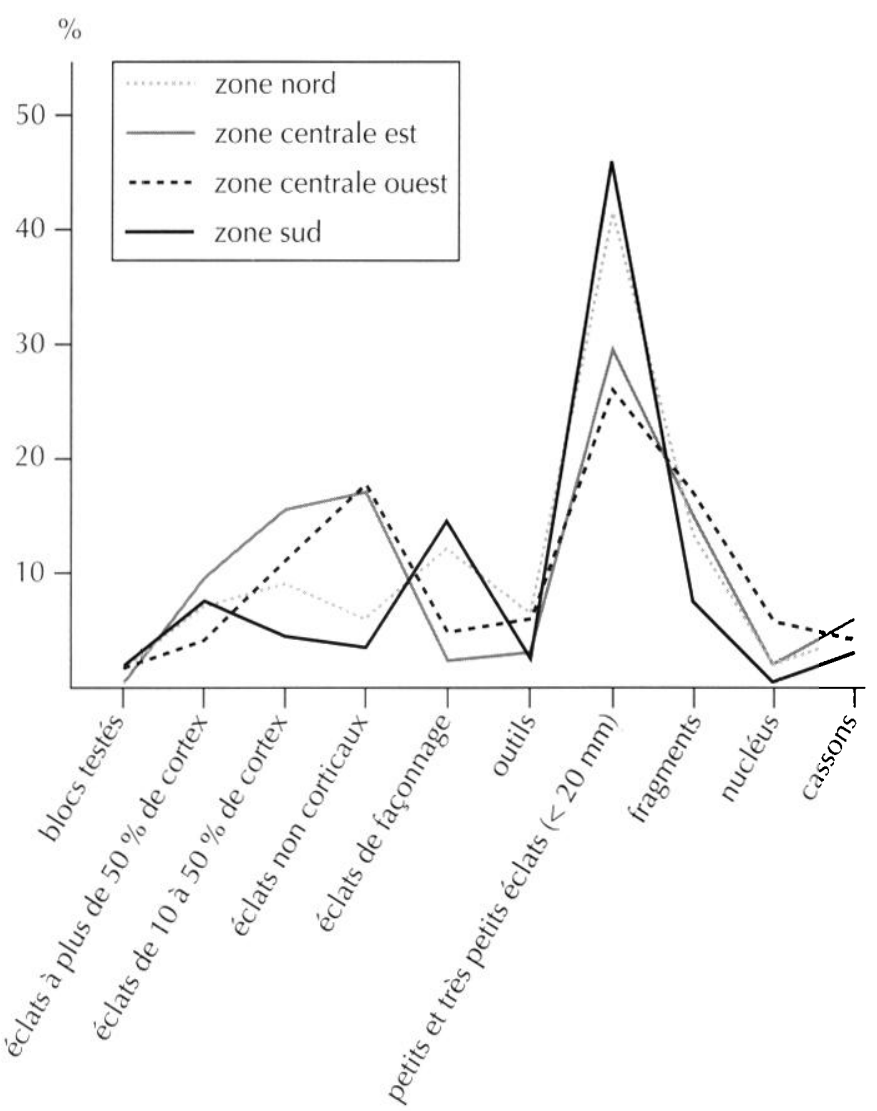

Fig. 21 - Soncy 1 : pourrentage des differents types de restes lithiques au sein des quatre zones distingueres.

matérialisent des relations entre les quatre grandes zones principales.

Si l'on examine pour chaque secteur la distribution des différentes catégories de restes lithiques ainsi que l'effectif et la nature des remontages présents (tabl. III et fig. 21), des différences se dessinent entre les secteurs : les zones nord et sud suivent une même tendance révélant la part importante du façonnage au détriment des 


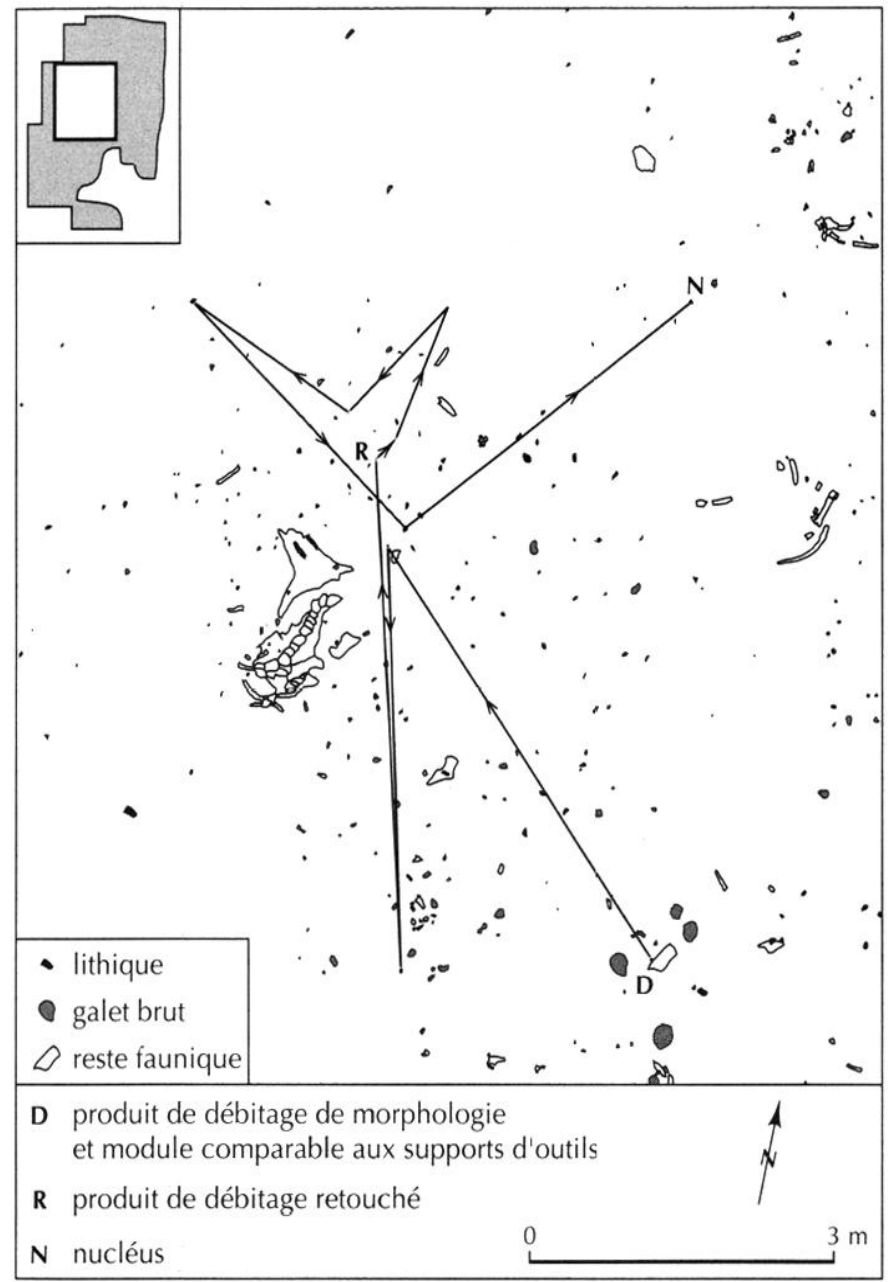

Fig. 22 - Soucy 1 : figuration dynamique des liaisons entre les différentes pièces formant le remontage $R 7$ (dans l'ordre de succession des enlèvements).

activités de débitage; les zones centrales est et ouest concentrant les activités de débitage.

Sur les 5 remontages de la zone nord, 2 sont attribuables aux activités de façonnage et un seul peut résulter d'une phase de débitage. Les deux autres remontages concernent 2 blocs gélifs testés et ne sont donc pas révélateurs des projets des tailleurs.

La zone centrale est renferme 37 remontages et 4 raccords (la moitié de l'ensemble des remontages et raccords du site) dont aucun ne peut être rapporté à du façonnage. Dans la majeure partie des cas, l'ensemble des phases de débitage (de l'éclat d'entame au nucléus abandonné) est attesté.

La zone centrale ouest présente la même configuration que la zone centrale est mais avec seulement
8 remontages et 1 raccord, tous attribuables à la chaîne opératoire de débitage.

La zone sud renferme 4 raccords et 12 remontages, dont 5 relèvent de la chaine opératoire de façonnage. Un remontage d'une série d'éclats corticaux peut, quant à lui, tout aussi bien être rapporté à une chaîne opératoire de façonnage qu'à une chaîne opératoire de débitage.

$\mathrm{Au}$ sein de chaque zone, les remontages numériquement les plus importants (hors blocs gélifs testés et abandonnés) montrent une grande dispersion des restes. Ainsi, en zone centrale ouest, les produits d'un des remontages les plus complets occupaient une aire de $31 \mathrm{~m}^{2}$ pour 10 éléments aux abords de la portion de carcasse d'aurochs (fig. 22) Ce remontage, regroupant les dernières étapes du débitage d'un bloc, contient un éclat retouché abandonné presque au centre de l'aire de dispersion du remontage. Les produits les plus excentrés, par rapport au secteur de $7 \mathrm{~m}^{2}$ où sont concentrés la majorité des déchets de taille, sont deux éléments parmi les premiers extraits et le nucléus. Ce remontage semble montrer une corrélation entre l'aire de débitage et l'aire de consommation des produits.

Dans la zone centrale est, qui concentre la majorité des activités de débitage, les aires de dispersion des éléments d'un même remontage sont conséquentes. Ainsi, pour les remontages associant plus de 5 éléments, les aires de dispersion varient de $3 \mathrm{~m}^{2}$ à $27 \mathrm{~m}^{2}$ (fig. 23 et 24). L'examen diacritique des remontages les plus complets n'a pas permis de mettre en évidence l'existence de relation directe entre les types de produits (éclats de réaménagement de plan de frappe ou très petits éclats et éclats de plein débitage) et leur répartition sur le site.

Plusieurs configurations apparaissent :

- les remontages correspondant à une unique étape de débitage d'un bloc et comportant tous les produits issus de cette étape (fig. 23) ;

- les remontages correspondant à plusieurs étapes du débitage d'un bloc mais présentant des séries incomplètes d'éclats (fig. 24).

Il est à noter que ces derniers montrent fréquemment une plus grande dispersion que les premiers. S'il n'est pas possible de trancher sur la superposition de l'aire de débitage avec l'aire de consommation des produits, les absences relevées dans certains remontages - toutes concernant des produits de plein débitage - semblent plaider dans certains cas pour une distinction spatiale entre production et utilisation. 


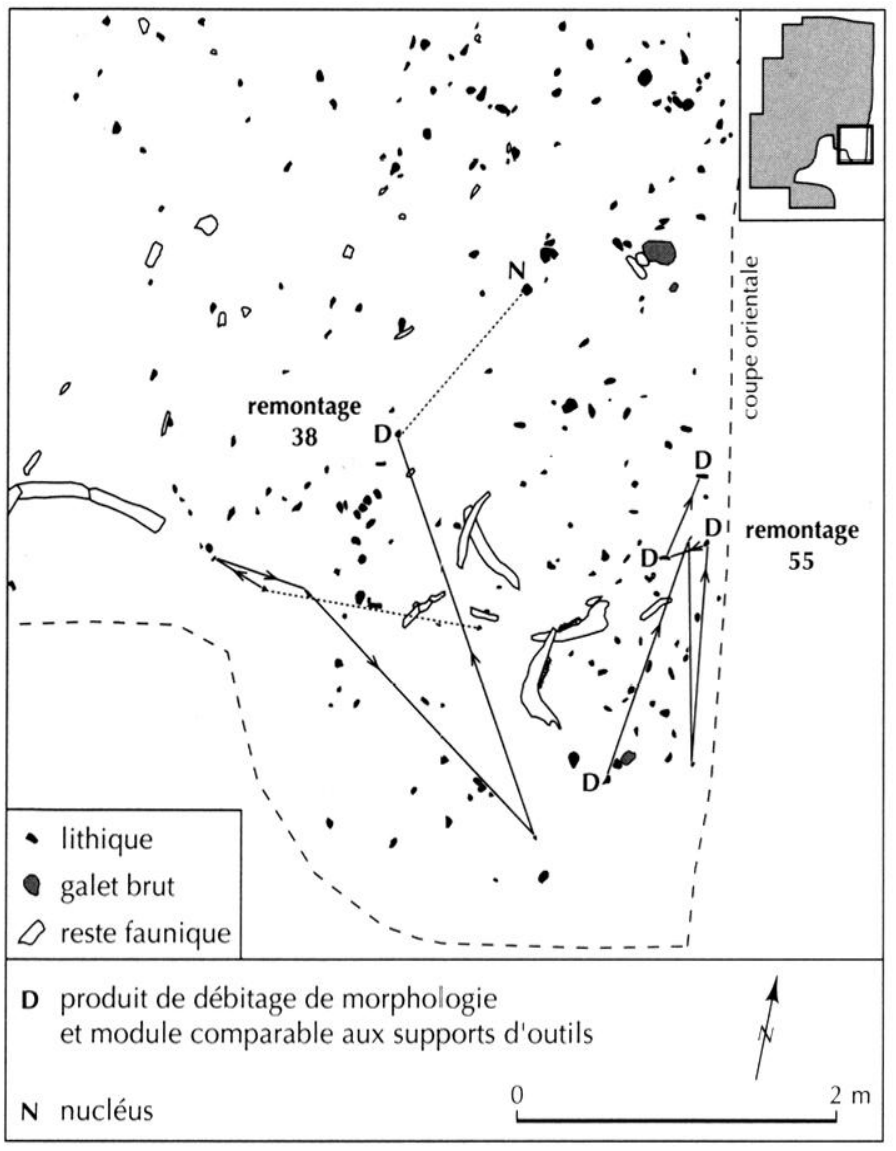

Fig. 23 - Soucy 1 : figuration dynamique des liaisons entre les différentes pièces formant les remontages $R 38$ et $R 55$ (dans l'ordre de succession des enlèvements). Les liaisons en tiretets matérialisent les phases de débitage absentes.

Les remontages effectués entre les différentes zones du site sont peu nombreux et se rapportent majoritairement aux différentes étapes de la chaine opératoire de débitage. Quelques remontages indiquent des déplacements importants.

On peut ainsi noter un éloignement de plus de $12 \mathrm{~m}$ entre l'aire principale de dispersion d'un remontage situé en zone centrale est et un éclat allongé mis au jour en zone sud (fig. 17, C6 et fig. 25). Cet éclat, de morphologie régulière et aux bords aigus occupe une position centrale dans le remontage qui regroupe 13 éléments au total, dont le nucléus. Dans ce remontage, 9 éléments sont répartis sur moins de $2 \mathrm{~m}^{2}$ et 12 sur moins de $12 \mathrm{~m}^{2}$. La concentration sur une aire restreinte de la majorité des éclats débités, la présence du nucléus à proximité immédiate de cette concentration, la position

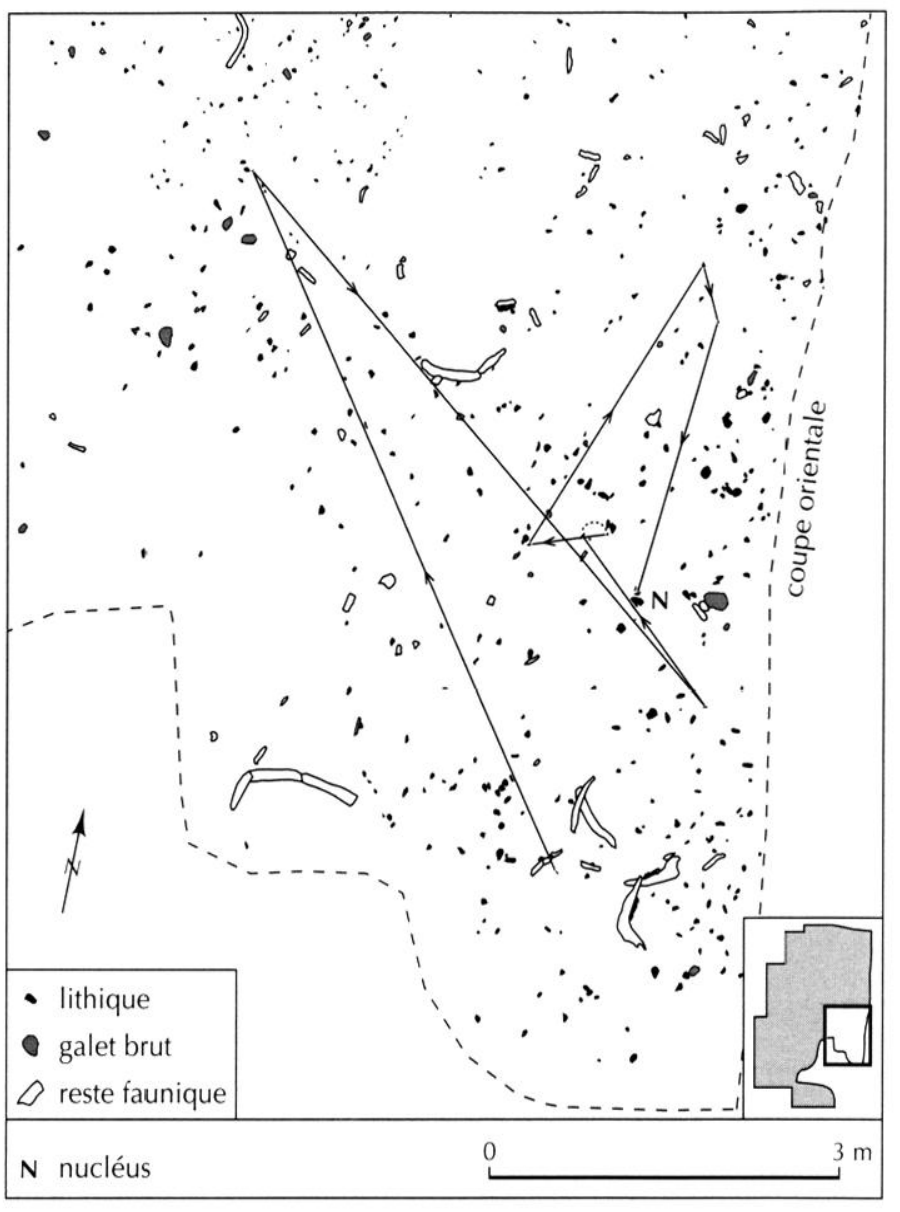

Fig. 24 - Soucy 1 : figuration dynamique des liaisons entre les différentes pièces formant le remontage $R 5$ (dans l'ordre de succession des enlèvements). La liaison en tiretets matérialise une phase de plein débitage absente.

centrale dans le remontage occupée par l'éclat «spatialement éloigné " ainsi que sa morphologie montrent qu'il y a eu transport de l'éclat en dehors de la zone de débitage plutôt que délocalisation du débitage lui-même.

Les zones centrales est et ouest présentent des liaisons à travers 6 remontages attribués à la chaîne opératoire de débitage. Le remontage le plus complet montre un éloignement de plus de $8 \mathrm{~m}$ entre un éclat long, partiellement cortical et présentant un bord aigu, et l'aire de dispersion principale des différents éléments du remontage, laquelle n'est que de $6 \mathrm{~m}^{2}$ (fig. 26). Comme dans l'exemple précédemment cité, l'éclat le plus éloigné de l'aire de dispersion principale est de morphologie comparable aux supports retouchés et occupe une place centrale dans le remontage, lequel ne représente qu'une étape dans le débitage du bloc. Cet exemple établit une 


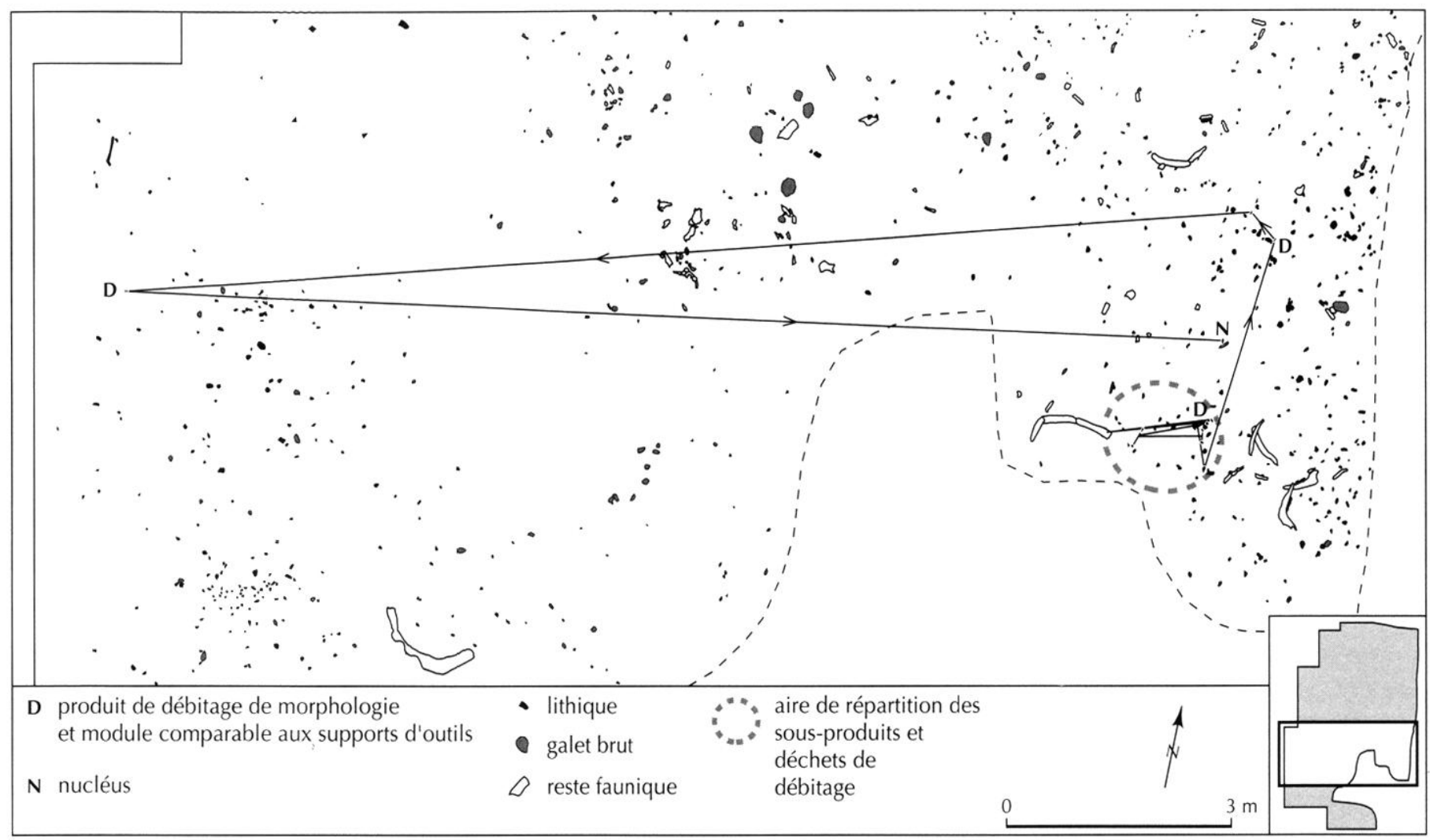

Fig. 25 - Soucy 1 : figuration dynamique des liaisons entre les différentes pièces formant le remontage $R 9$ (dans l'ordre de succession des enlèvements : $\mathrm{cf}$. fig. 17).

liaison entre l'aire principale de débitage située en zone centrale est et la zone centrale ouest. D'une façon générale, les relations se révèlent plus importantes entre ces deux zones qu'entre les autres mais l'on note cependant quelques liaisons de la zone centrale est vers la zone nord (fig. 19).

Dans les deux exemples développés ci-dessus, l'hypothèse du déplacement d'éclats depuis l'aire de débitage matérialisée par la concentration de produits, et notamment des déchets de taille, vers leur lieu d'abandon et d'utilisation présumée peut être retenue. D'un point de vue dynamique, ces déplacements confèrent à la zone centrale est un caractère d'aire de débitage. Toutefois, dans les deux exemples de remontages décrits ci-dessus, considérant la morphologie des produits bruts abandonnés et le peu d'éléments de plein débitage absents, la zone centrale est apparaît également être le lieu d'utilisation de l'essentiel des éclats issus de ces deux blocs.

Sur les zones centrales est et ouest, la vision diachronique obtenue par l'étude des remontages met en évidence dans les trois quarts des cas des distances infé- rieures à $2 \mathrm{~m}$ entre deux éclats issus d'une même phase de débitage. Les 10 cas illustrant un déplacement de plus de $2 \mathrm{~m}$ entre deux éclats extraits consécutivement sur le même nucléus peuvent attester des comportements particuliers : soit il peut être envisagé un déplacement du bloc entre deux étapes de production (3 cas observés), soit il est possible d'évoquer le transport d'un éclat (3 autres cas), soit enfin, un probable déplacement du bloc et de certains produits dans diverses directions.

Le remontage le plus complet reliant les zones nord et centrale est (fig. 27) regroupe 19 éléments dont un éclat retouché et le nucléus. L'aire complète de dispersion de ce remontage est de $33 \mathrm{~m}^{2}$. Quatre-vingt-dix pour cent des composants de ce remontage occupent une surface de $26 \mathrm{~m}^{2}$ et seul un élément marque un déplacement important $(7 \mathrm{~m})$ au nord de cette aire. L'élément le plus éloigné est un fragment partiellement cortical qui devait, entier, mesurer autour de $50 \mathrm{~mm}$ de longueur. Il provient de la première phase du débitage et c'est le troisième éclat extrait du bloc. La mise en relation de la répartition spatiale des différents produits et de leurs 


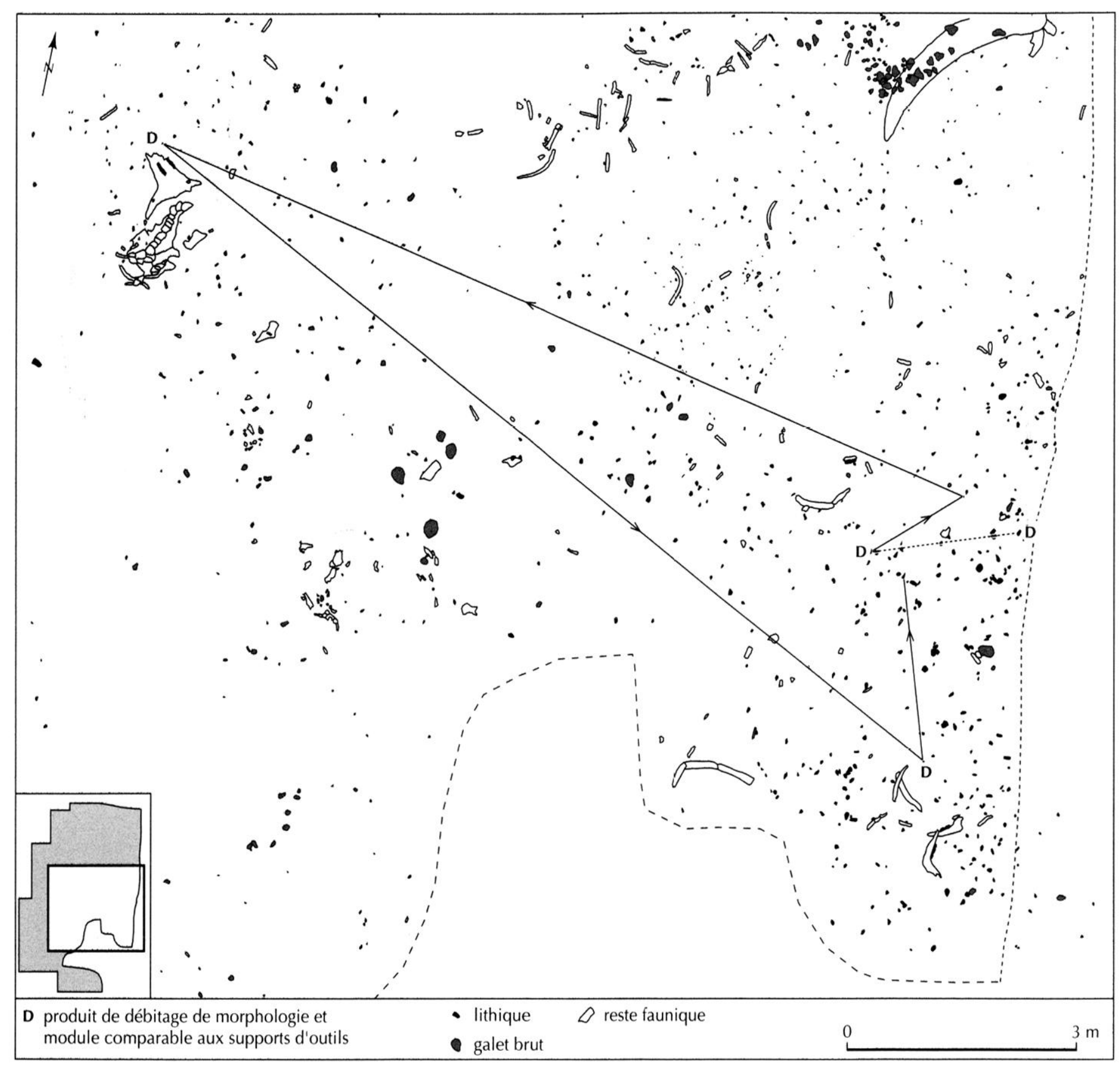

Fig. 26 - Soucy 1 : figuration dynamique des liaisons entre les différentes pièces formant le remontage R36 (dans l'ordre de succession des enlèvements).

caractéristiques techno-morphologiques montre que le nucléus, un éclat retouché et les éclats de morphologie régulière (et comparable aux supports d'outils) se situent à la périphérie orientale des éléments qui peuvent être considérés comme des déchets de taille. Une telle disposition des restes lithiques matérialise une zone d'activité dans la partie est du site. Malheureusement, la destruction (antérieure à la découverte) de la partie la plus orientale du site limite notre compréhension de cette portion du gisement. Cet exemple marque une correspondance directe entre aire de débitage et aire d'utilisation des produits dans la zone centrale est.

Ainsi, pour les zones où les produits de débitage dominent, les données issues de l'étude des remontages 


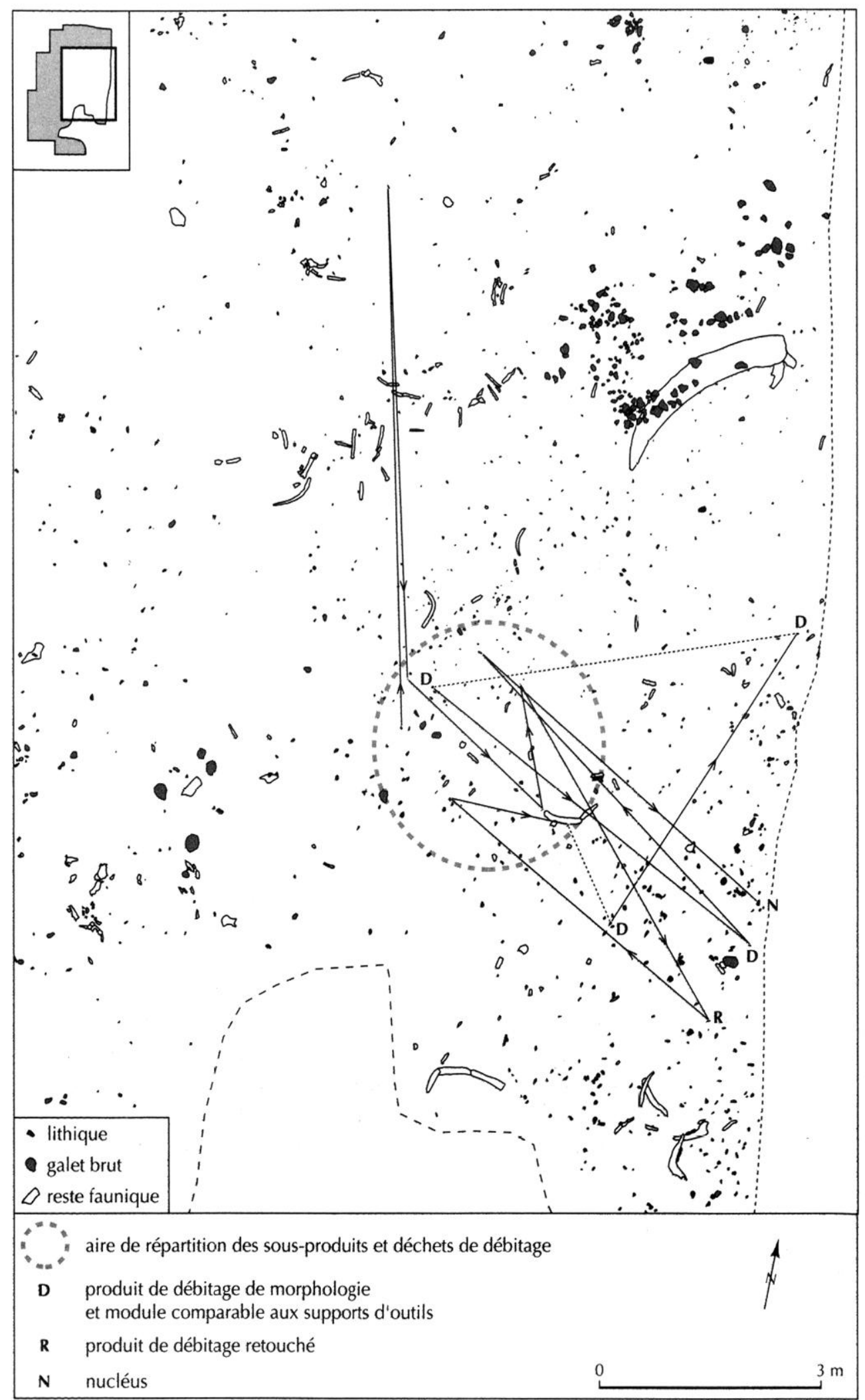

Fig. 27 - Soucy 1 : figuration dynamique des liaisons entre les différentes pièces formant le remontage $R 3$ (dans l'ordre de succession des enlèvements). 
mettent en avant l'adéquation entre lieu de production et lieu de consommation des produits de débitage. Toutefois, la zone centrale est présente une plus grande variété de comportements et il apparaît que dans de nombreux cas il y a unité de lieu entre production et consommation de produits lithiques, que dans d'autres, lieux de production et de consommation sont dissociés, et enfin que certains cas peuvent être plus complexes et montrer une unité de production/consommation parallèlement au déplacement d'au moins un élément.

Les liaisons entre la zone sud et le reste du gisement sont peu nombreuses. Nous pouvons citer pour exemple le cas d'un remontage de deux éléments éloignés de plus de $10 \mathrm{~m}$ reliant un éclat d'entame localisé au nord de la zone centrale est et un éclat cortical découvert en zone sud (fig. $28, n^{\circ} 1$ ). Ce remontage, grâce à son silex bien caractéristique, est appareillé avec 4 autres remontages, tous attribués à différentes étapes du façonnage d'une pièce bifaciale et localisés en zone sud. Le remontage entre la zone centrale est et la zone sud et ses appariements montrent un déplacement depuis le secteur de concentration de galets où le bloc aurait été entamé vers la zone sud dans laquelle s'est déroulée une partie importante du façonnage proprement dit.

La répartition spatiale des outils (fig. $28, \mathrm{n}^{\circ}$ 2) ne recoupe pas les secteurs de forte densité de mobilier lithique (fig. $28, n^{\circ} 3$ ). Les bifaces sont absents de la partie nord du gisement, mais ils sont bien représentés au sud-ouest du site où l'on note l'absence de racloirs et d'encoches.

Le plan de répartition spatiale des éclats de façonnage (fig. $28, n^{\circ} 1$ ) met en évidence trois secteurs principaux, d'une quarantaine de mètres carrés chacun, dans lesquels sont réunis plus des trois quarts de ces éclats.

Dans l'un de ces secteurs, en zone sud, nous avons pu effectuer des remontages relevant de phases d'ébauchage. Ce secteur se caractérise également par le nombre important de pièces bifaciales découvertes $(n=7$, entières et fragments) et la part d'éclats incontestablement attribuables à une chaîne opératoire de façonnage (34 sur 116, hors petits éclats). Les restes lithiques découverts dans ce secteur semblent donc principalement marquer une activité tournée vers la production de pièces bifaciales.

Dans un autre secteur, en zone centrale est, les éclats de façonnage se situent dans un locus riche en pièces bifaciales. Cette zone aurait donc accueilli des activités de façonnage parallèlement à une importante activité de débitage.

Au nord-est du gisement, à proximité de la coupe orientale de la zone nord, on note une concentration assez sensible d'outils (racloirs et éclats retouchés notamment), la présence de quelques éclats de façonnage et un remontage de 5 éclats corticaux issus d'une phase de façonnage de pièce bifaciale. Il semble donc que nous puissions être en présence d'un troisième secteur d'activité tourné vers la mise en forme d'outils, malheureusement cette partie du gisement est incomplète.

Les secteurs d'activité de façonnage et de débitage sont assez clairement dissociés; par contre les pièces bifaciales et les outils sur éclats ne présentent pas de répartition différenciée et sont présents sur l'ensemble du gisement.

\section{LES ÉLÉMENTS CHAUFFÉS}

Quelques éléments chauffés ont été mis au jour dans le niveau archéologique du site : 5 galets ou fragments de galets portant des traces de rubéfaction et 4 petits éclats de silex taillé. Les galets ne peuvent pas être considérés comme des témoins directs de combustion étant donné qu'ils ont pu être chauffés très antérieurement à l'occupation préhistorique.

La répartition spatiale de ces éléments (fig. $28, \mathrm{n}^{\circ} 2$ et fig. 29) met en évidence une certaine concentration associée à quelques charbons épars à proximité de la portion arrière de carcasse de rhinocéros. De même et dans une moindre mesure, deux petits galets chauffés sont présents aux abords de la portion antérieure de carcasse d'aurochs. Si cet état ne permet pas de nous prononcer sur la présence d'éventuels foyers, la concentration aux abords de la carcasse de rhinocéros sous-entend une origine directement ou indirectement anthropique de ces restes chauffés.

\section{SYNTHÈSE ET ESSAI D'INTERPRÉTATION DU FONCTIONNEMENT DU SITE}

Les analyses archéozoologiques et technotypologiques livrent un tissu d'informations spécifiques à chaque type de restes. Le regroupement et la confron- 

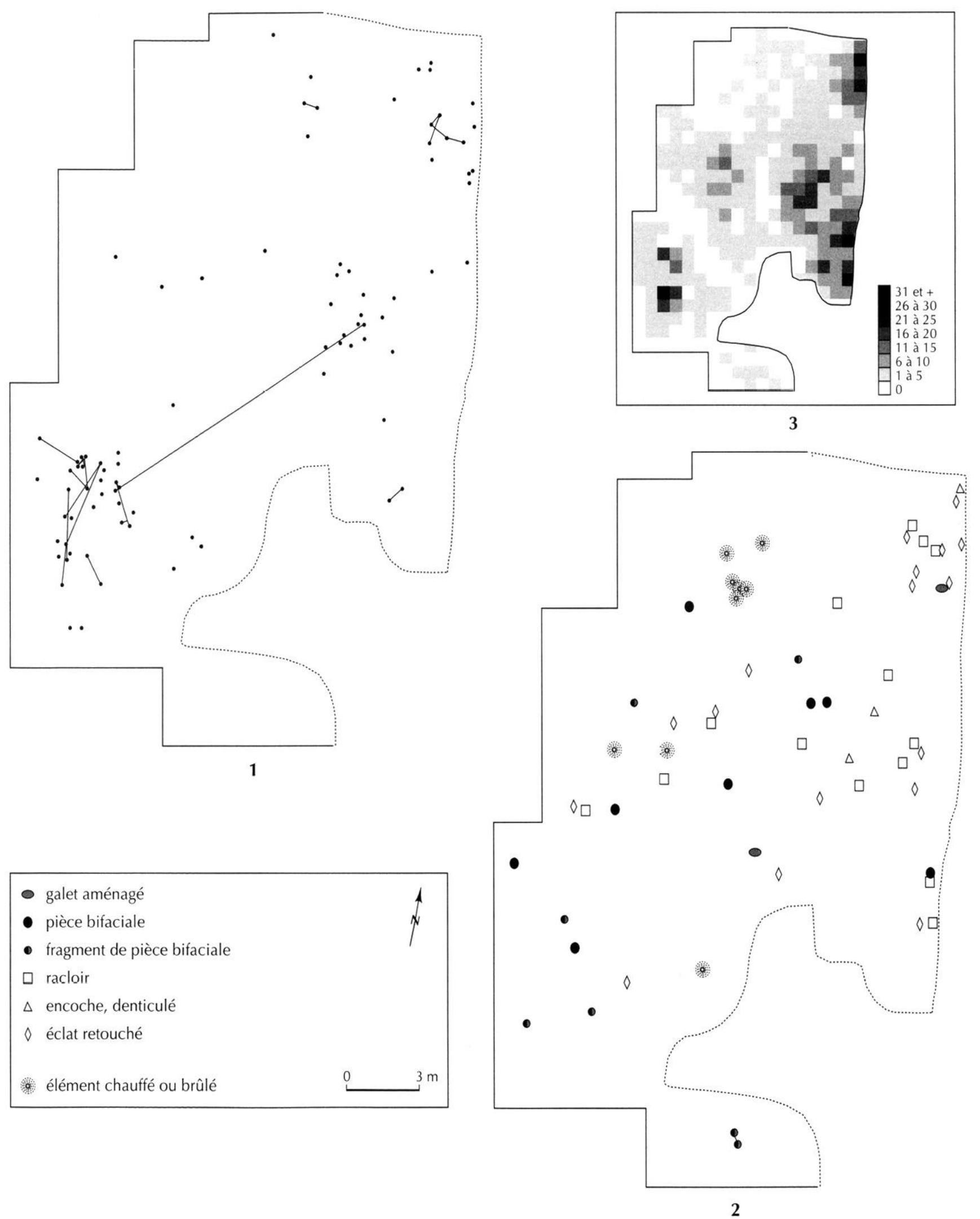

Fig. 28 - Soucy $1: 1$, plan de répartition des éclats de faşonnage et distribution horizontale des remontages et raccords d'éclats de façonnage ; 2 , plan de répartition des outils; 3 , nombre de restes lithiques par mètres carrés. 


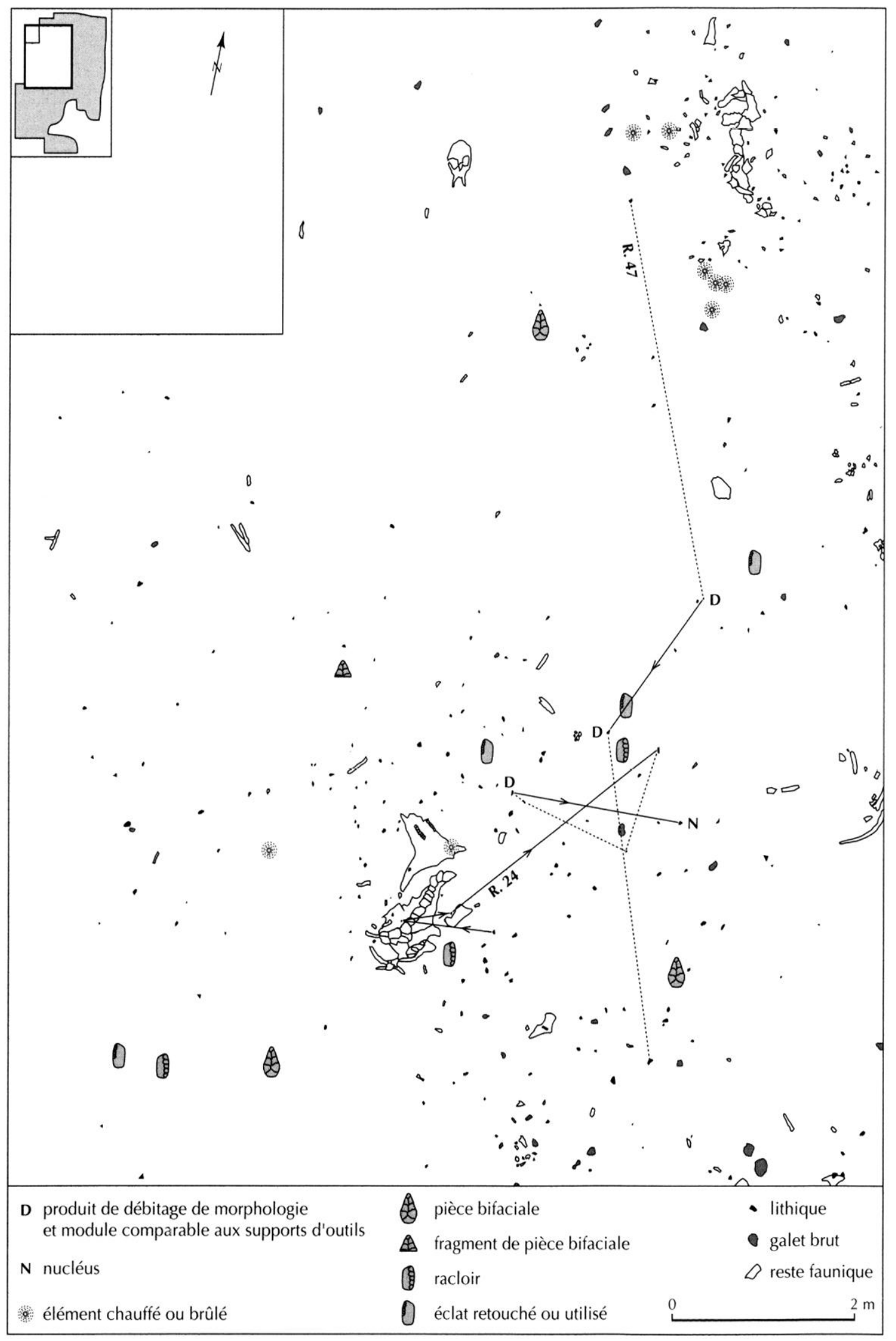

Fig. 29 - Soucy 1 : répartition des outils et des éléments chauffés aux abords des portions de carcasses de rhinocéros et d'aurochs et figuration dynamique des liaisons entre les différentes pièces formant les remontages $R 24$ et R47 (dans l'ordre de succession des enlèvements). Les liaisons en tiretets matérialisent les phases de débitage absentes. 
tation des données issues de ces deux études doivent permettre d'approcher la compréhension du fonctionnement du site.

Dans le contexte géographique et chronologique du site (site du Paléolithique inférieur en plaine alluviale avec niveau archéologique bioturbé) et malgré la précision de l'enregistrement lors de la fouille, il pourrait apparaître que la question de l'homogénéité du dépôt archéologique ne puisse être tranchée. Toutefois, la prise en compte, en amont des études archéologiques stricto sensu, des conditions de conservation du niveau et des processus taphonomiques postdépositionnels nous autorise à considérer que nous sommes en présence d'un dépôt archéologique homogène résultant d'activités anthropiques.

\section{SYNTHÈSE DES INFORMATIONS}

Les informations relatives aux activités de taille sont nombreuses et indiquent des déplacements et des zones d'activités distinctes. Les informations apportées par l'étude des restes fauniques bien que moins riches, notamment du fait de leur médiocre conservation, mettent néanmoins en évidence des concentrations de restes par espèces. C'est autour de ces zones de concentration de restes fauniques et en utilisant les données diachroniques et diacritiques résultant de l'étude du matériel lithique que nous proposons d'organiser une approche du fonctionnement du site.

Les Préhistoriques ont occupé une très légère pente formée par une levée de berge en limite de la plaine d'inondation et d'un bras de rivière. Les informations paléo-écologiques issues des différents cortèges zoologiques ${ }^{4}$ indiquent un environnement de forêts claires entrecoupées d'étendues herbeuses marquant un climat tempérè de rang interglaciaire.

Les données relatives à l'économie des matières premières permettent d'envisager l'existence d'un stockage de matériaux bruts dans une des zones du site (fig. 13 et 30). Ce comportement spécifique implique un investissement et une anticipation. L'établissement d'une réserve de matière première sous-entend une prévision

4. Malacologiques (Limondin-L.ozouet, in Chaussé et al., sous presse), micromammifères (Van Kolfschoten, in Lhomme et al., sous presse) et mammifères. d'utilisation et donc l'existence d'un projet plus ou moins étalé dans le temps.

Si nous postulons que la constitution de cette réserve de matériaux bruts est conditionnée par des besoins en silex taillés liés au traitement des matières carnées, nous affectons au site un caractère spécialisé qui n'est pas en contradiction avec la réflexion archéozoologique sur la configuration des restes osseux. C'est dans cet axe que nous pouvons tenter d'organiser les informations archéologiques afin de dégager les arguments en faveur de ce schéma.

Les remontages et appariements réalisés au sein de l'industrie lithique nous indiquent que le nombre de blocs exploités par les Préhistoriques ne devait pas dépasser la quarantaine ; le nombre de blocs de silex "stockés " non exploités est proche de 70. Tous les témoins des différentes étapes des chaînes opératoires de production de pièces bifaciales et de débitage sont présents sur le site mais apparaissent dans des secteurs relativement distincts.

Les secteurs de plus grande concentration d'outils (sur éclats et pièces bifaciales) se situent en zone centrale à proximité de la carcasse d'aurochs, aux abords des restes de cerf et d'aurochs et à l'est de la zone nord (fig. 29 et 30) :

- autour de la carcasse d'aurochs, sur un rayon de $3 \mathrm{~m}$, on observe la présence de 9 outils ( 3 racloirs, 3 pièces bifaciales dont 1 fragment, 3 éclats retouchés); dans cet ensemble deux racloirs portent des traces d'utilisation attestant une activité de boucherie ;

- à proximité de la concentration de restes de cerf, dans un rayon cette fois légèrement supérieur, apparaissent 14 outils ( 5 racloirs, 3 pièces bifaciales dont 1 fragment, 4 éclats retouchés et 2 encoches) ; 2 pièces témoignent d'un travail de boucherie et deux autres du travail des végétaux ;

- dans la partie nord-est du site, 12 outils ( 3 racloirs, 7 éclats retouchés, 1 denticulé et 1 galet aménagé) sont concentrés sur $10 \mathrm{~m}^{2}$.

Deux des trois secteurs de concentration d'outils sont situés à proximité immédiate ou sont inclus dans des zones ayant accueilli des activités de façonnage. Dans le périmètre de la carcasse d'aurochs, en revanche, les éclats de façonnage sont très rares (4 pièces sur un rayon de $4 \mathrm{~m}$ ). Même si l'on n'observe pas de réelle concentration d'outils dans la partie sud-ouest du site où les activités de façonnage sont prédominantes, nous pouvons 


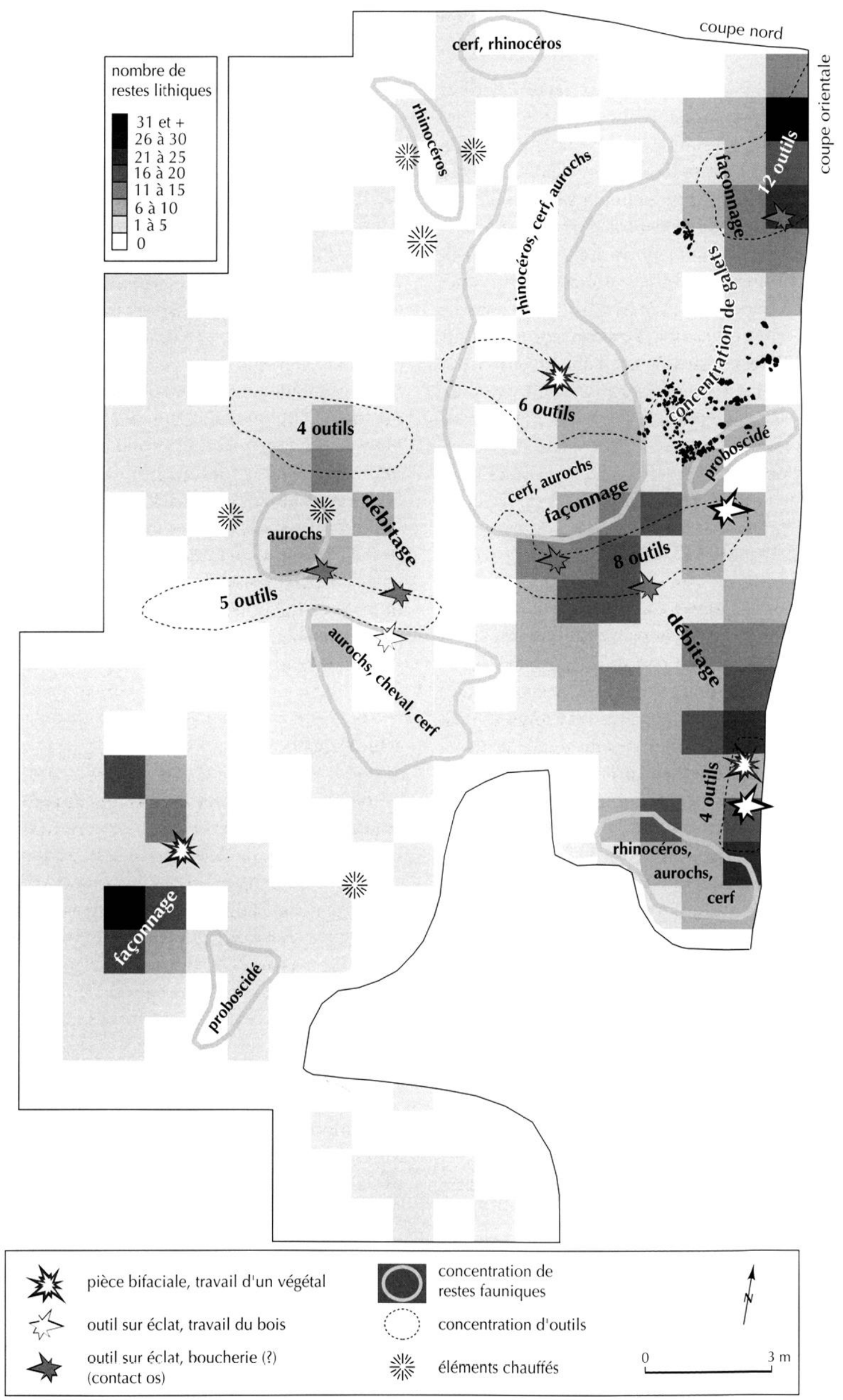

Fig. 30 - Soucy 1 : figuration synthétique des différentes informations issues de l'étude du site. 
cependant remarquer qu'une pièce bifaciale entière et trois fragments y apparaissent.

Dans les secteurs à forte concentration d'artefacts issus de la chaîne opératoire de production de supports, les restes fauniques sont épars et appartiennent à différentes espèces. Dans la zone centrale est qui regroupe plus de la moitié des témoins d'activité de débitage du site, six espèces sont représentées par des restes variés (fragments d'os longs, dents, côtes) disséminés sur une quarantaine de mètres carrés. Dans la zone centrale ouest, près de 130 restes issus de la chaîne opératoire de débitage sont regroupés sur une surface d'environ $25 \mathrm{~m}^{2}$ ( $5 \mathrm{~m} \times 5 \mathrm{~m}$ ) se développant au nord et à l'est de la carcasse d'aurochs (fig. 29 et 30 ).

Le transport de deux éclats provenant de blocs différents est constaté entre la zone centrale est, où ils ont à l'évidence été débités, et la portion de carcasse d'aurochs à côté de laquelle ils ont été abandonnés. Ces déplacements semblent indiquer une certaine synchronie dans le fonctionnement de ces deux secteurs d'activités.

Les restes osseux des espèces les plus représentées montrent trois configurations: l'aurochs est présent à travers une carcasse, des éléments du squelette axial et des extrémités de patte; le rhinocéros est représenté par une portion de carcasse et des restes du squelette axial ; les restes de cerf appartiennent à l'ensemble du squelette. La principale différence entre les représentations des restes de ces trois espèces est l'absence d'os longs porteurs de viande pour les plus grands herbivores (rhinocéros et aurochs). Cette absence d'os longs ne s'explique pas d'un point de vue strictement taphonomique dans la mesure où les vertèbres et les côtes sont conservées. Elle peut donc être significative d'une différence d'exploitation par les hommes.

Si la répartition spatiale des restes lithiques autour de la carcasse d'aurochs (concentration d'outils, activité de débitage) évoque implicitement un traitement des matières animales par les hommes, il n'en est pas rigoureusement de même pour la portion de carcasse de rhinocéros dans la zone nord du site où les restes lithiques sont rares et où seuls quelques éléments chauffés apparaissent concentrés (fig. 29 et 30 ). Dans l'hypothèse d'un dépôt non anthropique de cette portion de carcasse, seule la mort naturelle de l'animal sur place peut être recevable. L'hypothèse d'un apport cynégétique impliquerait une similitude de traitement entre les deux grands herbivores que sont le rhinocéros et l'aurochs (extraction des membres), toutefois on observe une différence dans l'organisation des vestiges lithiques autour de ces deux carcasses. Dans l'hypothèse d'un traitement anthropique du rhinocéros deux cas sont possibles: soit les Préhistoriques ont déplacé la carcasse après traitement, ce qui expliquerait l'absence de restes lithiques à sa périphérie, soit l'aire de traitement du rhinocéros était totalement dissociée du ou des secteurs de production et d'abandon des outils utilisés dans la découpe de la carcasse.

Le tableau que nous venons de dresser du site de Soucy 1 semble pouvoir être rapproché du schéma général des sites spécialisés dans les activités de boucherie. Pour les plus grands herbivores, il est probable que le lieu d'abattage soit très proche du site, voire sur le site même. Les autres espèces selon leurs gabarits ont pu être apportées entières ou sous forme de portions. Le travail des végétaux mis en évidence par l'analyse tracéologique et notamment l'utilisation apparemment très spécialisée des pièces bifaciales (Beyries, in Lhomme et al., 1998) indiquent néanmoins une certaine variété des activités pratiquées sur le gisement.

\section{DISCUSSION}

Le gisement de Soucy 1 présente des affinités avec les sites espagnols d'Aridos I et II, tant du point de vue du contexte (plaine alluviale) que du type d'occupation évoqué (site de boucherie) et de la datation suggérée (interglaciaire Mindel-Riss: Santonja et al., 1980). Bien que les espèces exploitées dans ces gisements soient différentes - à Aridos il y a notamment exploitation d'une carcasse d'éléphant dans chaque site - le trait commun réside dans la disposition des artefacts autour des concentrations de restes osseux (Santonja, Villa, 1990; Villa, 1996).

Sur les six gisements identifiés dans la même formation fluviatile de la gravière de Soucy, les deux autres gisements fouillés ${ }^{5}$ (Soucy 3 et 5 ) présentent des configurations assez différentes (fig. 2). Soucy 3 niveau $P$, fouillé sur plus de $500 \mathrm{~m}^{2}$, a livré environ 7000 restes lithiques et plus de 10000 restes fauniques, représentant un minimum de 50 individus, répartis sur l'ensemble du

5. L.es différentes études sur ces sites sont en cours. 
site et parmi lesquels les os longs porteurs de viande sont nombreux et systématiquement fracturés (Lhomme et al., 1997). Fouillé sur environ $150 \mathrm{~m}^{2}$, le gisement de Soucy 5 a livré trois niveaux archéologiques dont les deux niveaux inférieurs présentaient de nombreux os longs fracturés (Lhomme et al., 2000). Le niveau P de Soucy 3 comme les niveaux I et II de Soucy 5 ont livré de nombreux os portant des traces de découpes attestant des activités de décarnisation.

Le niveau supérieur (niv. 0) du gisement de Soucy 5 a livré des restes osseux de grands herbivores $(\mathrm{NMIf}=3$ ) associés à 99 restes lithiques. La configuration des restes fauniques dans ce niveau (portions de colonne vertébrale en connexion, extrémités de pattes en connexion) montre une faible fragmentation des os longs. La présence de nombreux éléments en connexion anatomique évoque la configuration des restes fauniques de Soucy 1 . Les restes lithiques du niveau supérieur de Soucy 5 , peu abondants (un reste au $\mathrm{m}^{2}$ ), sont rapportables, comme à Soucy 1 , à deux chaînes opératoires (façonnage de pièces bifaciales et débitage). Aucune pièce bifaciale entière n'a été abandonnée sur le site et seul un fragment d'ébauche est présent. Les rares outils abandonnés se composent de deux denticulés et d'un éclat retouché.

Nous pouvons observer une différence de distribution anatomique et spécifique des restes fauniques entre ce niveau de Soucy 5 et Soucy 1 . À Soucy 5 , niveau 0 , les os des membres de grands herbivores (boviné et équidé) sont présents (radio-ulna et humérus) alors qu'ils sont absents à Soucy 1.

Le niveau supérieur de Soucy 3 (niveau S) fouillé sur près de $150 \mathrm{~m}^{2}$ a livré, comme Soucy 1 et le niveau 0 de Soucy 5, des restes osseux de grands herbivores en connexion anatomique (portions de carcasse, extrémités de membres). Les restes lithiques mis au jour (moins d'une pièce par $\mathrm{m}^{2}$ en moyenne) sont presque intégralement attribuables à la chaîne opératoire de production de pièces bifaciales. Le caractère très partiel de cette chaîne opératoire induit la consommation sur le site d'outils sur éclats de façonnage et de pièces bifaciales introduites sous une forme déjà élaborée.

Le gisement de Soucy 1 présente des affinités avec les niveaux supérieurs des gisements de Soucy 3 et 5 sur le plan de la configuration des restes osseux. En revanche, ces occupations diffèrent sur le plan de la représentation des différentes chaînes opératoires de production lithique: à Soucy 3 niveau $S$, la chaîne opératoire de débitage n'est pas représentée; à Soucy 5 niveau 0, la chaîne opératoire de façonnage est très partielle.

Il est important de noter, qu'à l'instar de Soucy 1 , les occupations des niveaux supérieurs de Soucy 3 et 5 se sont développées sur la plaine d'inondation, et donc en retrait du cours de la rivière. Les autres niveaux archéologiques de Soucy correspondent à des occupations de bancs sableux en période d'étiage (niveau II de Soucy 5 , Soucy 6 ) ou de berges et buttes graveleuses à proximité du lit mineur (niveau $\mathrm{P}$ de Soucy 3 , niveau I de Soucy 5 ).

La chronologie relative des différentes occupations (Chaussé et al., sous presse) place Soucy 1 dans une position intermédiaire entre les occupations en berges et buttes graveleuses et les occupations en plaine d'inondation. Si comme nous l'avons vu précédemment Soucy 1 présente des similitudes avec les occupations en plaine d'inondation sur le plan de la configuration des restes fauniques, le nombre de restes lithiques abandonnés à Soucy 1 indique des activités de production lithique quantitativement plus proches des occupations en bordure du lit mineur (niveau $\mathrm{P}$ de Soucy 3, niveau I de Soucy 5).

Cette position intermédiaire de Soucy 1 par rapport aux autres gisements de Soucy s'inscrit tant sur le plan chronologique et paléo-géographique que sur le plan de la configuration des vestiges. La nature et la disposition des vestiges osseux ainsi que la répartition des restes lithiques et les premières données tracéologiques indiquent l'existence d'une activité de boucherie sur certains animaux, toutefois l'absence d'os longs porteurs de viande fracturés n'autorise pas à envisager une consommation in situ des matières carnées. La production lithique apparaît segmentée sur le site et organisée selon des pôles d'activités, et ce depuis l'établissement d'une "réserve " de matière première, jusqu'à la consommation des outils. Une telle structuration des activités sousentend l'unité et la courte durée d'occupation du site ; cette occupation pouvant être de modalité continue ou procéder de courtes fréquentations.

Après examen de l'ensemble des données disponibles sur Soucy 1 et bien qu'il soit délicat d'envisager une réponse unique sur la modalité d'occupation du site, les informations issues des études archéologiques plaident en faveur d'une occupation liée au traitement de grands herbivores. Cette approche interprétative du site induit l'existence de stratégies d'exploitation d'un territoire et 
apporte des éléments nouveaux au débat sur la complexité des comportements au Paléolithique inférieur.

\section{Remerciements}

La fouille et l'étude du site de Soucy l ont reçu le soutien financier du ministère de la Culture (Sous-Direction de l'Archéologie) et du Conseil général de l'Yonne, et le soutien logistique de l'entreprise Lafarge Granulats.

Nous tenons à remercier Jean-Paul Bravard et Michel Campy d'avoir bien voulu examiner in situ la concentration de galets. Nous tenons également à remercier Éric Boëda pour la relecture de notre manuscrit et ses précieuses suggestions. 


\section{BIBLIOGRAPHIE}

Ashton N. M., COOK J., LeWIS S. G., RosE J.

1992 : High Lodge. Excavations by $G$. de G. Sieveking 1962-68 and J. Cook 1988, London, British Museum Press, $265 \mathrm{p}$.

Auglste P.

1994 : Actions climatiques et édaphiques, synthèses générales, in: Outillage peu élaboré en os et en bois de cervidé, $I V$ : taphonomie/bone modification, Artefacts, 9 , p. 17-27.

\section{BEHRENSMEyER A. K.}

1978 : Taphonomic and economic information from Bone Weathering, Paleobiology, 4, 2, p. 150-162.

1983 : Patterns of natural bone distribution on recent land surfaces : implications for archaeological site formation, in: Clutton-Brock J., Grigson C. (eds), Animals and Archapology: 1. Hunters and their Prey, BAR International Series, 163, p. 93-106.

1991 : Terrestrial vertebrate accumulation, in: Taphonomy: Releasing the Data Locked in the fossil Record, Topics in Geobiology, New York, Plenum Press, p. 128-142.

Behrensmfier A. K., Hil... A. P.

1980 : Fossile in the making. Vertebrate taphonomy and paleoecology, Chicago and London, University of Chicago Press, $44 \mathrm{p}$.

Bertrax P., Texifr J.-P.

1995 : Fabric analysis: application to Paleolithic sites, Journal of Archaeological Science, 22, p. 521-535.

BINFORD L. R.

1981 : Bones: Ancient man and modern myths, New York, Academic Press, $320 \mathrm{p}$.

Bilimenschine R. J., Marean C. W. 1993 : A carnivore's view of archaeological bone assemblages, in: Hudson J. (ed.), From bones to behavior: ethnoarchaenlogical and experimental contritutions to the interpretation of faunal remains, p. 273-300.

BOËDA E.

1993 : Le débitage discoïde et le débitage Levallois récurrent centripète, Bulletin de la Société préhistorique française, 90, 6, p. 392-404.

1997 : Technogenèse de systèmes de production lithique au Paléolithique inférieur et moyen en Europe occidentale et ProcheOrient, Habilitation à diriger des recherches, univ: de Paris XNanterre, 2 vol., 260 p.

BORIDES F.

1961 : Typologie du Paléolithique ancien et moyen, Bordeaux, Delmas, 85 p.

Bol:chlid J.

1975 : La conservation différentielle des os et le problème des mesures biométriques, in: Problèmes artuels de Paléontologie-Evolution des Vertébrés, Colloque international du C.NRS, $\mathrm{n}^{\circ} 218$, Paris, juin 1973, p. 861-871.

BRAIN C. K.

1981 : The Hunters or the hunted? An introduction to African cave taphonomy, The University of Chicago Press, $365 \mathrm{p}$.

BRI (rin. J.-P.

1994 : Introduction générale : action de l'eau sur les ossements et les assemblages fossiles, in : Outillage peu élaboré en os et en bois de cervidé, IV : laphonomie/bone modification, Artefacts, 9 , p. 121-129.

BUNN H. T.

1983 : Comparative analysis of modern bone assemblages from a San huntergathered camp in the Kalahari Desert, Botswana, and from a spotted hyena den near Nairobi, Kenya, in: Clutton-Brock J., Grigson C. (cds), Animals and Archaeology: 1. Hunters and their Prey, BAR International Series, 163, p. 143-148.

Bi Nitac; B. T., FÉdoroff N.

1973 : Micromorphological aspect of soil development in the canadian High Arctic Soil Microscopy, in: Rutherford (ed.), Kingston Ontario, p. $350-354$.

Chalssé C., Limondin-Lozolet N., Occhitet S., Vonchet P., Bacox J.-C.

Sous presse: La nappe alluviale de Soucy-les-Grandes-Pièces (Yonne, France) : reconstitution pluridisciplinaire du fonctionnement d'un cours d'eau du Pléistocène moven, Géographie physique et Quaternaire.

Crader D. C.

1983 : Recent single-carcassbone scatters and problem of "butchery " sites in the archaeological record, in: Clutton-Brock J., Grigson C. (eds), Animals and Archaeology: 1. Hunters and their Prey, BAR International Series, 163, p. 107-142.

Crl\%-Uribe K.

1991 : Distinguishing Hyena from Hominid Bone Accumulations, Journal of Field Archaeology, 18, 4, p. $467-486$.

Delplä F., DoNitro E., GILBERT A.,

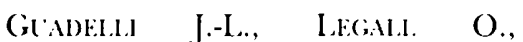

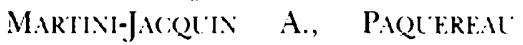
M.-M., Pritt F., Tol rnepiche J.-F.

1983 : Contribution à la lecture des paléoclimats quaternaires d'après les données de la paléontologie en milieu continental. Quelques exemples de flore et de faune d'Ongulés pris dans le Pléistocène supérieur, in: Actes du colloque, Association de géologie du Sud-Ouest, Bordeaux, mai 1983, Cahiers du Quaternaire, CNRS, $\mathrm{n}^{\circ}$ spécial, p. $165-177$. 
Forestiter H.

1993 : Le Clactonien : mise en application d'une nouvelle méthode de débitage s'inscrivant dans la variabilité des systèmes de production lithique au Paléolithique ancien, Paléo, 5, p. 53-82.

\section{Fosse P.}

1994 : Taphonomie paléolithique : les grands mammiferes de Soleilhac (Haute-Loire) ef de Lunel-Viel 1 (Hérault), thèse de $3^{4}$ cycle, univ. de Provence, AixMarseille I, $233 \mathrm{p}$.

Fosse P., BrLcill. J.-P., GLiddil.t. J.-L., Michel. P., Tol R.'PlPICHE J.F.

1998 : Les repaires d'hvènes des cavernes en Europe occidentale : présentation et comparaison de quelques assemblages osseux, in : Economie préhistorique: les comportements de subsistance au Paléolithique, XVIII ${ }^{c}$ rencontres internationales d'Antibes, oct. 1997. Sophia Antipolis, APDCA, p. 43-61.

\section{GIFFORD-GONZALES D.}

1989 : Ethnographic analogues for interpreting modified bones : some cases from East Africa, in : Bonnischen R., Sorg M. H. (eds), Bones Modifications, Orono, Center for the study of first americans, p. 179-246.

GLADELII J.-L.

1987 : Contribution à létude des zoocénoses préhistoriques en Aquitaine (Würm ancien et interstades Würmiens), thèse de Doctorat, univ. de Bordeaux I. $\mathrm{n}^{\circ} 148,3$ t., 568 p., 163 fig., 424 tabl.

GuÉRIN C.

1980 : Les rhinocéros (Mammalia. Perissodactyla) du Miocène terminal au Pleistocène supérieur en Europe occidentale. Comparaison avec les espèces actuelles, Documents $d u$ Laboratoire de géologie de Lyon, 79, 1-3. $1185 \mathrm{p}$.

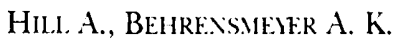

1984 : Disarticulation patterns of some modern East African mammals. Paleobiology, 10, p. 366-376.
INIAN M.-L., RhDtRoN M., ROCHE H., TIXIER J.

1995 : Technologie de la pierre laillée, Meudon, Centre de recherches et d'études préhistoriques, $200 \mathrm{p}$.

ISALC: $\mathrm{G}$.

1978 : The food-sharing behavior of protohuman hominids, Scientific American, 238, p. 80-108.

JAL'BERT J., I.ORBLANCHET M., LAIILE. H., Si.ott-Moller R., TLRQ A., BRLIGAI.J.-P.

1990 : Les chasseurs d'Aurochs de La Borde. Un sile $d u$ Paléolithique moyen (Livernon, Lot), Paris, éd. de la Maison des sciences de l'homme, Documents d'archéologie française, $27,160 \mathrm{p}$.

LAMOTTE A.

1995 : Données nouvelles sur l'Acheuléen de l'Europe du NordOnest, Bulletin de la Société préhistorique française, 92, 2, p. 193-199.

liomme V., Bemilli C., Beyries S., Christensen M., ConNet N.

1998 : Soucy 1 (Yonne) : interprétations et réflexions sur un site du Pléistocène moyen en contexte alluvial in : Economie préhistorique : les comportements de subsistance au Paléolithique, XVIII" rencontres internationales d'Antibes, oct. 1997, Sophia Antipolis, APDCA., p. 259-271.

linome V., Bemilli C., Chalssé C., CONNE: N., VAN KOl.FSCHOTEN T., LIMONDIN-LOZOLET N.

2000 : Le gisement paléolithique inférieur de Soucy 5 (Yonne), Revue archéologique de l'Est de la France, 49, p. $5-30$.

Lhomme V., CoNNet N., BeMhl... C., CHAL'SSÉ C.

1997 : Soucy 3, site préhistorique $d u$ Pléistocène moyen, Document final de sunthèse, AFAN, Service régional de l'archéologie de Bourgogne, Dijon, $75 \mathrm{p}$.

Lhomme V., Coniet N., Chat ssé C. 1996 : Présentation du gisement paléoli- thique inférieur de Soucy 1 (Yonne France), Archäologisches Korrespondenzblatl, 26, 3, p. 219-223.

Lhomine V., Conjet N., Chal'ssé C., Datid F., GLadDell. J.-L.

1996 : La gravière des Grandes Pièces et les sites paléolithiques inférieurs de Soucy (Yonne). Premiers résultats, Bulletin de la Société préhistorique fransaise, 93,4 , p. $482-493$.

Llomme V., Connet N., Chalssé H., DaV'ID F., GUÉRIN C.

1995 : Soucy 1 , site préhistorique du Pléistocène moyen (Yonne), Document final de synthèse, AFAN, Service régional de l'archéologie de Bourgogne, Dijon, 140 p.

\section{LMMAN R. L.}

1984 : Bone density and differential survivorship of fossil classes, Journal of Anthropological Archaeology, 3, 4, p. 259-299.

1994 : Vertebrate taphonom; Cambridge University Press, 524 p.

PotTs R.

1983 : Foraging for faunal resources by early hominids at Olduvai Gorge, Tanzania, in: Clutton-Brock J., Grigson C. (eds), Animals and Archaeology : 1. Hunters and their Prey; BAR International Series, 163, p. 51-62.

Sintonja M., Lopez N., Perez A.

1980 : Ocupaciones achelenses en el valle del Jarama (Arganda, Madrid), Diputacion provincial de Madrid, Arqueologia y paleoecologia, 1 .

Santonja M., Vil.tat P.

1990 : The Lower Paleolithic of Spain and Portugal, Journal of World Prehistory, 4, 1, p. 45-94.

\section{SHIPMAN P.}

1983 : Early hominid lifestyle : hunting and gathering or foraging and scavenging, in: Clutton-Brocks J., Grigson C. (eds), Animals and Archeology: 1. Hunters and their prey, 
BAR, International Series, 163 , p. 31-50.

Tlffreal A., Antoine P., Chase P. G., Dibble H. L., El.lwood B. B., VAN KOLFSChoteN T., LAMOTTE A., Laurent M., Mc: Pherron S. P., MoIgne A.-M., MLNalt A.-V.

1995 : Le gisement acheuléen de Cagnyl'Épinette (Somme), Bulletin de la Société préhistorique française, 92, 2, p. 169-191.

VAN VLIET-LANOË B.

1987 : Cryoreptation, gélifluxion et coulées boueuses : une dynamique conti- nue en relation avec le drainage et la stabilité de l'agrégation cryogénique, in: Pésci M. , French H. M. (eds), Loess and Periglacial Phenomena, Budapest, Akademial Kiado, p. 203-225.

VAN VIIIET-I ANOÉ B., VAladas B.

1983 : À propos des formations déplacées des versants cristallins des massifs anciens: le rôle de la glace de ségrégation dans la dynamique, Bulletin de l'Association française d'études quaternaires, 4, p. 153-160, 4 fig.
VII.IA P.

1996 : Torralba et Aridos : chasse, charognage et dépeçage d'éléphants au Pléistocène moyen en Espagne, in: Tuffreau A. (éd.), L'Acheuléen dans l'Ouest de l'Europe, Publication du Centre d'études et de recherches préhistoriques, 4, univ. des Sciences et technologies de Lille, p. 61-71.

ZAcW'JN W. H.

1992: The beginning of the ice age in Europe and its major subdivisions, Quaternary Science Reviews, 11, p. 583-591. 